Florida International University FIU Digital Commons

1996

\title{
Tribological study of PS-23 for possible automotive applications
}

Roberto R. Carballo

Florida International University

DOI: $10.25148 /$ etd.FI14052570

Follow this and additional works at: https://digitalcommons.fiu.edu/etd

Part of the Mechanical Engineering Commons

\section{Recommended Citation}

Carballo, Roberto R., "Tribological study of PS-23 for possible automotive applications" (1996). FIU Electronic Theses and Dissertations. 2041.

https://digitalcommons.fiu.edu/etd/2041

This work is brought to you for free and open access by the University Graduate School at FIU Digital Commons. It has been accepted for inclusion in FIU Electronic Theses and Dissertations by an authorized administrator of FIU Digital Commons. For more information, please contact dcc@fiu.edu. 
FLORIDA INTERNATIONAL UNIVERSITY

Miami, Florida

\section{TRIBOLOGICAL STUDY OF PS-23® FOR POSSIBLE AUTOMOTIVE APPLICATIONS}

A thesis submitted in partial satisfaction of the requirements for the degree of

MASTER OF SCIENCE

IN

MECHANICAL ENGINEERING

by

Roberto R. Carballo

1996 
The thesis written by Roberto R. Carballo, and entitled, TRIBOLOGICAL STUDY OF PS-23® FOR POSSIBLE AUTOMOTIVE APPLICATIONS, having been approved in respect to style and intellectual content, is referred to you for judgment.

We have read this thesis and recommend that it be approved.

\author{
Kuang-Hsi Wu
}

Ibrahim N. Tansel

Tachung Yih

Qian Wang, Major Professor

Date of defense: $\quad 08-12-96$

The thesis of Roberto R. Carballo is approved.

Dean Gordon R. Hopkins

College of Engıneering and Design

Dr. Richard L. Campbell

Dean of Graduate Studies

Florida International University, 1996 


\section{DEDICATION}

I dedicate this work to my parents, Elba and Roberto, who have always encouraged me to strive for the best, and especially to my wife Damaris whose love and support have kept going. 


\section{ACKNOWLEDGMENTS}

I would like to thank all the people who in some way or another have helped me get through this, members of my family and friends who have encouraged me to go on and who have helped me with sometimes the smallest of things but which have meant very much. I would also like to thank Mr. Gang Chen who has helped me in many of the details of this work while becoming a good friend in the process, and professor Yanching Liu for being so generous in providing his SEM expertise and work.

I would also like to thank Mr. Peter Vega, vice-president of Bridgers Group, Inc., for the financial support and equipment he provided, and especially for the opportunity to do the research work which provides the foundation of this thesis.

To my major professor Dr. Qian Wang I would also like to thank her for the opportunity and support she gave me and for her close help in all aspects of this work. 


\title{
ABSTRACT OF THE DISSERTATION
}

\section{TRIBOLOGICAL STUDY OF PS-23® FOR POSSIBLE}

\section{AUTOMOTIVE APPLICATIONS}

\author{
by \\ Roberto R. Carballo \\ Florida InternationaI University, 1996 \\ Dr. Qian (Jane) Wang, Major Professor
}

PS-23® is a new oil conditioner developed in South Africa by Lubrioil S.A. Chemical and physical analysis, and experimental studies were conducted to investigate the possibility of using PS-23® as an engine oil additive package. Mobil 10W-30 is used as the engine oil. The experimental results indicate that PS-23@ contains unexpectedly high levels of calcium and phosphorus, and that mixing $10 \%$ PS- $23 \AA$ in volume decreases the lubricant viscosity and increases its volatility. The start-stop tests using small engines were used to test PS-23 ${ }^{\circledR}$ in a severe operating condition. The experimental observation suggests that under such an adverse combustion environment, the PS-23 ${ }^{8} 10 \mathrm{~W}-30$ mixture is more likely to degrade. Further studies were conducted using a block-on-pin machine to determine the tribological behavior of PS-23 as an additive using a prepared steel sample and rotating piston pin, under both full film and boundary lubricating conditions. Both 10W-30 motor oil and $80 \mathrm{~W}-90$ gear oil were used for these tests as the reference oil. It was found that under full film lubrication there were no substantial differences in the frictional coefficient with the use of PS-23®. However, under boundary lubricating 
conditions it was found that the use of PS- $23 \AA$ extended the time before failure was observed by a substantial amount. Other popular lubricant additives such as Slick-50 and Duralube were also used in the boundary lubrication tests, and although they performed better than the reference oil alone, they did not achieve the level of performance achieved with the use of PS-23 $\AA$ 
I: INTRODUCTION

1-1. OIL ADDITIVES AND THEIR FUNCTIONS ….......................... 1

1-2. ADDITIVES USED IN GEAR OILS …..................................... 9

1-3. OUTLINE OF RESEARCH …................................................... 10

A. ROAD TEST DESCRIPTION ................................................... 11

B. SMALL ENGINE TESTS DESCRIPTION ............................... 11

C. BLOCK-ON-PIN MACHINE TESTS .......................................... 11

D. CHEMICAL AND PHYSICAL LUBRICANT ANALYSIS ... ......... 12

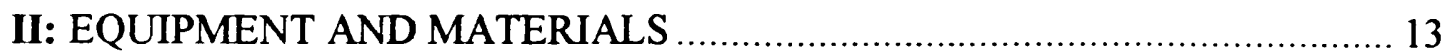

2-1. USED VEHICLES ......................................................................... 13

2-2. BRIGGS AND STRATTON ENGINES WITH WATER PUMP ........... 14

2-3. BLOCK-ON-PIN MACHINE FOR TRIBOLOGICAL TESTS ............. 14

2-4. INSTRUMENT FOR SURFACE MEASUREMENT ….................... 15

2-5. SAMPLES USED FOR TRIBOLOGICAL TESTS …....................... 16

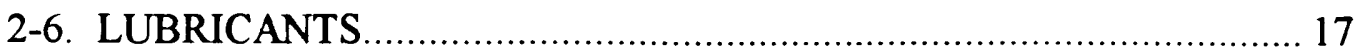

III: RELATED THEORIES OF LUBRICATION AND

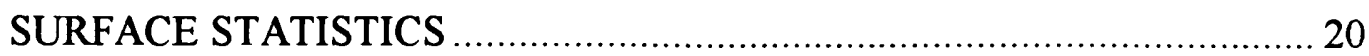

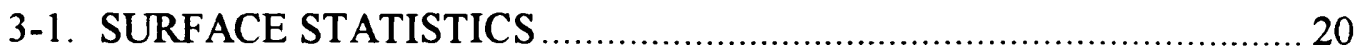

3-2. VOLATILITY CALCULATIONS AND

VISCOSITY-TEMPERATURE RELATIONS …............................. 22

3-3. EQUATIONS FOR FLUID FILM THICKNESS AND

TEMPERATURE CALCULATIONS …............................................. 23

IV: EXPERIMENTAL RESULTS FROM ENGINE TESTS …........................ 29

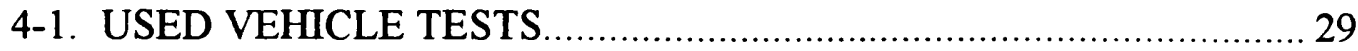

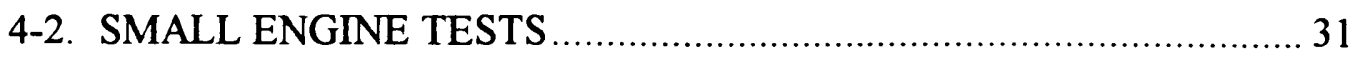

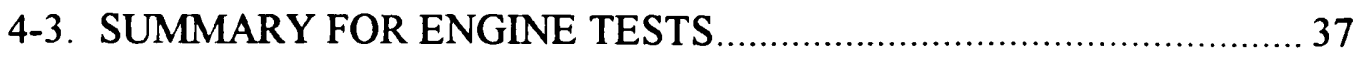

V: EXPERIMENTAL RESULTS FROM BENCH TESTS ….......................... 38

5-1. FULL FILM LUBRICATION TESTS .......................................... 38

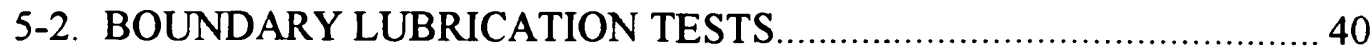

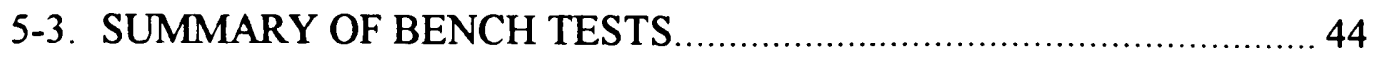






\section{LIST OF TABLES}

TABLE

PAGE

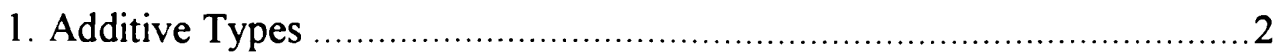

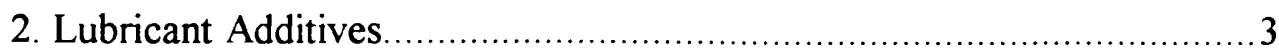

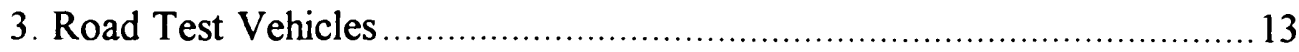

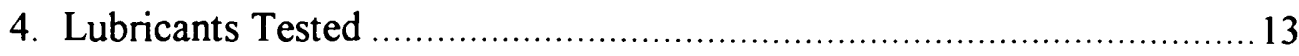

5. Properties of 1144 Medium Carbon Steel ............................................. 16

6. Physical Characteristics of Lubricants ............................................... 17

7. Spectrochemical Analysis Results for Oil Additives .............................. 18

8. Solutions to Fluid Film Thickness Equation by Regimes of Contact........26

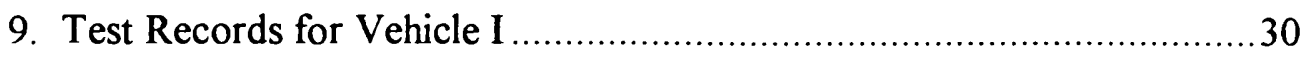



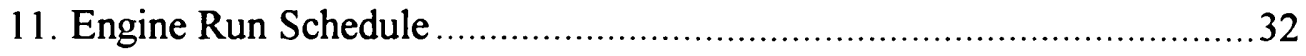

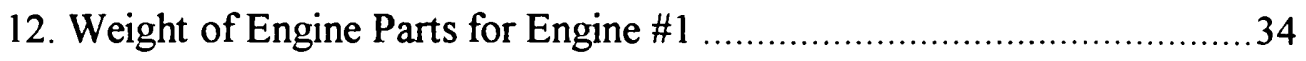

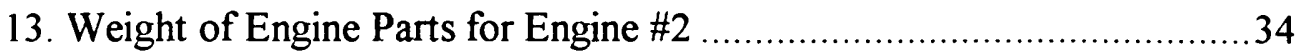

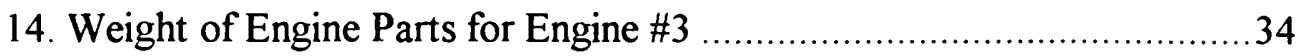

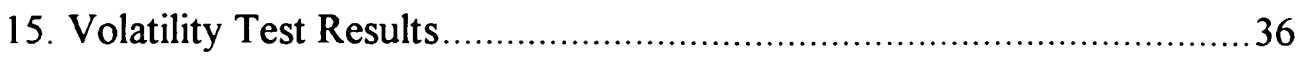

16. Loads Applied for Full Film Lubrication Tests...........................................

17. Viscosity of Oils and Film Thickness Calculations for Full Film

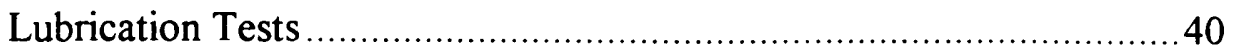

18. Results of Boundary Lubrication Tests - Untreated Samples.................42

19. Estimated Surface Temperature for Boundary Lubrication Tests ..........43 


\section{LIST OF FIGURES}

Figure

1. Experimental Set-up for Small Engine Tests ................................................. 47

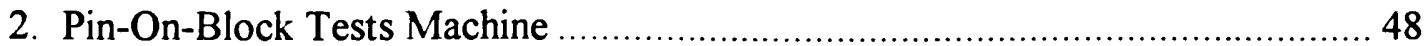

3. Taylor-Hobson Surtronic 3+ Profilometer ....................................................... 49

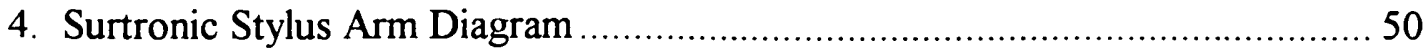

5. Samples Used for Tribological Tests .......................................................... 51

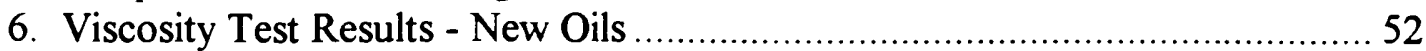

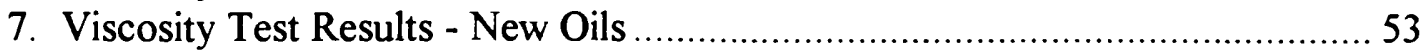

8. Formal and Counterformal Contact Between Two Surfaces ............................ 25

8. Regimes of Rectangular Contact Chart.......................................................... 54

10. Micrographs of Road Test \# 1 Engine Parts ..................................................... 55

11. Micrographs of Road Test \# 1 Engine Parts .................................................... 56



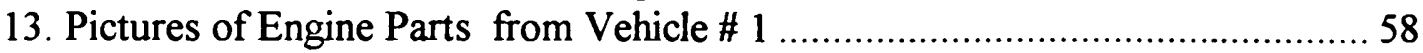

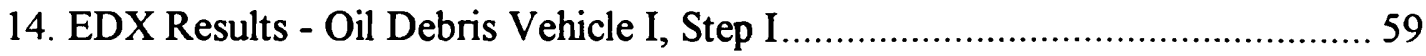

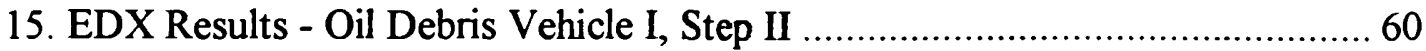

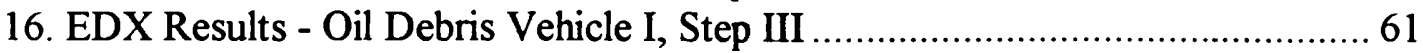

17. Viscosity Results Used Oils Vehicle I, Steps I - II ..........................................6. 62

18. Comparisons of Pistons from Small Engines, Run \# 1 ....................................63

19. Comparisons of Pistons from Small Engines, Run \# 2 ....................................6 64

20. Comparisons of Wrist Pins from Small Engines, Run \# 1 ...............................65

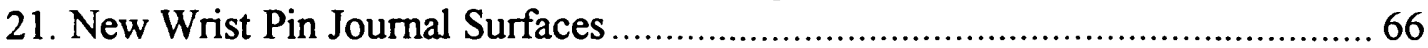

22. Comparisons of Wrist Pin Contact Surfaces, Run \# 1 ................................. 67

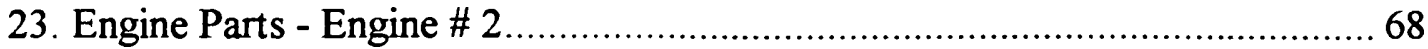

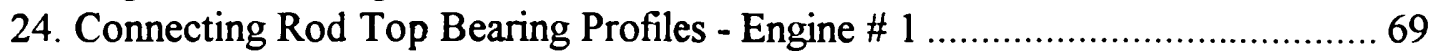

25. Connecting Rod Top Bearing Profiles - Engine \# 2 …................................ 70

26. Connecting Rod Bottom Bearing Profiles - Engine \# 1 …............................ 71

27. Connecting Rod Bottom Bearing Profiles - Engine \# 2 ............................. 72

28. Wrist Pin Surface Profiles - Engine \#1 Using 10W-30 Oil ............................. 73

29. Wrist Pin Surface Profiles - Engine \#1 Using 10W-30 + 10\% PS-23 .............. 74

30. Viscosity of Used Oils from Small Engine Tests ........................................... 75

31. Viscosity Change in Oils After Small Engine Tests ....................................... 76

32. Diagram of Oil Supply Set-up for Full Film Tests ........................................ 77

33(a). Full Film Test Results - Oil at Room Temperature …............................... 78

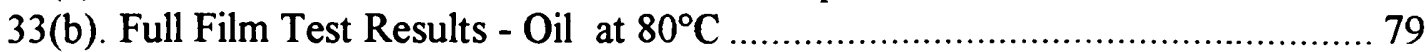

34. Boundary Lubrication Tests Results - Using $10 \mathrm{~W}-30$ as the Base Oil ............. 80

35. Boundary Lubrication Tests Results - Using $80 \mathrm{~W}-90$ as the Base Oil .............. 81

36. Micrographs of Wear Scars from Boundary Lubrication Tests....................... 82

37. Micrographs of Wear Scars from Boundary Lubrication Tests....................... 83

38. EDX Analysis Results for Surfaces Used in Boundary Lubrication Tests ......... 84

39. EDX Analysis Results for Surfaces Used in Boundary Lubrication Tests .......... 85

40. EDX Analysis Results for Surfaces Used in Boundary Lubrication Tests ......... 86

41. EDX Analysis Results for Surfaces Used in Boundary Lubrication Tests ......... 87 


\section{CHAPTER I.}

\section{INTRODUCTION}

\section{1-1. OIL ADDITIVES AND THEIR FUNCTIONS}

Engine lubrication has come a long way since the design of the first internal combustion engines. The development of modern engine and transmission technologies is closely related to the development of the necessary lubricant additives(Copan \& Richardson, 1992). The purpose of said additives varies, but is primarily focused on the reduction of friction and wear. Since the 1930's additives have been developed to satisfy the requirements of new engine technology which was not possible with base oils alone. As additives have been developed, widespread use of technological advances has become possible. There are requirements such as higher durability, long term emission controls, and enhanced fuel efficiency which have come from the need to save energy and protect our environment. So far additive technologies have kept pace with these advances and it is necessary that they continue to do so in the future.

There are different types of additives which perform different functions. It is by the right combination and concentrations of these additives that lubricants are developed for specific engine applications.

The basic functions of a lubricant are: friction reduction, heat removal, dispersion of contaminants, and wear reduction. Additives enhance the physical and chemical properties of base lubricants so as to perform their functions more efficiently. 
For example, friction and wear reduction can be accomplished by controlling the viscosity of the lubricant, while dispersion is accomplished chemically.

There are many types of lubricant additives as can be seen from Tables 1 and 2(Asseff). They can be divided generally into two major types: basefluid modifiers and metal protectors (Table-1). The basefluid modifiers are those which enhance the performance of the basefluid, while metal protectors do just what their name implies. Within these two broad categories additives can be classified more specifically into groups which describe their precise functions, these are: metallic detergents, detergent-inhibitors, ashless dispersants, antioxidants, anti-wear agents, rust \& corrosion inhibitors, friction modifiers, extreme pressure agents, anti-foam agents, viscosity improvers, pour point depressants, and seal swell agents.

\section{TABLE-1}

ADDITIVE TYPES

\begin{tabular}{|l|l|}
\hline \multicolumn{1}{|c|}{ BASEFLUID MODIFIERS } & \multicolumn{1}{|c|}{ METAL PROTECTORS } \\
\hline ANTIOXIDANTS & ANTIWEAR \\
DISPERSANTS & ANTIRUST \\
ANTIFOAM AGENTS & ANTICORROSION \\
POUR POINT DEPRESSANTS & DETERGENTS \\
VISCOSITY MODIFIERS & FRICTION MODIFIERS \\
\hline
\end{tabular}




\section{TABLE - 2}

\section{LUBRICANT ADDITIVES}

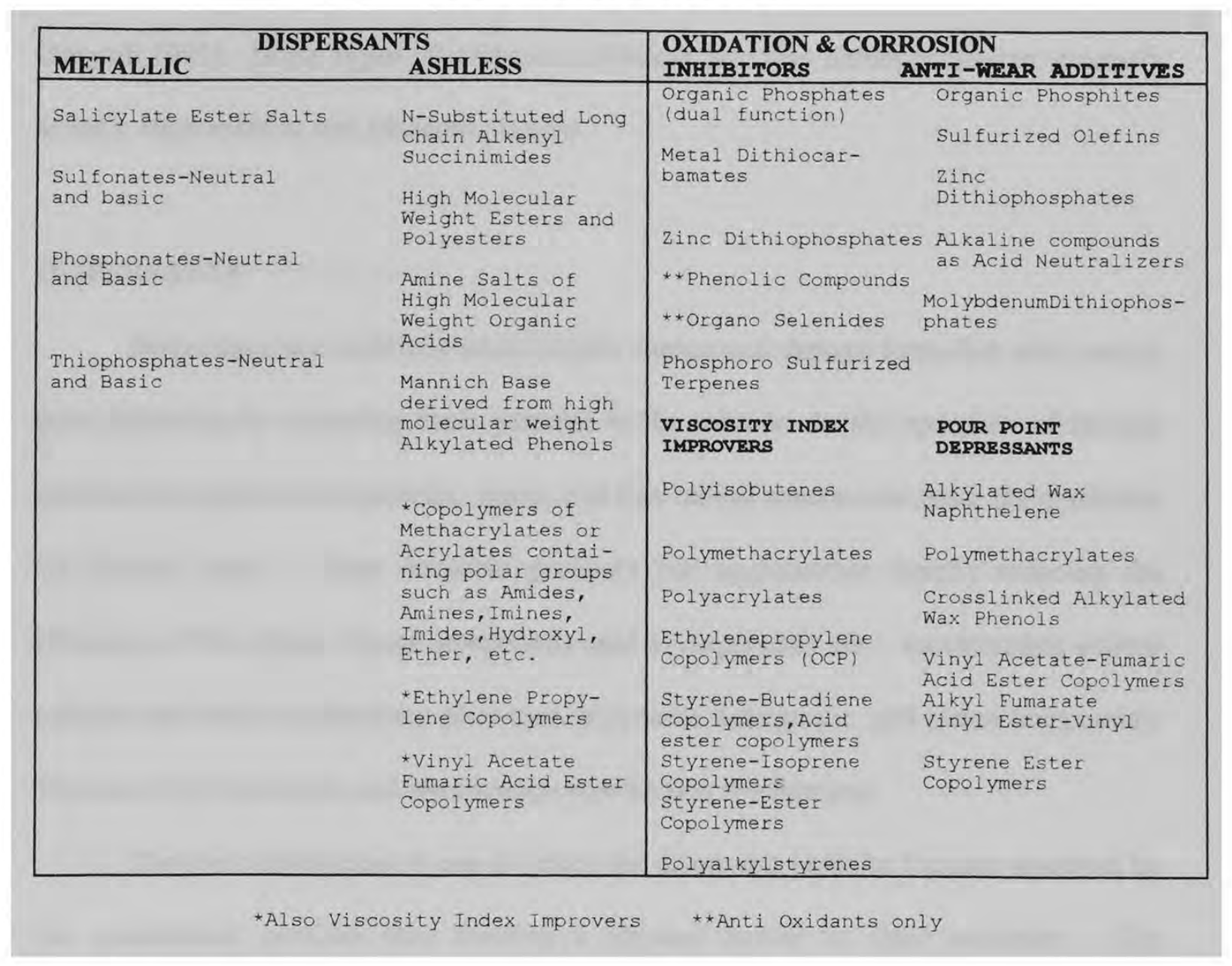

\section{BASEFLUID MODIFIERS}

\section{ANTIOXIDANTS}

The function of antioxidants is to prevent the oxidative decomposition of the basefluid. Oxidation combined with continuous operating temperatures above $150^{\circ} \mathrm{C}$ can break down the oil chemically causing viscosity variations which severely impair the performance of the lubricant(Latto \& Yang, 1991). 
When mineral oils react with oxygen at high temperatures they can produce organic acids, sludge, and gum which lead to viscosity increases and darkening of color (Godfrey \& Herguth,1995). Some types of oxidation inhibitors are: zinc dithiophosphates; aromatic amines; alkyl sulfides; and hindered phenols.

\section{DISPERSANTS}

Dispersants are additives which inhibit sludge and deposit formation and control soot thickening by scattering these particles in the solution. In the operation of internal combustion engines soot particles, water, and free radical sources can enter the crankcase via blowby gases. These insoluble products can agglomerate thereby reducing the efficiency of the engine. Some compounds used as dispersants are: succinimides; neutral calcium and barium sulfonates; phenates; polymeric detergents; and amine compounds. They work by both steric and electrostatic stabilization mechanisms.

The steric mechanism is one in which the dispersant particles become absorbed by the contaminant particles thus forming a physical barrier to their attraction. The electrostatic mechanism develops surface charges on the particles which counteract the attractive forces between particles dispersed in the lubricant.

\section{ANTI-FOAM AGENTS}

Foam can be produced on the oil surface due to the agitating effect produced in an engine turning at high speeds. It is defined as the production and coalescence of gas bubbles on a lubricant surface. 
Foaming can cause bearings and pumps to be starved of liquid lubricant due to cavitation which in turn can cause failure. Anti-foam additives prevent this build-up by modifying the surface tension of the basefluid. Common antifoam agents used are silicone and organic copolymers.

\section{POUR POINT DEPRESSANTS}

At low temperatures mineral oils can exhibit an increase in viscosity due to the gelling of the oil by the precipitation of crystalline wax. Pour point depressants interfere with the crystallization of the wax by limiting the volume of each crystal formed. This reduction in crystal volume permits the flow of lubricant at low temperatures. Some additives used as pour point depressants include: alkylated wax naphthalene, polymethacrylates, and alkylated wax phenols.

\section{VISCOSITY MODIFIERS}

Base oils can vary their viscosity by factors which are too large to maintain proper fluid film lubrication for large temperature changes, therefore viscosity modifiers are used to control this effect. These modifiers raise the viscosity of the oil at all temperatures but the effect is more pronounced at higher temperatures which significantly improves the viscosity index of the lubricant. The increase in the viscosity index is defined as a decrease in slope of the viscosity-temperature line plotted on ASTM log paper. Compounds such as polymethacrylates and polyisobutenes are commonly used as viscosity modifiers. 


\section{METAL PROTECTORS}

\section{ANTIWEAR AGENTS}

Antiwear agents form thin boundary layers on metal surfaces which prevent the moving parts from coming in contact with one another. This function, as a result, reduces metal loss due to wear. One of the principal causes of failure in engines is due to wear of the piston assembly.

Some compounds widely used for anti-wear are: zinc dithiophosphates(ZDTP), molybdenum dithiophosphates(MoDTP), organic phosphites and others containing phosphorus and sulphur. There have been tests conducted on several of these compounds in order to examine their effectiveness(Vipper \& Bartz, 1995). It has been shown that ZDTP can increase the thermal stability of the lubricating films at temperatures not exceeding $150^{\circ} \mathrm{C}$. Another compound tested, MoDTP, also shows improvement in the antiwear properties of the oil as long as there are also organic $\mathrm{P}=\mathrm{O}$ and $\mathrm{P}=\mathrm{S}$ mixtures present(Lin, 1995).

\section{ANTIRUST AND ANTICORROSION}

Antirust and anticorrosion agents prevent moisture, oxygen, acids, and other harmful elements from coming in contact with the metal surfaces where they can react chemically with the metals to form rust and corrode the surfaces. There are two mechanisms by which this is accomplished, one is called chain breaking and the other is peroxide destroying. In chain breaking, the additive destroys the free radicals of the corrosive acids before they can do harm. 
These acids can be produced as a result of the blowby of gases during combustion. Commercially, a variety of hindered phenols are used for this purpose. ZDTP is an additive with many uses, and is considered a peroxide destroying compound for its corrosion protection properties. It acts by interacting with the peroxides which are the main culprits involved in the oxidation mechanism. ZDTP is also capable of forming a protective film on the bearing surface making it resistant to acid attack.

\section{DETERGENTS}

Detergents do a job similar to the dispersants in that they do not allow deposits to accumulate. However, their job is to prevent these deposits from collecting on the metal surfaces. They do this by holding in suspension the solid and semi-solid particles produced as byproducts of oxidation and combustion(Schilling, 1968). If these deposits were allowed to collect on some vital engine parts such as piston rings, the engine's performance would be impaired and premature failure could occur. Detergents can be of two classes, metallic and non-metallic or "ashless".

\section{FRICTION MODIFIERS}

Friction modifiers work in conjunction with the antiwear agents to form a thin film on the surface of moving parts but with the effect of reducing the frictional forces and thus providing better fuel economy. The mechanism by which they work is that they are either absorbed on, or react with the metal surface to form monolayers with low shear strength. This process is only effective under conditions of boundary lubrication. 
Since the fluid film has a lower shear strength, the force which keeps the moving surfaces from sliding freely is reduced.

There exist other additives which do not have to do with the performance of the lubricant itself or the engine tribology. An example of these are the seal swell agents which are used to expand the rubber of oil seals so that they perform their job more efficiently. There also exist additives which are specific to applications other than engines. These can be additives used for differentials and transmissions whose operating conditions require other functions from their lubricants.

\section{PS 23 - AN OVERVIEW}

Engine oil additives normally are available as ingredients already mixed into the motor oils which are available on the market. There now exist many types of additives such as Slick 50, and Duralube which are designed to be mixed with motor oils in order to enhance the oil's lubricating qualities. PS- $23 \AA$ is a newly developed additive package of this type.

PS-23® is a concentrated sulfonate-based oil conditioner containing petroleum additives and natural hydrocarbons designed to minimize friction and wear. The manufacturer recommends that it be mixed with oil in a $3 \%$ to $10 \%$ concentration and is to be used for all types of machinery and engines. The manufacturer of PS-23 8 has been served with many letters and testimony from users of their product which praise PS-23® for it exceptional qualities. It has been claimed to even allow seized engines to run once again for long periods of time without any mechanical repairs. 
Based on this testimony it is clear that this product is worth a detailed study of its function in the battle against friction and wear.

\section{1-2. ADDITIVES USED IN GEAR OILS}

Gear oils have a different composition of additives than do motor oils mainly because of the lack of fuel degradation products. The emphasis for gear lubricants is in wear reduction, heat dissipation, and oxidation prevention. Some of the oxidation, rust and foam inhibitors used for gear oils are in general the same ones used for motor oils, however, the anti-wear and extreme pressure additives must be chosen carefully so that they become active only under the temperature and pressure conditions which require their activity(Asseff). This is needed in order to avoid reactions which could be harmful to the system such as excessive wear or formation of deposits in oil passages.

Straight tooth gears such as those in manual transmissions and differentials require lubricants with enough viscosity to maintain a hydrodynamic film under load. Higher loaded gears require the use of extreme pressure and anti-wear additives in addition to the higher viscosity of the base oil. The most common additives used for this purpose are highly active extreme pressure (EP) compounds containing sulphur and phosphorus (Trabert, 1990).

The mechanism by which sulphur-phosphorus additive chemistry works in gear oils is as follows. High local temperatures produce a chemical reaction with the metal and forms a thin film of iron oxides, sulfides, and phosphates on the gear surfaces. This film protects the gear surfaces from excessive wear or welding of the surfaces. 
However, this process does produce some sacrificial wear which over time goes beyond the allowable tolerances for the design. Ideally, these additives should only work in areas where there is danger of welding or areas of high temperature. If the reaction rate with the metal is too high, such as when the (EP) additives are too chemically reactive, then the continuos removal of surface film can produce excessive wear which can manifest itself as polishing (Errichello, 1991).

Another type of gear oil anti-wear package was developed by Chevron Research and Technology company which uses potassium triborate. This additive package works by forming a potassium borate film on the gear surfaces about four times thicker than sulfur phosphorus film and does so without reacting with the metal. Since there is no reaction with the metal, much less wear occurs (Trabert, 1990).

\section{1-3. OUTLINE OF RESEARCH}

The objective of the research conducted was to determine the effectiveness of PS$23 \otimes$ as an additive to commercially available automobile lubricants. For this purpose three types of experimental studies were designed and conducted. The first was a road test using two used vehicles, the second involved new small displacement 4-cycle engines, and the third was a bench test of the product. In the second and third tests, performance of the additive was determined by means of comparison under the same conditions between oils with no additives and oils mixed with other commercially available additives including PS-23®. 


\section{A. ROAD TEST DESCRIPTION}

A series of road tests were scheduled in the metropolitan area adjacent to Florida International University, Miami, Florida in order to observe the effect of PS-23® as a lubricant additive on vehicle operation. These tests were to utilize used passenger vehicles under normal to severe operating conditions and were designed to provide information on vehicle operating parameters, they were not designed to be capable of analyzing wear and friction.

\section{B. SMALL ENGINE TESTS DESCRIPTION}

A second set of tests were designed using three Briggs and Stratton 3.5 HP 4 cycle engines to test the effect of PS-23® on engine wear. By using new engines for these tests, this effect could be studied in a controlled fashion.

\section{BLOCK-ON-PIN MACHINE TESTS}

The third series of tests designed consisted of two types of bench tests using a block-on-pin testing apparatus. The first one was designed to determine the effect from each of the oils tested on the frictional coefficient under full film lubricating conditions, while the second was designed under boundary lubricating conditions. 


\section{CHEMICAL AND PHYSICAL LUBRICANT ANALYSIS:}

The chemical and physical analysis were scheduled to include spectrochemical tests along with viscosity and volatility measurements to study the variation of lubricant properties as a result of adding PS-23.

It was expected that the combination of these tests would produce a research work capable of evaluating the tribological behavior of PS-23 as a lubricant additive package, and thus suggest the possible applications for PS-23 in lubrication. 


\section{CHAPTER II:}

\section{EQUIPMENT AND MATERIALS}

\section{2-1. USED VEHICLES}

The vehicles used for the road tests are described in Table- 3 while Table- 4 describes the test oils used in these vehicles. Both vehicles were purchased without any knowledge as to their prior service history, therefore the internal conditions of the engines were unknown. The vehicles were tuned and minor mechanical repairs were performed in order for them to be in good running condition.

Table-3

ROAD TEST VEHICLES

\begin{tabular}{|ll|lc|}
\hline Vehicle & Make $\quad$ Model & Year & Engine Displacement \\
\hline Vehicle I & Ford Lincoln Continental Mark VI & 1979 & 6.6 liter \\
\hline Vehicle II & Ford Mercury Grand Marquis LS & 1983 & 5.8 liter \\
\hline
\end{tabular}

Table-4

LUBRICANTS TESTED

Oil I: Mobil 10W-30 Motor Oil

Oil II: Mobil $10 \mathrm{~W}-30$ with $15.8 \% \pm 0.05 \%$ PS- 23 by volume 


\section{2-2. BRIGGS AND STRATTON ENGINES WITH WATER PUMP}

Three Homelite $\otimes$ AP-220 140 GPM portable engine driven water pumps were purchased new for use in the small engine tests. These pumps are powered by a Briggs \& Stratton 3.5 HP 4 cycle gasoline engine model 91232 . The pumps were mounted on a wheeled table as shown in Figure-1. By running the pumps with a continuous water supply, the engines operated under their intended load. The engines were equipped with single barrel carburetors which were governed to run the engines at speeds close to 3600 RPM with no load. The idle speed of the engines is 1800 RPM as specified by the manufacturer.

\section{2-3. BLOCK-ON-PIN MACHINE FOR TRIBOLOGICAL TESTS}

The block-on-pin machine used for the tribological tests was designed according to the block-on-ring test referenced by ASTM standard G-77 (Blau, 1995). This type of test machine can be purchased commercially and is in widespread use for tribological tests. The block-on-pin machine consists of a rotating pin upon which the material sample is placed under load. The load is measured by a load cell from which the sample holder is suspended and which is placed perpendicular to the rotating contact area. A second load cell is mounted tangentially to the rotating contact area keeping the sample holder steady during the tests and at the same time measuring the frictional force exerted between the rotating pin and the test sample.

The test unit used in these experiments belongs to the Florida International University Mechanical Engineering Dept., and is pictured in Figure-2. The pin is 
replaceable on the machine before each test with a new pin. The machine is designed to accept a standard hollow steel piston pin which is 0.9 " diameter by 3.0 " in length.

The pin is rotated by a $1.5 \mathrm{HP}$ electric motor mounted in the back section of the machine with its speed controlled by an $\mathrm{A} / \mathrm{C}$ inverter. The speed of the pin can be adjusted from 10-1740 RPM simply by adjusting the hertz output from the inverter.

\section{2-4. INSTRUMENT USED FOR SURFACE MEASUREMENT}

All the surface profile readings taken from the internal engine parts as well as the readings taken from the tribological test samples, were done using the Taylor-Hobson Surtronic $3+$ profilometer pictured in Figure-3. The stylus used has a conical tip with a diameter of $10 \mu \mathrm{m}$. The stylus arm, shown in Figure-4, has an integrated skid set behind the stylus which runs over the surface being measured and provides a reference point for the reading.

The profilometer contains a small electric motor which moves the arm over the surface to be tested at a steady speed. The data collected by the profilometer is sent via a serial port connection to a P.C. equipped with the Taylor-Hobson software. The information collected can be stored as ASCII files or formatted to the software's specifications. The software has the capability of using various types of statistical methods in order to filter the data. For all tests conducted in this report, the data was to be collected unfiltered. 


\section{2-5. SAMPLES USED FOR TRIBOLOGICAL TESTS}

The samples used were made from $3 / 4$ " rod 1144 "stress proof" medium carbon steel containing $0.44 \%$ carbon. It is recommended for use in car and truck axles and for gear assemblies due to its high strength and easy machining properties. The AISI 1100 series of steel contain high sulfur $(0.24-0.33 \%)$ in the form of manganese sulfide inclusions. Table-5 lists some of the properties of 1144 steel.

Table-5

Properties of 1144 Medium Carbon Steel

\begin{tabular}{cccccc}
\hline \multicolumn{2}{c}{ Tensile Strength } & \multicolumn{2}{c}{ Yield Strength } & Brinell & Thermal Conductivity \\
$\mathrm{MPa}$ & $1,000 \mathrm{psi}$ & $\mathrm{MPa}$ & $1,000 \mathrm{psi}$ & Hardness & $\left(\frac{\text { watts }}{\mathrm{mm}^{2}}\right) /\left(\frac{{ }^{\circ} \mathrm{C}}{\mathrm{mm}}\right)$ \\
\hline 772 & & 95.2 & 223 & 0.048 \\
\hline
\end{tabular}

Figure- 5 shows a diagram of the samples used for the tribological tests. Figure5(a) shows the samples used in the boundary lubrication runs, and Figure-5(b) shows the samples used in the full film lubrication tests. The basic difference between the two is the contact area which is of a smaller diameter for the full film tests since a higher load per unit area was needed, and the inclusion of a small hole near the contact surface used for the insertion of a thermocouple. 


\section{2-6. LUBRICANTS}

The base oils used for all tests were either Mobil 10W-30 motor oil or Valvoline $80 \mathrm{~W}-90$ gear oil. Both are sold commercially and to the public and thus are in widespread use for all types of vehicles. Table- 6 shows some of the physical characteristics of the lubricants used for this study.

TABLE-6

PHYSICAL CHARACTERISTICS OF LUBRICANTS

\begin{tabular}{|c|c|c|}
\multicolumn{1}{c}{ LUBRICANT } & VISCOSITY(cSt) @ ${ }^{\circ} \mathrm{C}$ & FLASH POINT $\left({ }^{\circ} \mathrm{C}\right)$ \\
\hline Slick-50 & $72.0 @ 40$ & 191 \\
\hline Duralube & $32.3 @ 40$ & 115 \\
\hline PS-23 & $24.9 @ 40$ & 196 \\
\hline Mobil 10W-30 & $70.0 @ 40$ & 207 \\
\hline Valvoline 80W-90 & $137 @ 40$ & 191 \\
\hline
\end{tabular}

The additives used for comparison were Slick-50® and Duralube ${ }^{\mathrm{TM}}$, these were always mixed with one of the base oils in their recommended proportions in order to carry out tests on their performance. Slick- $50 ®$ is an additive marketed to the end user which uses DuPont Teflon ${ }^{\circledR}$ as its active ingredient. Duralube ${ }^{\mathrm{TM}}$ is also marketed as an additive to motor oil but its ingredients are a company secret.

Both products, Duralube ${ }^{\mathrm{TM}}$ and Slick-50®, have undergone tests by private laboratories in order to test their effectiveness. A few technical papers have been published based on the tests performed on Slick-50®. These tests have shown that Slick-50® 
reduces the amount of wear on internal engine parts and reduces friction (Wilson, 1995;

Schaub et al, 1994; Treuhaft et al, 1994).

The spectrochemical tests for PS-23® and Duralube were performed by Analysts, Inc., an independent laboratory. The results are printed in Table-7.

TABLE-7

SPECTROCHEMICAL ANALYSIS RESULTS FOR OIL ADDITIVES

\begin{tabular}{l} 
COMPOUND \\
\begin{tabular}{|l|c|l|}
\hline SODIUM & PS-23 (PPM) & DURALUBE (PPM) \\
\hline PHOSPHORUS & 3 & 100 \\
\hline ZINC & 859 & 387 \\
\hline CALCIUM & 1518 & 693 \\
\hline MAGNESIUM & 3059 & 235 \\
\hline POTASSIUM & 10 & 90 \\
\hline MOLYBDENUM & $<10$ & $<10$ \\
\hline BARIUM & $<5$ & $<5$ \\
\hline ANTIMONY & $<10$ & $<10$ \\
\hline ALUMINUM & $<30$ & $<30$ \\
\hline
\end{tabular} \\
\hline
\end{tabular}

NOTE: ALL OTHER COMPOUNDS PRESENT WERE AT LEVELS OF LESS THAN 2 PPM.

PS-23 contains very high concentrations of zinc, calcium and phosphorus. The ratio between phosphorus and zinc for both PS-23 and Duralube are quite close; 0.566 for PS-23 and 0.558 for Duralube. These ratios suggest that the (EP) additive in both products may be the same or similar. The high concentration of calcium in PS 23 suggests a possibility of high concentrations of detergent.

Viscosity analysis was conducted on the base oils with and without the lubricant additives by following ASTM designation D 446 - 85a. Three sizes of Cannon-Fenske 
routine viscometers were used. Size 300 was used for readings at $30^{\circ} \mathrm{C}$ and $40^{\circ} \mathrm{C}$, Size 200 was used at $50^{\circ} \mathrm{C}$ and $60^{\circ} \mathrm{C}$, and size 150 at $80^{\circ} \mathrm{C}$ and $100^{\circ} \mathrm{C}$.

First the viscometers are filled with the oil to be tested and put into the constant temperature bath for 10 minutes. The oil sample is then siphoned to above the upper mark on the viscometer. The time it takes for the fluid meniscus to flow from the upper to the lower mark on the viscometer is measured in seconds. The viscosity is then calculated by multiplying the time result by the viscometer calibration constant supplied with each individual viscometer. Viscosity test results for $10 \mathrm{~W}-30$ and $80 \mathrm{~W}-90$ oils with and without PS-23 additive are shown in Figures 6 and 7. 


\section{CHAPTER III:}

\section{RELATED THEORIES OF LUBRICATION AND SURFACE STATISTICS}

\section{3-1. SURFACE STATISTICS}

In modern gear and engine designs there is not much of a problem relating to complete breakage of parts except those involving manufacturing or material defects. With the use of computer aided design and finite element analysis, parts are being designed very efficiently and are able to withstand the loads they have been intended for. Because of this most of the problems involving failure of engine and gear parts, are due to surface wear and or surface damages caused by improper lubrication.

Surface texture is an important aspect in the field of tribology. Surface texture can influence the thickness of the fluid lubricant film, and the frictional coefficient between two moving parts. For tribological elements lubricant films may be very small, therefore, a small amount of surface wear and or drastic variation in surface roughness can render them unusable.

When examining surface texture three different terms are used which describe the spacing of the irregularity heights, they are: roughness, curvature, and waviness. If a surface profile is considered in terms of constant amplitude waves along the surface, the fluctuations with the largest wavelengths would be considered the curvature, those which are slightly smaller would be the waviness, and yet those which have the smallest wavelength would be the roughness. Roughness (also called microroughness) and 
waviness (also called macroroughness), constitute the texture of the surface and are the parameters commonly examined in tribological studies (Halling, 1975).

It has been universally agreed that in general applications one of the most important factors of surface texture is the roughness height (Dagnall, 1986). Since the roughness of a surface is in the order of magnitude of micrometers, the way it is examined is by means of surface statistics whereby irregularities are represented generally as averages. Two parameters based on the roughness height are used to define the texture of a surface, these are C.L.A. (center line average) and R.M.S (root mean square). Mathematically they are written as

$$
\text { C.L.A. }=\frac{1}{n} \sum_{i=1}^{n}\left|z_{i}\right|
$$

and

$$
\text { R.M.S. }=\left[\frac{1}{n} \sum_{i=1}^{n}\left(z_{i}\right)^{2}\right]^{1 / 2}
$$

Where $z_{i}$ is the digitized asperity height in micro-meters, and $n$ is the number of data collected.

Using these parameters one may arrive at the same C.L.A. and R.M.S. values for surfaces with widely differing profiles, therefore they should be used to classify surfaces of the same type produced by the same method. Even though it is possible to visually inspect the profile graphs of the different surfaces, the analysis can be somewhat subjective. In this 
study, the surface roughness was used to compare the same parts before and after their respective test runs.

\section{3-2. VOLATILITY CALCULATIONS AND VISCOSITY-TEMPERATURE RELATIONS}

Volatility is defined as the rate at which a liquid will become a vapor at a relatively low temperature. The volatility of a fluid as tested by the following method provides a guide as to the amount of volatile matter that will be emitted from the tested oils. These tests were performed based on ASTM designation C $681-84$ of 1989.

First, an aluminum foil dish of a $3 "$ diameter was weighted to the nearest $0.01 \mathrm{~g}$ and then filled with approximately $5 \mathrm{~g}$ of oil sample, where the difference between the two samples is less than $.01 \mathrm{~g}$. The dish and sample were then weighed together to the nearest $0.01 \mathrm{~g}$ and the weight recorded. Thirdly, the dish and sample were placed in an oven for 3 hours at a temperature of $220^{\circ} \mathrm{F}$. Finally, the sample was allowed to cool for 10 minutes and re-weighed.

The percent of volatile matter, $\mathrm{V}$, was calculated by the formula:

$$
V=[(A-B) / C] \times 100
$$

where:

$$
\begin{aligned}
& \mathrm{A}=\text { weight of the dish plus the sample, } \mathrm{g} \text {, } \\
& \mathrm{B}=\text { weight of the dish plus the sample after heating, } \mathrm{g} \text {, and } \\
& \mathrm{C}=\text { sample weight, } \mathrm{g} \text {. }
\end{aligned}
$$


The viscosity of the lubricant can be expressed as a function of temperature, except under conditions of extreme pressure, by the logarithmic relation

$$
\log (\log (v+0.6))=A_{1}+\left(A_{2} \log T\right)
$$

where $v$ is the measured viscosity of the lubricant in cSt at a constant temperature $T\left({ }^{\circ} \mathrm{K}\right)$, and $A_{1}, A_{2}$ are constants.

\section{3-3. EQUATIONS FOR FLUID FILM THICKNESS AND SURFACE TEMPERATURE CALCULATIONS}

The most important parameter in determining whether moving surfaces are properly lubricated is the minimum fluid film thickness. Elastohydrodynamic (EHL) analysis usually consists of producing a formula which will give the minimum film thickness based on the operating conditions. It is usually desirable to obtain a minimum film thickness which is of a larger magnitude than the roughness of the surfaces being analyzed. The formulas used in this work are based on the work of Greenwood(1969) and Johnson(1970).

First, the parameters to be used are expressed in the following dimensionless groups.

The dimensionless film thickness: $\quad \hat{H}=\frac{h_{o}}{R}$

The load parameter:

$$
\hat{W}=\frac{W}{E^{\prime} R B}
$$

The speed parameter:

$$
\hat{U}=\frac{\eta_{o} U}{E^{\prime} R}
$$


The materials parameter: $\quad \mathrm{G}=\alpha E^{\prime}$

where:

$h_{0}=$ minimum film thickness $(\mu \mathrm{m})$

$\mathbf{R}=$ equivalent radius $(\mathrm{mm})$

$\mathrm{W}=$ load (newtons)

$E^{\prime}=$ equivalent Young's modulus

$B=$ contact area width $(\mathrm{mm})$

$\eta_{\mathbf{0}}=$ viscosity of lubricant at atmospheric pressure and a constant temperature, pose

$\mathrm{U}=$ linear speed of surfaces $(\mathrm{m} / \mathrm{s})$

$\alpha=$ pressure viscosity parameter $=2.3 \times 10^{-7}$, may be used for most mineral oils (Arnell et al, 1993)

The equivalent radius $\mathrm{R}$ and equivalent Young's modulus $E^{\prime}$ are calculated according to the following formulas:

For counterformal contacts:

$$
R=\frac{R_{1} R_{2}}{R_{2}+R_{1}}
$$

For conformal Contacts:

$$
R=\frac{R_{2} R_{1}}{R_{2}-R_{1}}
$$

An illustration of conformal and counterformal contacts is shown in Figure-8.

The equivalent Young's Modulus $E^{\prime}$ is calculated by:

$$
\frac{2}{E^{\prime}}=\frac{\left(1-\gamma_{1}^{2}\right)}{E_{1}}+\frac{\left(1-\gamma_{2}^{2}\right)}{E_{2}}
$$


Where $\gamma$ is Poisson's ratio of the material. In the cases studied for this report, the contacts tested are all steel on steel, therefore $\mathrm{E}_{1}=\mathrm{E}_{2}=208 \times 10^{9} \mathrm{~Pa}$ and $\gamma_{1}=\gamma_{2}=0.3$, which when calculated gives a value for $E^{\prime}$ of $228 \times 10^{9} \mathrm{~Pa}$.


\section{FIGURE - 8}

Formal (a) and counterformal (b) contact between two surfaces

From the dimensionless parameters previously calculated, the following equations are used:

$$
\begin{gathered}
g_{h}=\left(\frac{\hat{W}}{\hat{U}}\right) \hat{H} \\
g_{v}={\frac{\hat{W}^{\frac{3}{2}}}{\hat{U}^{\frac{1}{2}}} \hat{G}}^{g_{e}}=\frac{\hat{W}}{\hat{U}^{1 / 2}}
\end{gathered}
$$

film thickness can know be expressed by the use of Table- 8 and the equation:

$$
g_{h}=Z g_{v}^{m} g_{e}^{n}
$$


Table-8

Solutions to Fluid Film Thickness Equation by Regimes of Contact

\begin{tabular}{llll}
\hline Regime & $\mathrm{Z}$ & $\mathrm{m}$ & $\mathrm{n}$ \\
\hline$(1)$ & 2.45 & 0 & 0 \\
$(2)$ & 1.05 & $2 / 3$ & 0 \\
$(3)$ & 2.45 & 0 & 0.8 \\
$(4)$ & 1.654 & 0.54 & 0.06 \\
\hline
\end{tabular}

In order to determine the appropiate regime, it is necessary to refer to the "Regimes for Rectangular Chart" shown in Figure-9. Once the regime is established, the values for $Z, m$, and $n$ can be substituted into equation 3.14 , then by using equations 3.4 and 3.11 the value for $h_{o}$ can be calculated.

The region of mixed lubrication can be determined by the non-dimensional film thickness, $\Lambda$.

$$
\Lambda=\frac{h_{o}}{R M S} \quad \text { (3.15) (Cheng, 1993) }
$$

For $\Lambda>3$, the contact elements are in a full film lubrication state. A mixed lubrication state occurs if $0.5<\Lambda<3$, and for $\Lambda<0.5$ the lubrication state becomes boundary lubrication. 
Another parameter which will be needed in analyzing the block-on-pin tests, is the flash temperature. The flash temperature is the steady state temperature within the contact area. Based on the geometry of the block-on-pin tests carried out during this study, the proper analogy in calculating the flash temperature at the contact area is to consider the formulas used for a stationary heat source (Halling, 1975).

The mean temperature rise, $\Delta \theta$, at the surface is given by:

$$
\Delta \theta=\frac{Q}{4 a \alpha}
$$

Where $\alpha$ is the thermal conductivity of the body, $Q$ is the rate of heat supply, and $a$ is the equivalent surface area. For a simplified analysis, $a$ is calculated by taking an equivalent to the equation $A=\pi a^{2}$ where $A$ is a circular contact area (Archard, 1959). The value $A$ is calculated by multiplying the width by the length of the contact scar, and from this result together with Archard's equation, $a$ is calculated. The rate of heat supply, $Q$, can be calculated in this case by use of the equation, $Q=\mu P V \quad$ where $\mu$ is the frictional coefficient, and $P$ is the normal load (Halling, 1975). If it is assumed that the temperature of other points on the body far away from the source is zero, then $\Delta \theta=\theta_{S}$, were $\theta_{S}$ is the mean surface temperature of the body.

For the contact analyzed, both bodies can be considered semi-infinite and thus the surface temperature of both the pin and the sample can be separately calculated using the following equations:

$$
\theta_{1}=\theta_{s} \lambda
$$


where $\theta_{l}$ is the temperature on the surface of the sample.

$\lambda$ is known as the heat partition in two contact elements. The value of, $\lambda$, is defined as the ratio of the thermal diffusivities of the two bodies, that is

$$
\frac{\lambda}{1-\lambda}=\frac{\alpha_{1} / \rho_{1} c_{1}}{\alpha_{2} / \rho_{2} c_{2}}
$$

Where $\alpha_{1}, \rho_{1}$ and $c_{1}$ are the thermal conductivity, specific heat and density of body 1 respectively, and $\alpha_{2}, \rho_{2}$ and $c_{2}$ are the same properties for body 2 . 


\section{CHAPTER IV:}

\section{EXPERIMENTAL RESULTS FROM ENGINE TESTS.}

\section{4-1. USED VEHICLE TESTS}

Used vehicle tests were designed to observe the effect of PS-23 as a lubricant additive on vehicle operation. Two used passenger cars, vehicles I and II, as listed in Table-3 (Section 2-1) were utilized as the test vehicles. Two oils, oil I, which was commercial Mobil 10W-30 oil, and oil II, which was oil I with PS-23® additive as shown in Table-4(Section 2-1), were used as engine lubricants. The road test duration for each of these vehicles was six hours in three steps: (1). two-hour run with oil $I,(2)$. two-hour run with oil II, (3). two-hour run with a dry sump after complete drainage of oil II used for step (2). Each two-hour run was designed to provide sufficient time to the lubricant to perform the desired functions. In the oil changes for each step of the test, complete drainage of the used oil was followed by a five minute engine flush with oil I and a new replacement filter. The flush oil was then drained and replaced with the test oil and new oil filter.

The driving tests for both vehicles were performed under similar environmental and road conditions, and the tested vehicles experienced both high speed (above $50 \mathrm{mph}$ ) and low speed driving. During the tests. oil sump temperature, oil pressure, and water temperature were monitored. The test conditions and results are listed in Tables-9 and 10. 
Adding PS-23 to the 10W-30 base oil did not result in changes of oil and water temperatures.

Table-9

Test Records for Vehicle I

\begin{tabular}{|c|c|c|c|c|c|c|}
\hline Test Step & Time & $\begin{array}{c}\text { Outdoor } \\
\text { Temp } \\
\left({ }^{\circ} \mathrm{C}\right)\end{array}$ & $\begin{array}{c}\text { Avg.Water } \\
\text { Temp }\left({ }^{\circ} \mathrm{C}\right)\end{array}$ & $\begin{array}{c}\text { Avg. Oil } \\
\text { Pressure } \\
(\mathrm{psi})\end{array}$ & $\begin{array}{c}\text { Avg. Oil } \\
\text { Temp. }\left({ }^{\circ} \mathrm{C}\right)\end{array}$ & $\begin{array}{c}\text { Running } \\
\text { Distance } \\
(\text { miles})\end{array}$ \\
\hline Step I(oil II) & $10: 05-12: 05$ & $31.0-31.5$ & 92 & 23 & 109 & 75 \\
\hline Step II (oil II) & $12: 55-14: 55$ & $32.5-33.5$ & 92 & 22 & 109 & 79 \\
\hline $\begin{array}{c}\text { Step III (dry } \\
\text { Sump,wet Filter) }\end{array}$ & $17: 10-19: 17$ & $29.0-30.0$ & 91 & N/A & N/A & 63 \\
\hline
\end{tabular}

Table-10

Test Records for Vehicle II

\begin{tabular}{|c|c|c|c|c|c|c|}
\hline Test Step & Time & $\begin{array}{c}\text { Outdoor } \\
\text { Temp } \\
\left({ }^{\circ} \mathrm{C}\right)\end{array}$ & $\begin{array}{c}\text { Avg.Water } \\
\text { Temp }\left({ }^{\circ} \mathrm{C}\right)\end{array}$ & $\begin{array}{c}\text { Avg. Oil } \\
\text { Pressure } \\
(\mathrm{psi})\end{array}$ & $\begin{array}{c}\text { Avg. Oil } \\
\text { Temp. }\left({ }^{\circ} \mathrm{C}\right)\end{array}$ & $\begin{array}{c}\text { Running } \\
\text { Distance } \\
(\mathrm{miles})\end{array}$ \\
\hline Step I(oil II) & $09: 15-11: 15$ & $29.0-31.0$ & 78 & 31 & 95 & 81 \\
\hline Step II (oil II) & $12: 55-14: 55$ & $32.0-32.5$ & 80 & 28 & 97 & 81 \\
\hline $\begin{array}{c}\text { Step III (dry } \\
\text { Sump,dry Filter) }\end{array}$ & $\begin{array}{c}15: 10-15: 35 \\
\text { failed }\end{array}$ & 30.0 & $92 \uparrow$ & N/A & N/A & 6.51 \\
\hline
\end{tabular}

For step III an extreme condition of engine lubrication was tested: dry sump with no oil supplied to the engine elements. Vehicle II with a dry filter ran for about 25 minutes covering 6.51 miles before engine seizure, as indicated by the drastic water temperature increase. Vehicle I with an oil-wet filter ran for the entire two-hour dry sump test on road conditions similar to those in steps I and II.

Since vehicle I did not experience engine failure during the dry sump test the engine was disassembled and the engine elements such as crankshaft, piston rings, and 
skirts were examined using the scanning electron microscope. Upon examination of the micrographs, shown in Figures 10-12, it can be seen that only normal wear has taken place in these elements, and there was no detrimental damage even after running step III. Other pictures of the engine elements, shown in Figure-13, confirm that step III did not result in very severe damage to the parts.

The drained oils from vehicle I were collected and the debris analyzed with the EDX to its composition after each step, the results are shown in Figures 14-16. The high concentration of iron in the debris collected from the oil of step III, suggests that there was a high degree of wear in the parts due to the non-continuous oil supply. Also tested was the viscosity of the used oils from the road tests of vehicle \# 1 , the results show a lower viscosity in the oil with the use of PS-23 (Figure-17).

\section{4-2. SMALL ENGINE TESTS}

The purpose of the small engine tests was to determine the effect of PS-23 on engine wear. Two small 4-cycle engines were purchased new and each powered a 140 GPM centrifugal water pump. Since the small engines were designed with a very short life, it was anticipated that their combustion environment would provide one of the worst conditions necessary for testing of the oil.

Engine \# 1 was run using Mobil 10W-30 motor oil, while engines 2 and 3 used the same Mobil 10 W-30 with $10 \%$ by volume mixture of PS-23@. In order to provide load to the engines, the pumps were set up as a closed loop from a 55 gallon drum (Figure-1). Each engine was disassembled before and after each run and the piston assembly parts 
weighed and subjected to surface roughness measurements. The parts tested were the connecting rod, wrist (piston) pin, and piston rings.

Each run consisted of start-stop cycles where the engines were run for approximately 15 minutes and stopped for 5 minutes (Table-11). The total running time per run was 8 hours. The revolutions were continuously monitored so as to verify proper engine performance.

TABLE-11

ENGINE RUN SCHEDULE

$\begin{aligned} & \text { ENGINE } \\
& \text { NO. }\end{aligned}$
\begin{tabular}{|l|l|l|l|l|}
\hline RUN & \multicolumn{1}{l}{ NUMBER CYCLES } & \multicolumn{1}{l}{$\begin{array}{l}\text { AVERAGE CYCLE } \\
\text { RUN TIME(MIN) }\end{array}$} & TOTAL \\
\hline 1 & 1 & 40 & 12.075 & 483 \\
\hline 2 & 1 & 40 & 12.075 & 483 \\
\hline 3 & 1 & 32 & 15.00 & 480 \\
\hline 1 & 2 & 31 & 15.48 & 480 \\
\hline 2 & 2 & 31 & 15.48 & 480 \\
\hline 3 & 2 & 32 & 15.00 & 480 \\
\hline 1 & 3 & 16 & 16.56 & 265 \\
\hline 2 & 3 & 16 & 16.56 & 265 \\
\hline 3 & 3 & 16 & 16.56 & 265 \\
\hline
\end{tabular}

Engine \# 1 - with $10 \mathrm{~W}-30$ oil

Engine \# 2 - with 10W-30 + 10\% PS-23®

Engine \# 3 - with 10W-30 + 10\% PS-23®

Wear of the piston assembly parts was monitored by surface changes and weight variations. The results are shown in Figures 18 through 29, where Figs. $18-23$ are photographs and micrographs showing the surface wear, and Figs. $24-29$ are surface profiles representing the topographical change of surface asperities. The micrographs were taken using a scanning electron microscope (SEM). 
The surface profile readings are sometimes useful in determining the wear characteristics of a contact surface. Surface profile readings were taken from some of the internal engine parts contact surfaces using the Taylor-Hobson Surtonic $3+$ profilometer. The results of these readings show the differences in roughness between new surfaces and the same surfaces after a test run. The profile readings shown in Figs 24-29 compare the parts new (top) with the same part after an 8 hour run (bottom).

Comparison of the connecting rod bearing surface's top half is seen in Figs. 24 and 25. Both engines show a definite wear pattern after the first run, however engine $\# 2$ shows a deep rut which might indicate slightly higher wear (Figure 19, bottom). Figures 26 and 27 show the profile pattern for the connecting rod bottom bearing surface. They show a normal wear pattern indicating that fluid film lubrication was taking place and no obvious difference between them. The wrist pin surface can be seen in figs 28 and 29 . Again, no significant difference can be observed between these two wear patterns which would imply that normal wear took place in both cases. Although profiles for the parts after both engine tests are similar, SEM examination on the pin surfaces, which were cleaned with acetone, shows that the pin from engine 2 was worn more severely (Figure22).

Weights were taken of all parts before and after each run. The results are printed in Tables 12-14 for the first run of all three engines. Based on this table it can be seen that there is no definite pattern which suggests more wear in any of the engines. Some of the parts show an increase in weight due to the accumulation of deposits as in the piston rings. Other parts show no difference in weight. The results in Tables 12-14 indicate that wear 
of the parts of the piston assembly was complicated, involving both weight loss due to wear and weight gain due to interaction with the lubricant.

TABLE - 12

WEIGHT OF ENGINE PARTS FOR ENGINE \#1

PART DESCRIPTION
\begin{tabular}{|l|l|l|l|}
\hline CONNECTING ROD & NEW & \multicolumn{1}{c}{$8 \mathrm{HRS}$} & \%DIFFERENCE \\
\hline CONNECTING ROD LOWER BEARING & $15.819 \mathrm{~g}$ & $50.596 \mathrm{~g}$ & -.1027 \\
\hline PISTON PIN & $30.528 \mathrm{~g}$ & $30.817 \mathrm{~g}$ & -.0126 \\
\hline PISTON LOWER RING & $13.680 \mathrm{~g}$ & $13.666 \mathrm{~g}$ & -.0066 \\
\hline PISTON CENTER RING & $7.731 \mathrm{~g}$ & $7.731 \mathrm{~g}$ & -.0000 \\
\hline PISTON TOP RING & $8.437 \mathrm{~g}$ & $8.442 \mathrm{~g}$ & +.0593 \\
\hline
\end{tabular}

TABLE - 13

WEIGHT OF ENGINE PARTS FOR ENGINE \#2

PART DESCRIPTION
\begin{tabular}{|l|l|l|l|}
\hline CONNECTING ROD & NEW & 8HRS & \%DIFFERENCE \\
\hline CONNECTING ROD LOWER BEARING & $15.881 \mathrm{~g}$ & $15.877 \mathrm{~g}$ & -.0252 \\
\hline PISTON PIN & $30.426 \mathrm{~g}$ & $30.413 \mathrm{~g}$ & -.0427 \\
\hline PISTON LOWER RING & $13.614 \mathrm{~g}$ & $13.588 \mathrm{~g}$ & -.1909 \\
\hline PISTON CENTER RING & $7.803 \mathrm{~g}$ & $7.805 \mathrm{~g}$ & +.0026 \\
\hline PISTON TOP RING & $8.368 \mathrm{~g}$ & $8.368 \mathrm{~g}$ & .0000 \\
\hline
\end{tabular}

TABLE - 14

WEIGHT OF ENGINE PARTS FOR ENGINE \#3

PART DESCRIPTION
\begin{tabular}{|l|l|l|l|}
\hline CONNECTING ROD & NEW & 8HRS & $\%$ DIFFERENCE \\
\hline CONNECTING ROD LOWER BEARING & $15.8199 \mathrm{~g}$ & $49.469 \mathrm{~g}$ & .0000 \\
\hline PISTON PIN & $30.519 \mathrm{~g}$ & $15.819 \mathrm{~g}$ & .0000 \\
\hline PISTON LOWER RING & $13.539 \mathrm{~g}$ & $13.510 \mathrm{~g}$ & .0000 \\
\hline PISTON CENTER RING & $7.832 \mathrm{~g}$ & $7.834 \mathrm{~g}$ & -.2142 \\
\hline PISTON TOP RING & $8.418 \mathrm{~g}$ & $8.407 \mathrm{~g}$ & -.0255 \\
\hline
\end{tabular}


The engines tested ran normally during each run except for engine \#2 which seized during the third run. The revolutions were monitored continuously and only engine \#2 showed a significant drop in RPM's during its last run. All engines were stopped after the seizure of engine \#2. Engine \# 3 survived the test of the same time period, however, oil darkening and parts wear were similar to that of engine \# 2 .

Comparison of the pistons between engines 1 and 2 after the first run shows that the piston from engine \#2 had a higher degree of darkening through the piston ring area which intensifies on the second run (Figures 18-19).

Figure-20 compares the wrist pins between the 3 engines for the first run, the results for run 2 were similar. The two visible bands are the areas where there was no contact with any other surface. For engine 1 it can be seen that a dark color is present on this band area which would be due to oil deposits, while for engines 2 and 3 these deposits are not present as evidenced by the shiny band surface.

Pictures were taken of the wrist pin surfaces through a scanning electron microscope using a magnification of 1000 . Figure-21 are SEM micrographs showing the journal surface of a new wrist pin and its cross section which was cut using a fine diamond blade and then polished in order to analyze its metallurgical structure. Apparently, from the micrograph, the pin was made from a carbon steel and hardened as suggested by the martensite structure.

After the first run the pins were taken out and cleaned using degreaser then acetone in order to clean the surface deposits. Figure-22 shows the pins from engine \#1 and engine \#2 after the first run at the connecting rod contact area. The more frequent 
pits show a higher degree of wear in pin $\# 2$. The results for run 2 were very similar. The engine parts from engine $\# 2$, third run, can be seen in Figure-23. There were very thick deposits present on the parts. It can be seen that the piston rings have become attached to the piston inside the ring grooves. This could have been a main cause of ultimate failure since the rings were no longer providing an adequate seal and the blowby of gases became severe.

The engine manufacturer recommends that when using multi-viscosity oils such as $10 \mathrm{~W}-30$ in their engines, the oil should be checked frequently because the high operating temperatures cause high oil consumption (Briggs \& Stratton Inc., 1994). The used oil from engines 1 and 3, third run, were collected and the viscosity analyzed, the results are plotted in Figure-30. As expected the viscosity of the oils after the tests was higher due to oil consumption. Figure-31 shows a comparison of the percent rise in viscosity between the oil with PS-23 additive and the standard 10W-30 oil. The percent rise in viscosity for the oil with PS-23 additive was higher at all temperatures, this indicates a higher oil consumption. For engine $\# 2$, third run, the oil was consumed to the point where its consistency was so thick that the viscosity could not be measured. Once the oil in engine $\# 2$ became consumed, no lubrication was present and the engine seized. The oil consumption and viscosity change are consistent with the volatility test results (Table-15).

Table-15

Volatility Test Results

\begin{tabular}{cc}
\hline Oil Description & Volatility \% \\
\hline Mobil 10W-30 Motor Oil & 0.398 \\
Mobil 10W-30 with 10\% PS-23 & 0.477 \\
\hline
\end{tabular}


Due to a higher loss of oil as a result of vaporization at high temperatures, 10W-30 with PS-23 would become thicker and more viscous resulting in the rings sticking in the ring grooves and finally, failure.

\section{3-3. SUMMARY OF ENGINE TESTS}

The engine tests results show some of the effects of PS-23 on lubrication. It can be seen that PS-23 will cause failure in adverse combustion environments as evidenced by the failure of small engine \#2 and the condition of engine \#3. The causes for this failure may be the resulting lower viscosity and higher volatility of the oil with the addition of PS23. 


\section{CHAPTER V:}

\section{EXPERIMENTAL RESULTS FROM BENCH TESTS}

The engine test results revealed the tribological behavior of PS-23 in combustion environments. It is necessary to investigate its performance in non-combustion environments. Bench tests using a block-on-pin machine were conducted to observe the tribological effect of PS-23 on friction and temperature. The tests were designed in two parts, the first was done under conditions of full film lubrication and sufficient lubricant supply, while conditions for the second part were boundary lubrication with a minimal oil supply.

\section{5-1. FULL-FILM LUBRICATION TESTS}

The first series of bench tests were done in order to analyze the effects of PS-23 on the frictional coefficient and temperature under conditions of full film lubrication. A continuous oil supply needed to be provided to the rotating contact area which was achieved using the set-up shown in Figure-32. The oil supply set-up was designed to be used with the block-on-pin machine and provides adjustments for the rate of oil supply as well as maintaining a constant temperature of the lubricant. The rate of flow was adjusted during the first test so that the contact surfaces would be completely soaked of oil for the duration of each test. This rate was maintained for all subsequent tests. 
All the full film tests were performed using $80 \mathrm{~W}-90$ gear oil as the base oil. The tests were divided into four categories of comparison: (1) $80 \mathrm{~W}-90$ gear oil at room temperature, (2) $80 \mathrm{~W}-90$ gear oil at $80^{\circ} \mathrm{C}$, (3) $80 \mathrm{~W}-90$ gear oil $+10 \%$ PS-23 at room temperature, and (4) $80 \mathrm{~W}-90$ gear oil $+10 \%$ PS-23 at $80^{\circ} \mathrm{C}$.

At first, some tests were run in order to optimize the test conditions such as load increase increments and intervals. The maximum load was set at a point were failure was observed to occur in some cases. It was determined that the load would be incremented at one minute intervals according to Table- 16 .

Table-16

Loads Applied for Full Film Lubrication Tests

\begin{tabular}{|l|l|l|l|l|l|l|l|l|l|l|l|l|l|l|}
\hline $\begin{array}{l}\text { TIME } \\
(\mathrm{MIN})\end{array}$ & 0 & 1 & 2 & 3 & 4 & 5 & 6 & 7 & 8 & 9 & 10 & 11 & 12 & 13 \\
\hline $\begin{array}{l}\text { LOAD } \\
(\mathrm{LBS})\end{array}$ & 9.8 & 51.8 & 85.4 & 107.8 & 110.6 & 120.4 & 128.1 & 135.8 & 145.6 & 153.3 & 170.8 & 191.1 & 207.2 & 225.4 \\
\hline
\end{tabular}

Equations 3.4 to 3.14 from section 3-3 were used to estimate the minimum fluid film thickness, $h_{o}$, using the viscosity for each of the four categories of oil. The results are printed in Table-17. The roughness was measured from each of the samples tested prior to the runs and it was found that all had a roughness, $R M S$, between 2.42 and 3.43 . Since the lowest value of $h_{o}$ was estimated to be $2.5 \mu \mathrm{m}$, it can be shown that the contacts were running under full film lubrication. 
Table-17

Viscosity of Oils and Film Thickness Calculations for Full Film Lubrication Tests

\begin{tabular}{|c|c|c|}
\hline Description of Oil & Viscosity (cSt) & Minimum Film Thickness, $h_{o}$ \\
\hline $80 \mathrm{~W}-90$ Gear Oil+10\% PS-23 @ 40 ${ }^{\circ} \mathrm{C}$ & 137.29 & $8.35 \mu \mathrm{m}$ \\
\hline $80 \mathrm{~W}-90$ Gear Oil+10\% PS-23 @ 80 C & 24.26 & $2.50 \mu \mathrm{m}$ \\
\hline 80W-90 Gear Oil@40C & 160.53 & $9.28 \mu \mathrm{m}$ \\
\hline 80W-90 Gear Oil@80 @ C & 27.70 & $2.87 \mu \mathrm{m}$ \\
\hline $80 \mathrm{~W}-90$ Gear Oil 10\% PS-23 @ $128^{\circ} \mathrm{C}^{*}$ & 7.04 & $1.15 \mu \mathrm{m}$ \\
\hline
\end{tabular}

*For the case were failure occurs estimates were made as to the viscosity of the oil using the temperature measured during the experiments. From that result the minimum film thickness was estimated. The estimated non-dimensional film thickness was $\Lambda \cong 0.5$, and the lubrication state was mixed to boundary lubrication state indicating that failure is related to the solid-solid contact at high load.

Figures-33(a) and 33(b) show the results of friction vs. load for the full film lubrication tests. For all the tests, the same pattern of the curves can be observed, although, the ones in which PS-23 additive was used show that they ran with a slightly higher friction coefficient than those where only $80 \mathrm{~W}-90$ gear oil was used. No apparent advantage of using PS-23 was observed at full film lubrication.

\section{5-2. BOUNDARY LUBRICATION TESTS}

Since failure is closely related to solid-solid contact, tests in the boundary lubrication state may reveal more information. A series of tests was needed which would simulate engine and gear conditions during starting in which lubrication to the moving 
parts is insufficient. One of the claims expressed by the manufacturers of all three oil additives used in this study, is that their product forms a protective layer on the metal surfaces which reduces wear during starting. Also, the results of the road tests seem to point that a mechanism of that sort could be taking place.

The boundary lubrication runs were performed in the following manner. First the sample and the pin were cleaned using acetone then soaked in the oil to be tested. The test was run using only the oil which was soaking on the surfaces with no new supply of oil added for that run. The runs were done both using $10 \mathrm{~W}-30$ motor oil and then using $80 \mathrm{~W}$ 90 gear oil as the base oil. The pin was set into motion and the load added in ten second increments for the motor oil and in fifteen second increments for the gear oil. A higher total load was used when testing with $80 \mathrm{~W}-90$. Once all the load had been added the run was allowed to continue until failure was observed. Failure was noted when the frictional force rises in a sudden fashion to a large value, also high noise is emitted at such time. The comparison of each oil's performance was determined by the amount of time the run continued before failure.

The results for these tests are shown in Figures 34 and 35. For each of the oils tested at least two runs were performed in which after inspection of the sample, a wear scar was produced along its entire diameter. There were some variations as to the run times for each run with the same oil therefore the longest run for each oil was selected in the results.

Figure-34 shows the results of the boundary lubrication runs conducted with $10 \mathrm{~W}$ -30 as the base oil. Even though failures took place, improvement was shown with each of 
the additives by the longer running times as compared to $10 \mathrm{~W}-30$ motor oil alone. Of the three additives the best performance was shown by PS-23 which ran for 65 minutes with no failure at which time the test was stopped. The next best performance was by Slick-50 which ran for 40 minutes before failure occurred. All the samples were immersed in their respective oil-additive mixtures overnight so that metal treatment could take place.

The results for the boundary lubrication runs using $80 \mathrm{~W}-90$ as the base oil were a bit different, these are shown in Figure-35. Of the 3 additives only Slick-50 performed worse than the base oil alone, while PS-23 and Duralube both ran for 40 minutes without failure until the test was stopped.

It is important to note that some of the tests using $80 \mathrm{~W}-90+$ PS- 23 as the lubricant were done without submerging the samples in the lubricant overnight, these resulted in fast failure times of about 5 minutes on average. Table-18 shows the results of these tests.

Table-18

Results of Boundary Lubrication Tests - Untreated Samples

\begin{tabular}{ll}
\hline Run Number & Time Run Before Failure (min:sec) \\
\hline 1 & $4: 30$ \\
2 & $3: 32$ \\
3 & $6: 38$ \\
4 & $5: 52$ \\
\hline
\end{tabular}

The tests done after submerging the samples in the lubricant overnight, ran for long periods of time and are the ones whose results are used in the comparisons. 
With all other lubricants no tests were conducted in which the samples had not been submerged overnight.

Micrographs were taken and EDX analysis was done of each of the sample surfaces from the boundary lubrication runs conducted with 10W-30, 80W-90, 10W-30 $+10 \%$ PS-23, and $80 \mathrm{~W}-90+10 \%$ PS-23. Figures 36 and 37 show micrographs from the wear scar area of the samples. The EDX analysis results are shown in Figures 38-41. The elements shown to be present are iron, manganese and sulphur which are known to be from the sample material itself. Since the samples were cleaned with degreaser prior to the EDX analysis, it is likely that the ingredients from the lubricants which might have been attached to the metal were removed.

By the use equations $3.15-3.17$ and the width of each wear scar, the temperature on the surface of the samples, as a result of frictional heating, was estimated at a time close to the end of the test and the results recorded in Table-19.

Table-19

Estimated Surface Temperature For Boundary Lubrication Tests

\begin{tabular}{|l|l|}
\hline \multicolumn{1}{|c|}{ Oil Description } & Surface Temperature of Sample $\left({ }^{\circ} \mathrm{C}\right)$ \\
\hline 10W-30 Motor Oil & 153 \\
\hline 10W-30 Motor Oil + 10\% PS-23 & 117.7 \\
\hline $80 \mathrm{~W}-90$ Gear Oil & 170.9 \\
\hline $80 \mathrm{~W}-90$ Gear Oil $+10 \%$ PS-23 & 130.6 \\
\hline
\end{tabular}

It has been well noted that in boundary lubrication contacts, friction measurements go through a transition from smooth and low to rough and high values at a certain critical 
temperature due to physisorption of the surface film (Lee, 1990). Many authors have found this transition temperature to be around $150{ }^{\circ} \mathrm{C}$ ( Block, 1970; Kelley, 1968; Matveevsky, 1968). As a typical asperity passes through the ehl conjunction, a sudden rise in temperature occurs at that point and can cause the adsorbed surface film which protects the asperity from rapid adhesive wear to be subject to thermal desorption. The results shown in table-18 are consistent with these theories since the cases where failure occurred were estimated to have exceeded $150^{\circ} \mathrm{C}$.

\section{5-3. SUMMARY FOR BENCH TESTS}

The bench tests were designed to determine the effects from each of the additives tested on the frictional coefficient under both full film and boundary lubrication conditions. The only lubricant additive tested under full film lubrication was PS-23. No apparent advantage was observed with the use of PS-23 at fully lubricated contacts.

The boundary lubrication tests show that PS-23 may help increase the life of parts if they work in a dry-boundary lubrication state, provided that the parts are pretreated in PS-23 for a sufficiently long time. 


\section{CHAPTER VI}

\section{CONCLUSIONS}

This study was intended to analyze the effects of PS-23 additive on tribological elements related to automotive uses. The chemical tests show that the addition of PS-23 to $10 \mathrm{~W}-30$ motor oil and to $80 \mathrm{~W}-90$ gear oil, lowers the viscosity of the oil. The volatility tests performed on 10W-30 oil show that PS-23 raises the volatility of the oil. These changes may result in higher consumption of lubricant and speed lubricant degradation in adverse operating conditions.

The results from the road tests of vehicle \# 1 seem to show that the addition of PS-23 provided enough protection to the engine so that it could run for an extended period of time with insufficient lubrication. However, since no comparative dry sump driving tests were performed for a similar vehicle after running with the ordinary $10 \mathrm{~W}-30$ motor oil, the degree of PS-23's contribution to engine operation under such an extreme condition cannot be quantitatively evaluated.

The small engine tests show a higher degree of oil consumption with the use of PS-23 which could be caused by a reaction with the combustion products in the engine. However, this result could also be caused by the higher volatility of the oil resulting from the use of PS-23.

The bench tests show no apparent benefit in friction reduction with the use of PS23 under full film lubricating conditions. However, under conditions of boundary 
lubrication PS-23 seems to be beneficial in slowing down wear and preventing failure, possibly as a result of decreased lubricant degradation.

When all the test results are considered, conclusions can be made regarding the effects of PS-23 on lubrication. Under normal lubricating conditions the addition of PS23 seems to provide no significant improvement in friction reduction. Yet under extreme conditions such as dry starts, PS-23 can provide the protection needed to minimize wear and prevent failure. The best use for PS-23 in automotive applications would be in mechanisms where no combustion is present such as manual transmissions and differentials for protection under extreme conditions.

Other non-automotive applications can also be considered for the PS-23 formulation such as cutting fluids, multi purpose lubricants, and applications requiring the use of grease. As a grease the PS-23 formulation could be effective since these are known to be conditions where an oil supply is usually impractical and the resulting lubricating condition becomes extreme compared to conditions in which oil is used. However, further studies should be conducted to evaluate the performance of PS-23 in those lubricants before they are supplied to the market. 


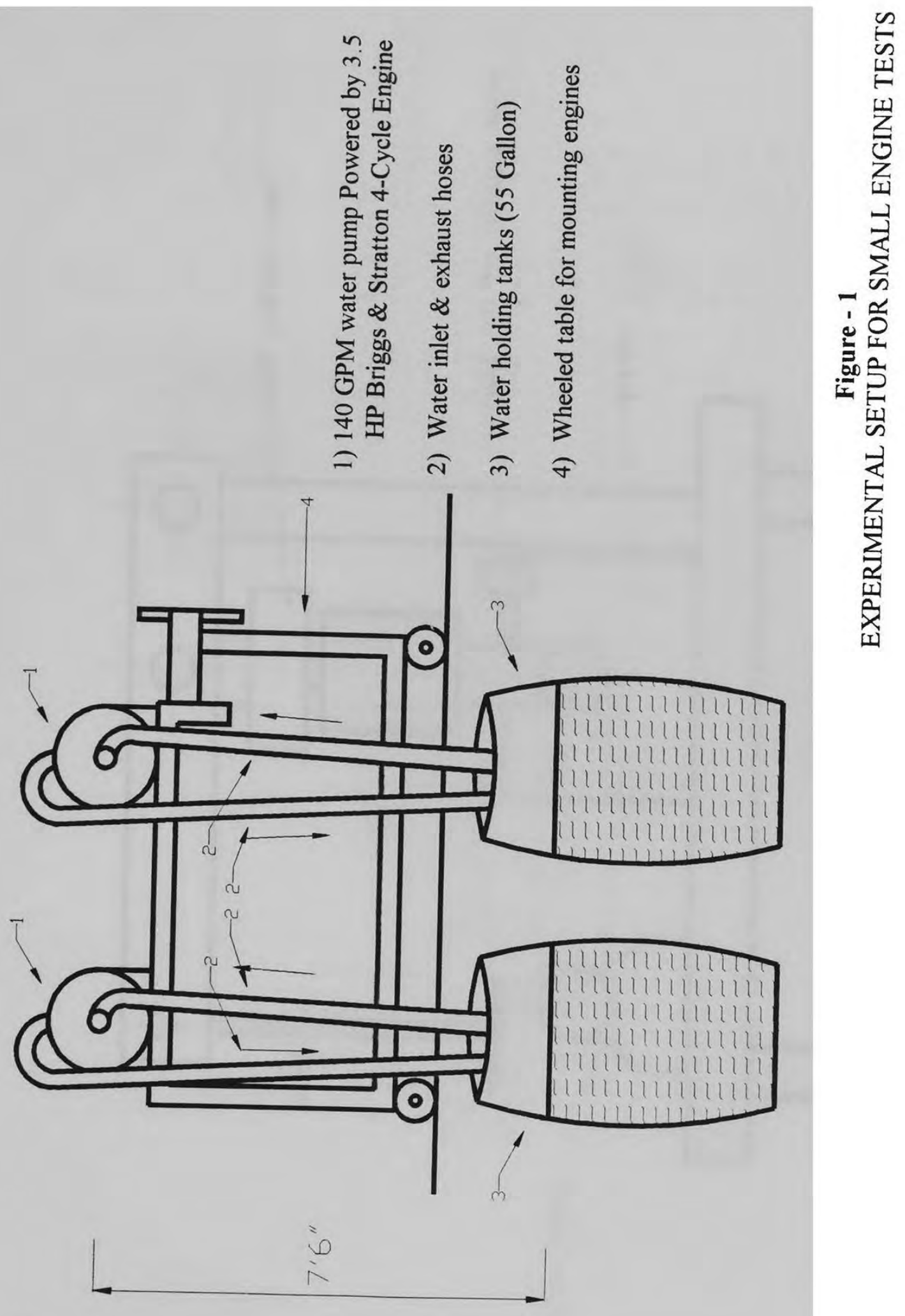




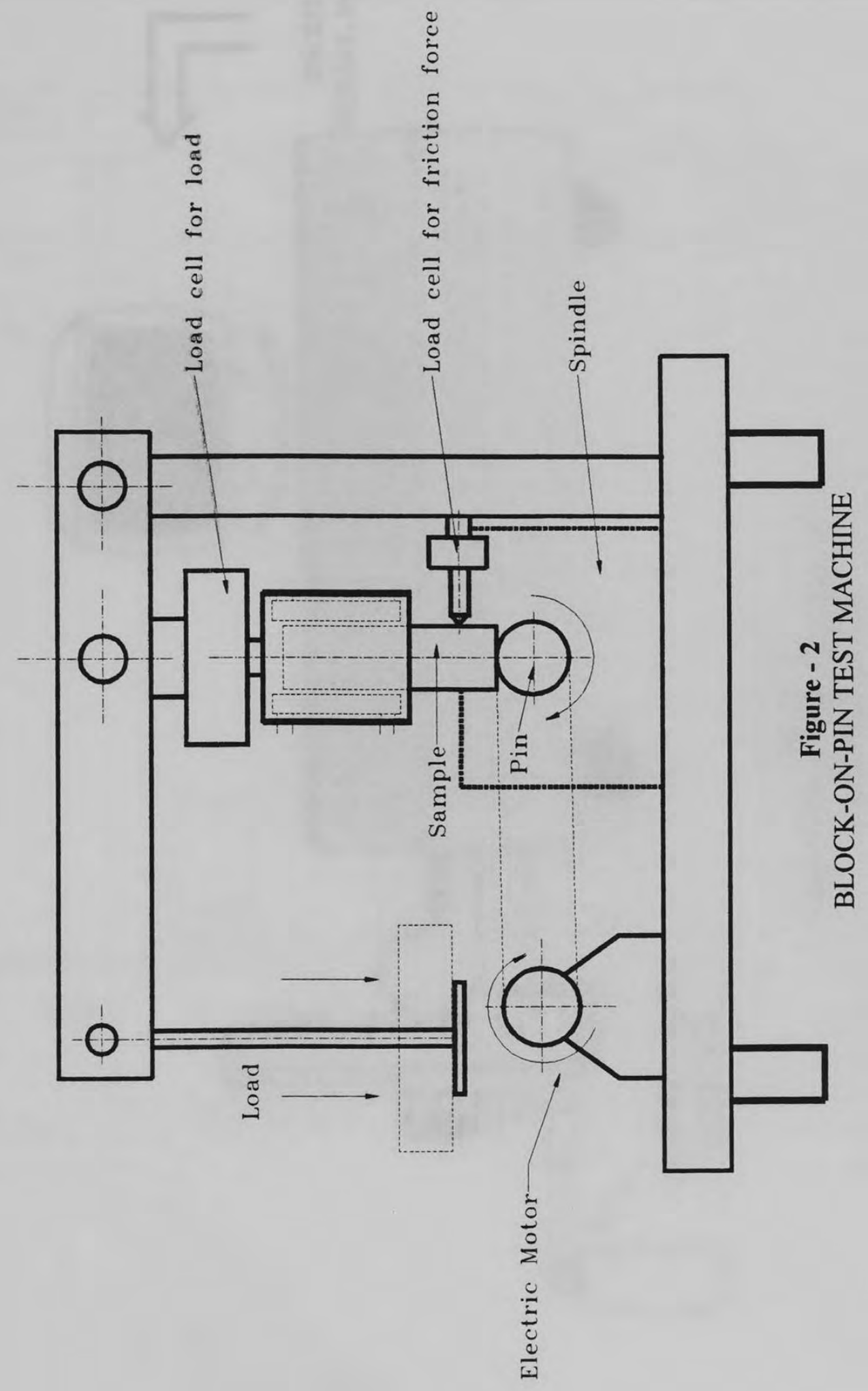




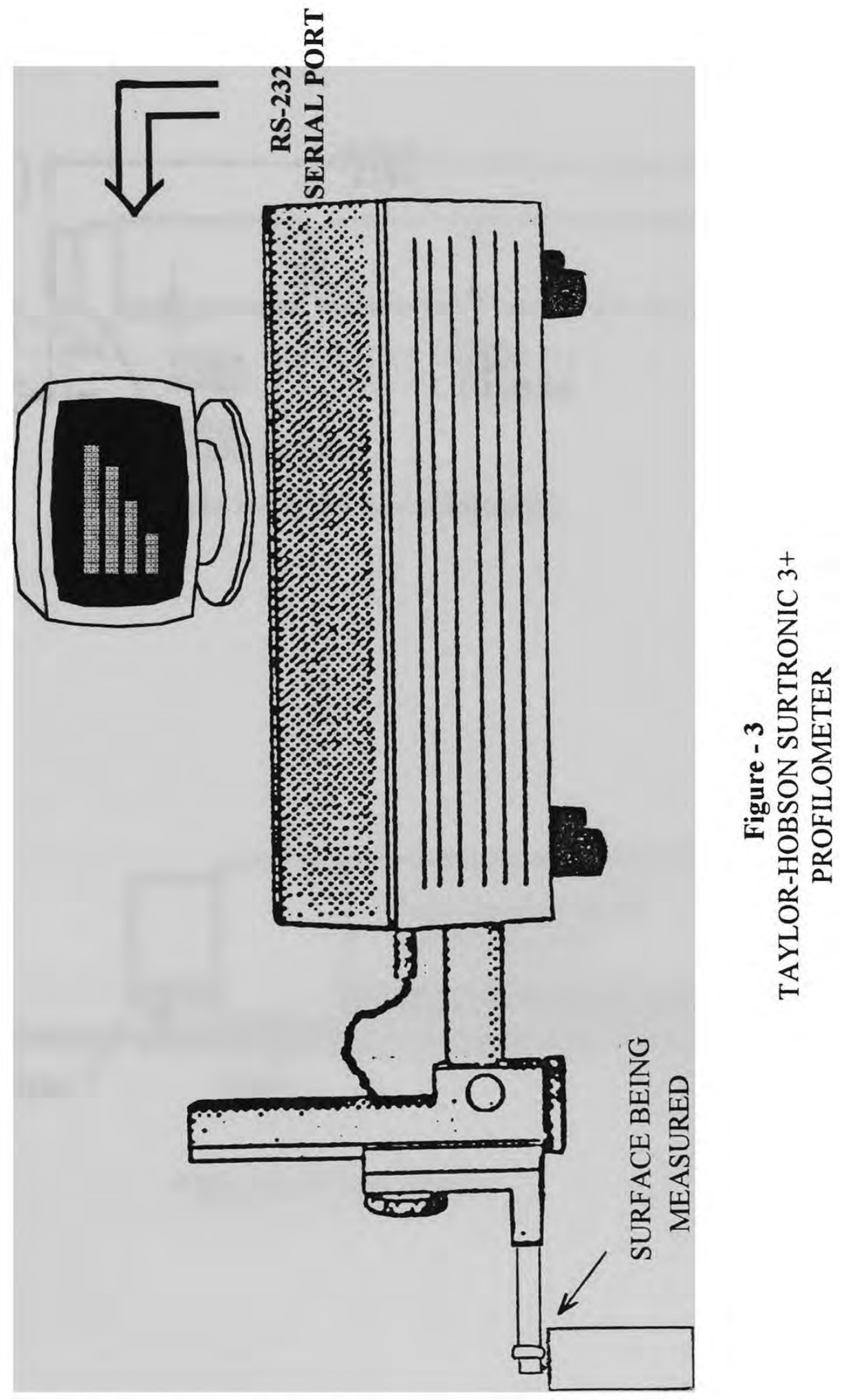



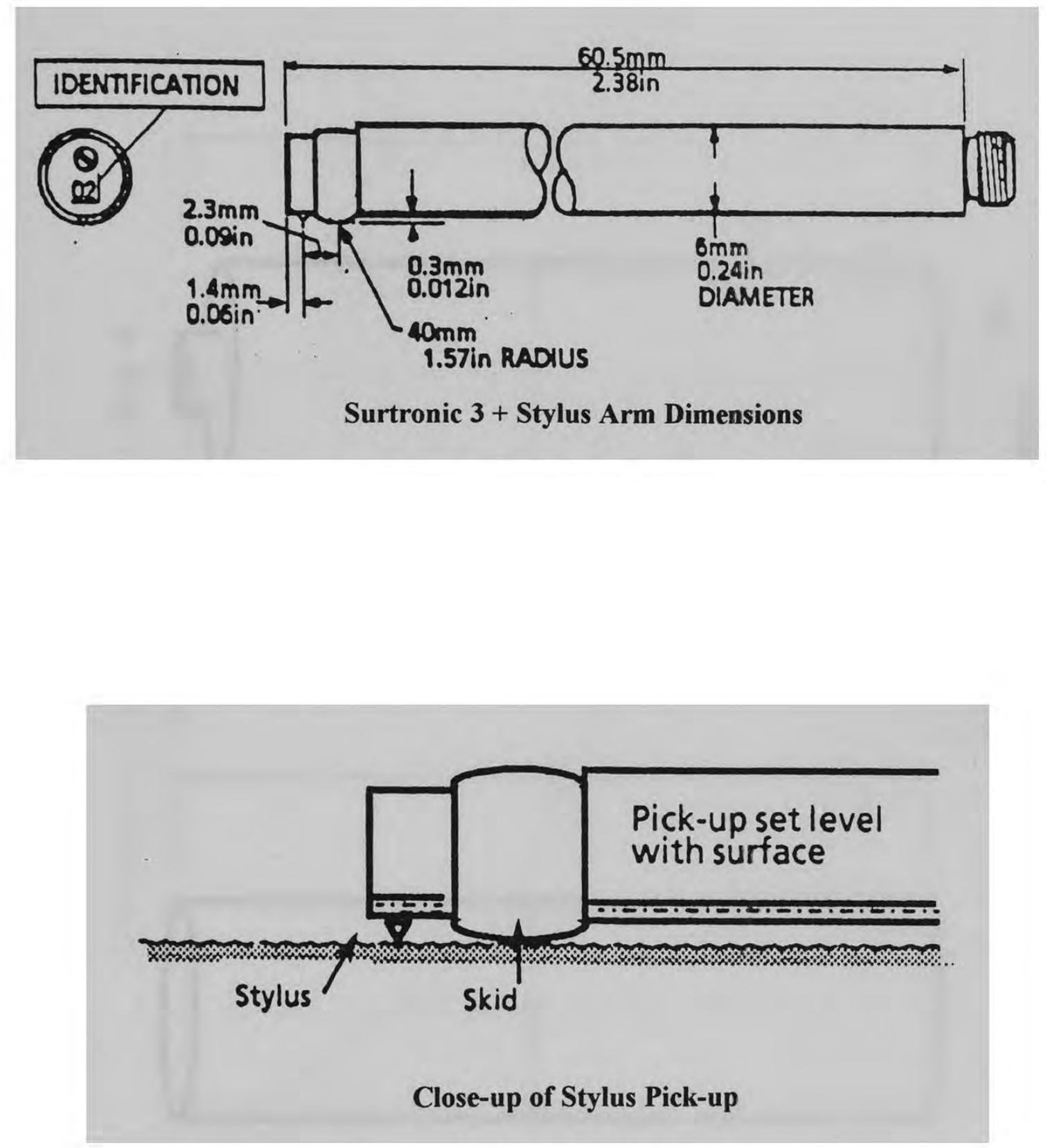

Figure - 4

Surtronic Stylus Arm Diagram 


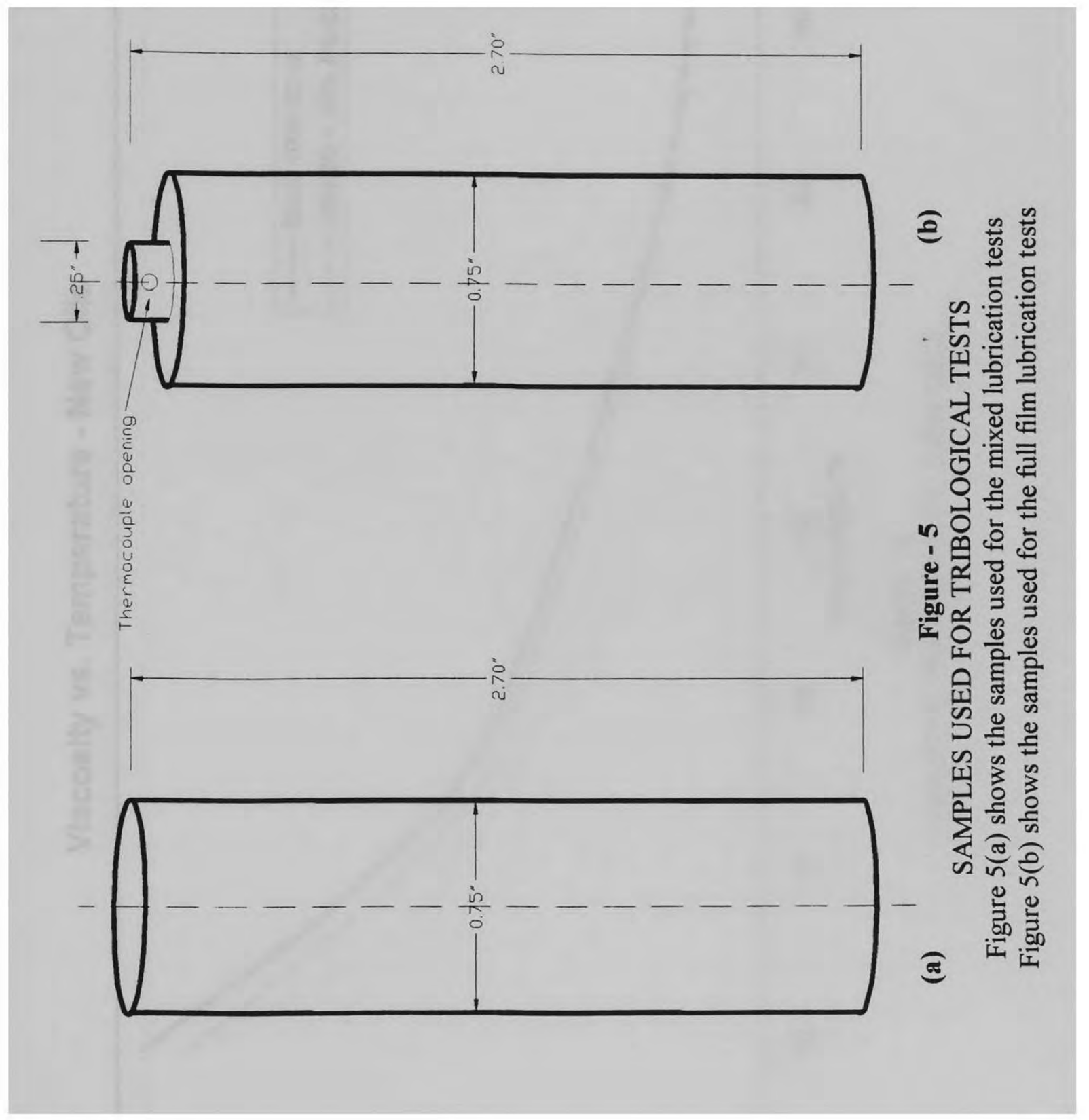




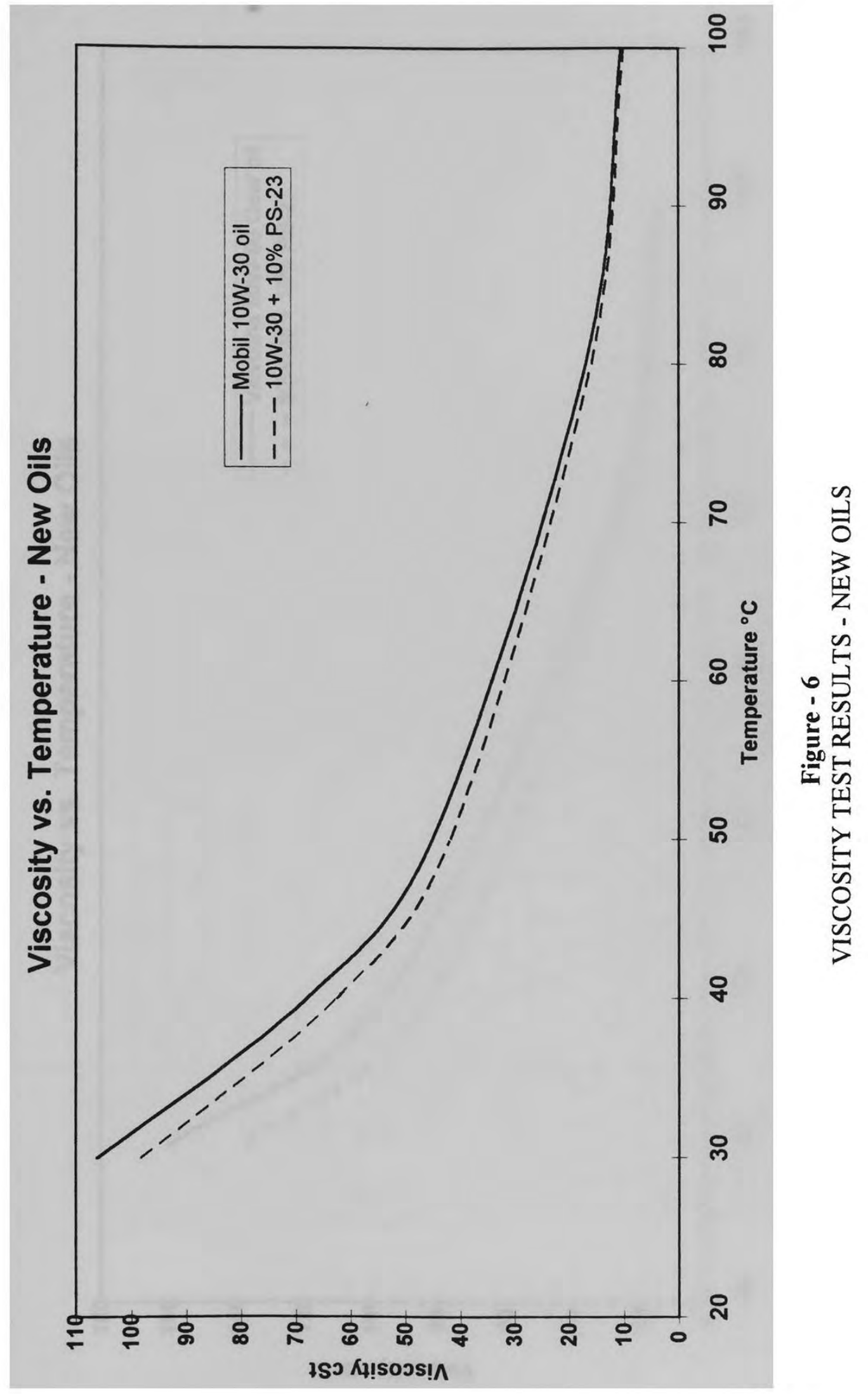




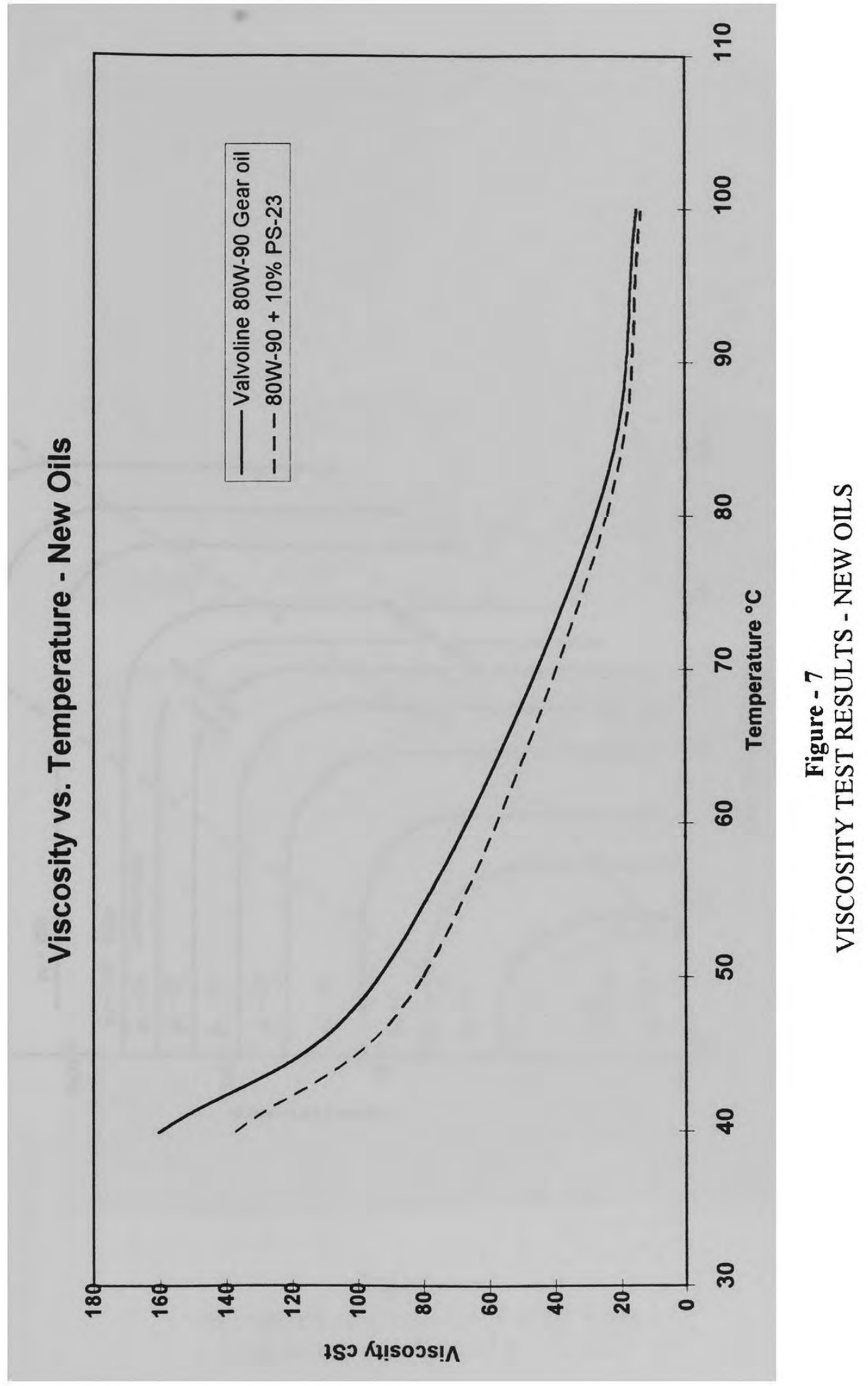




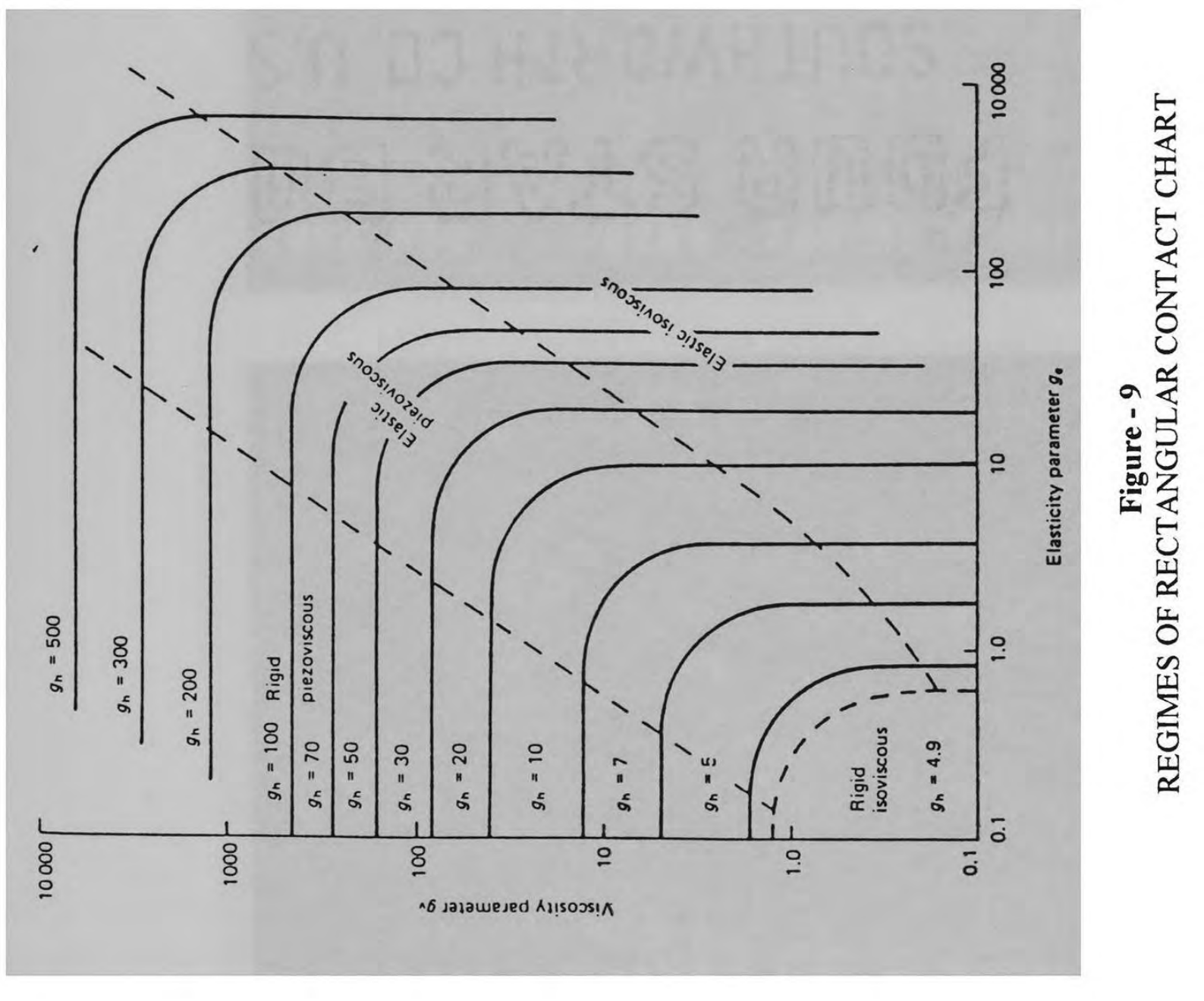




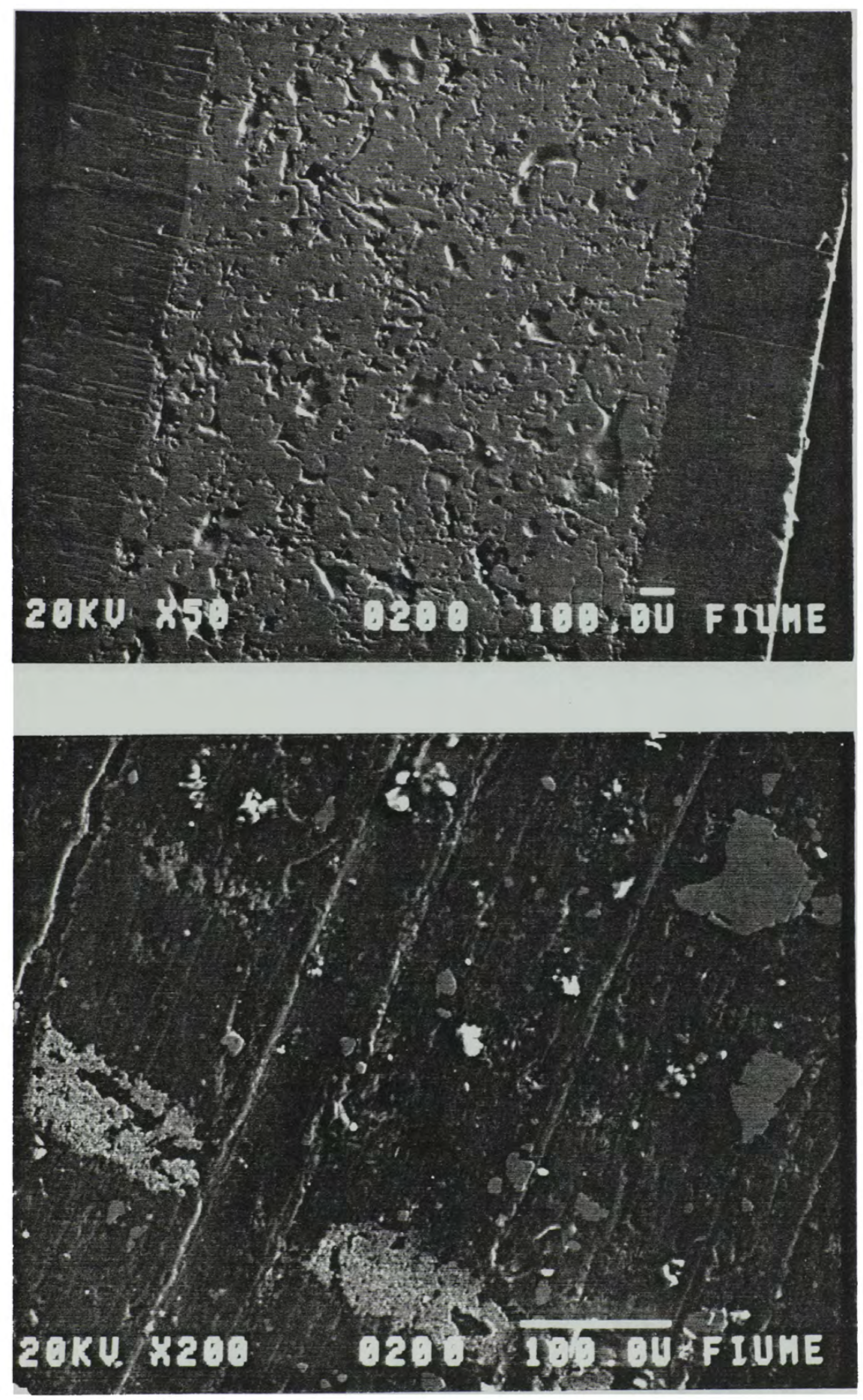

Figure - 10

Micrographs of Road Test \#1 Engine Parts

Ring Area (top), Piston Skirt (bottom) 

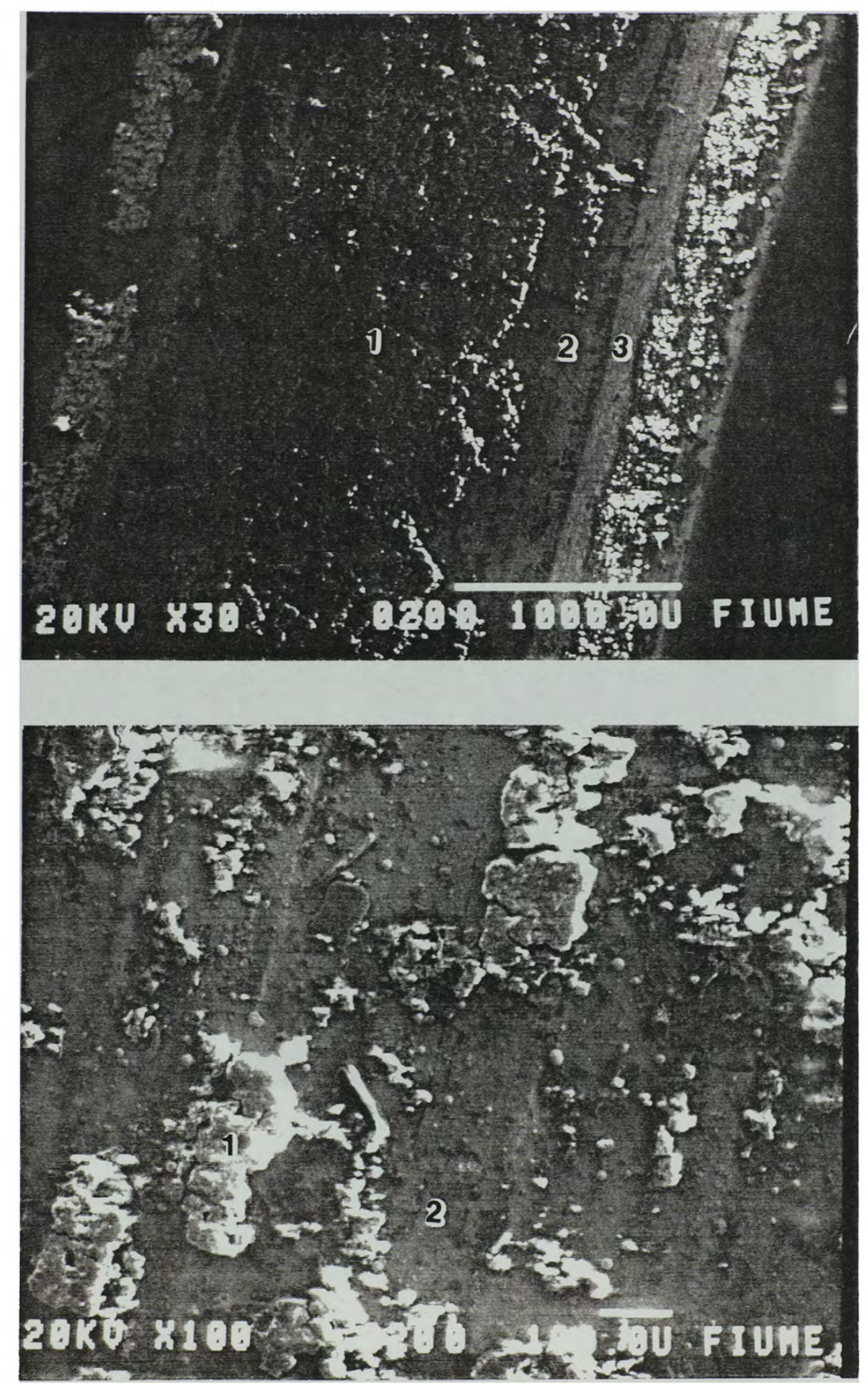

Figure - 11

Micrographs of Road Test \#1 Engine Parts

Ring Area (top), Top Land (bottom) 


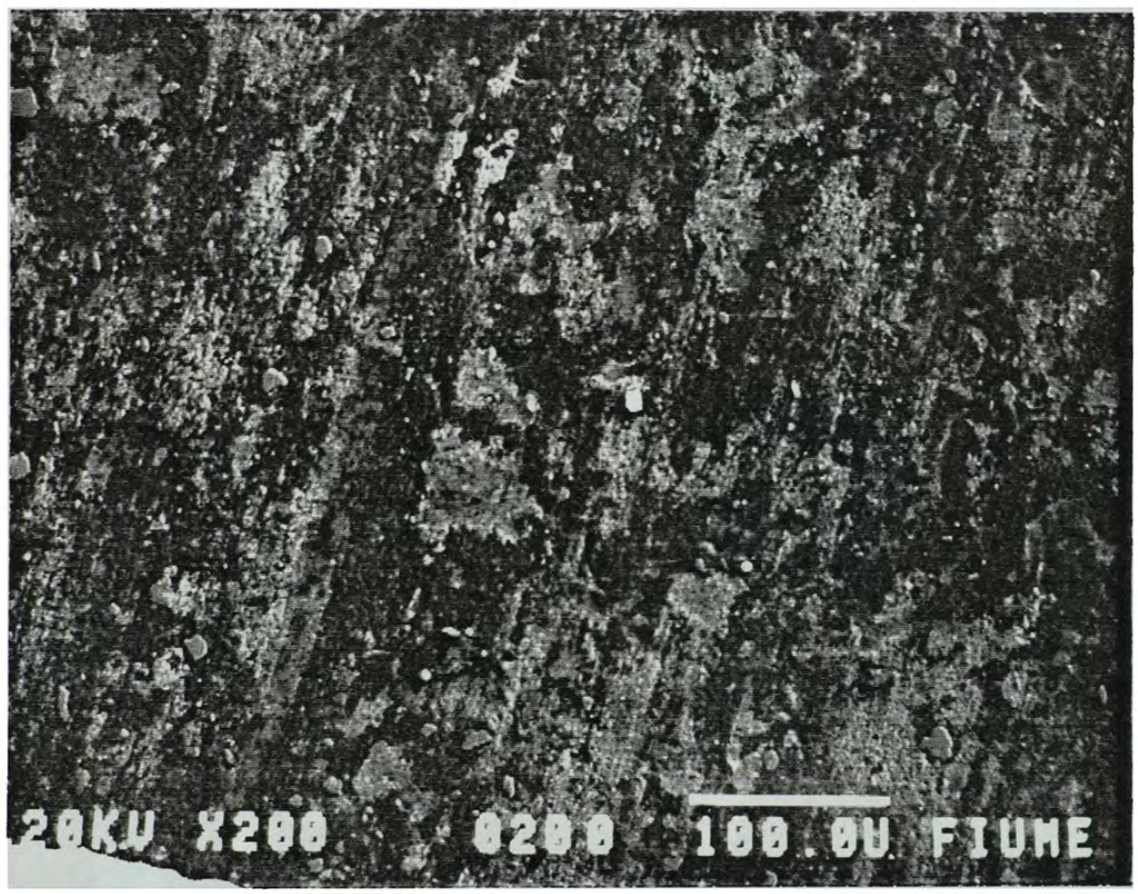

Figure - 12

Micrographs of Road Test \#1 Engine Parts

Piston Pin Bearing Area 


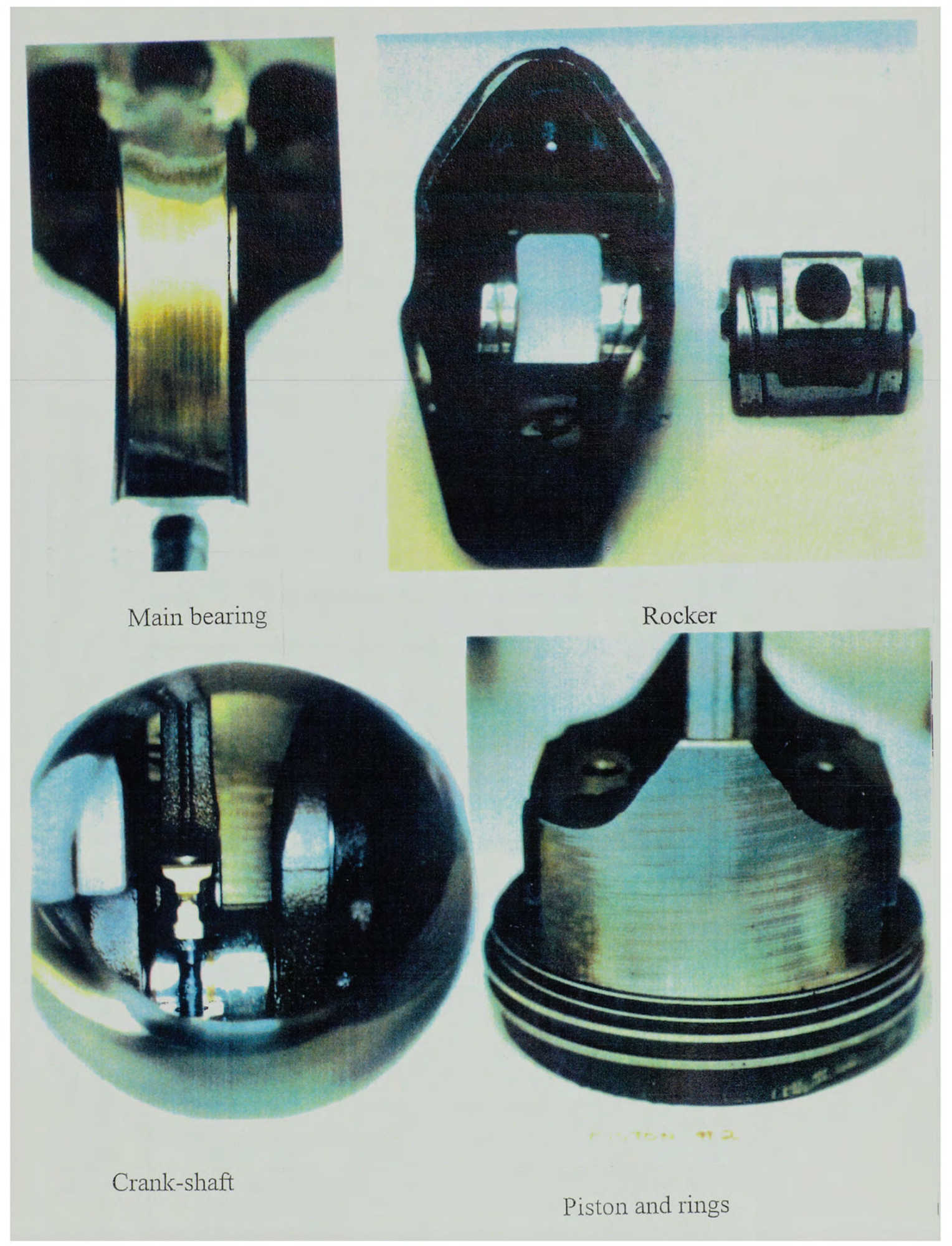

Figure - 13

Pictures of Engine Parts from Vehicle I

After Tests 

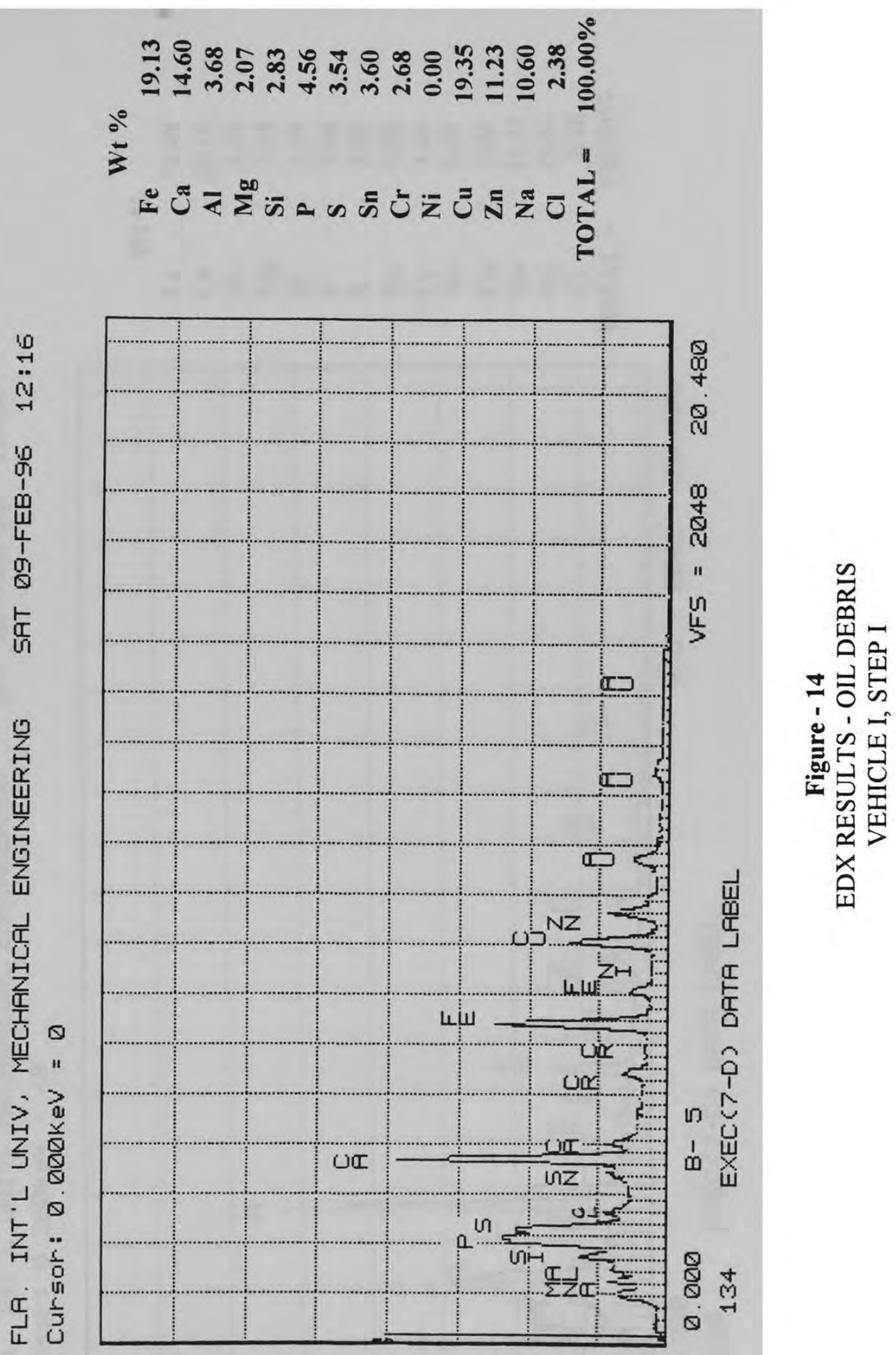

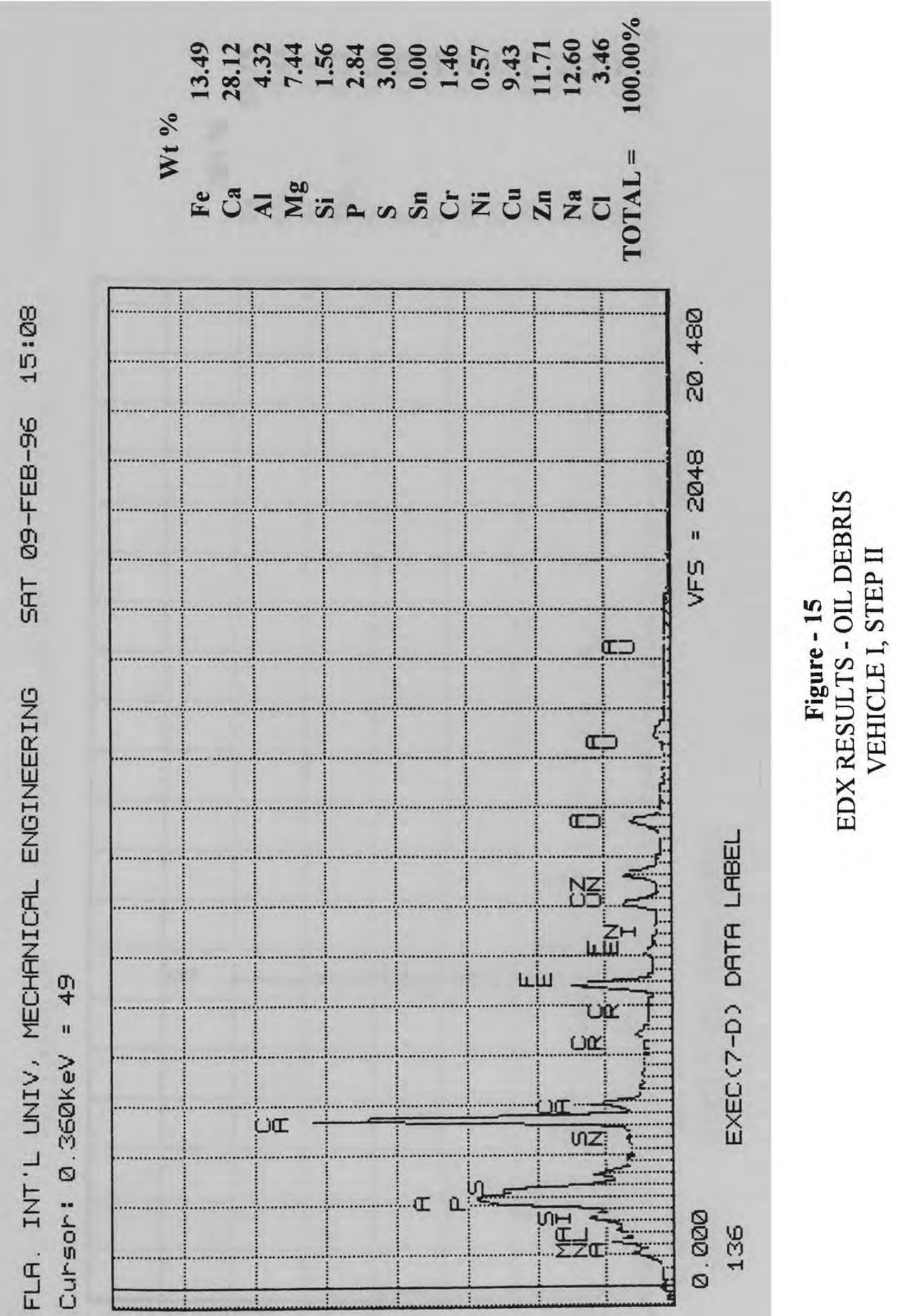

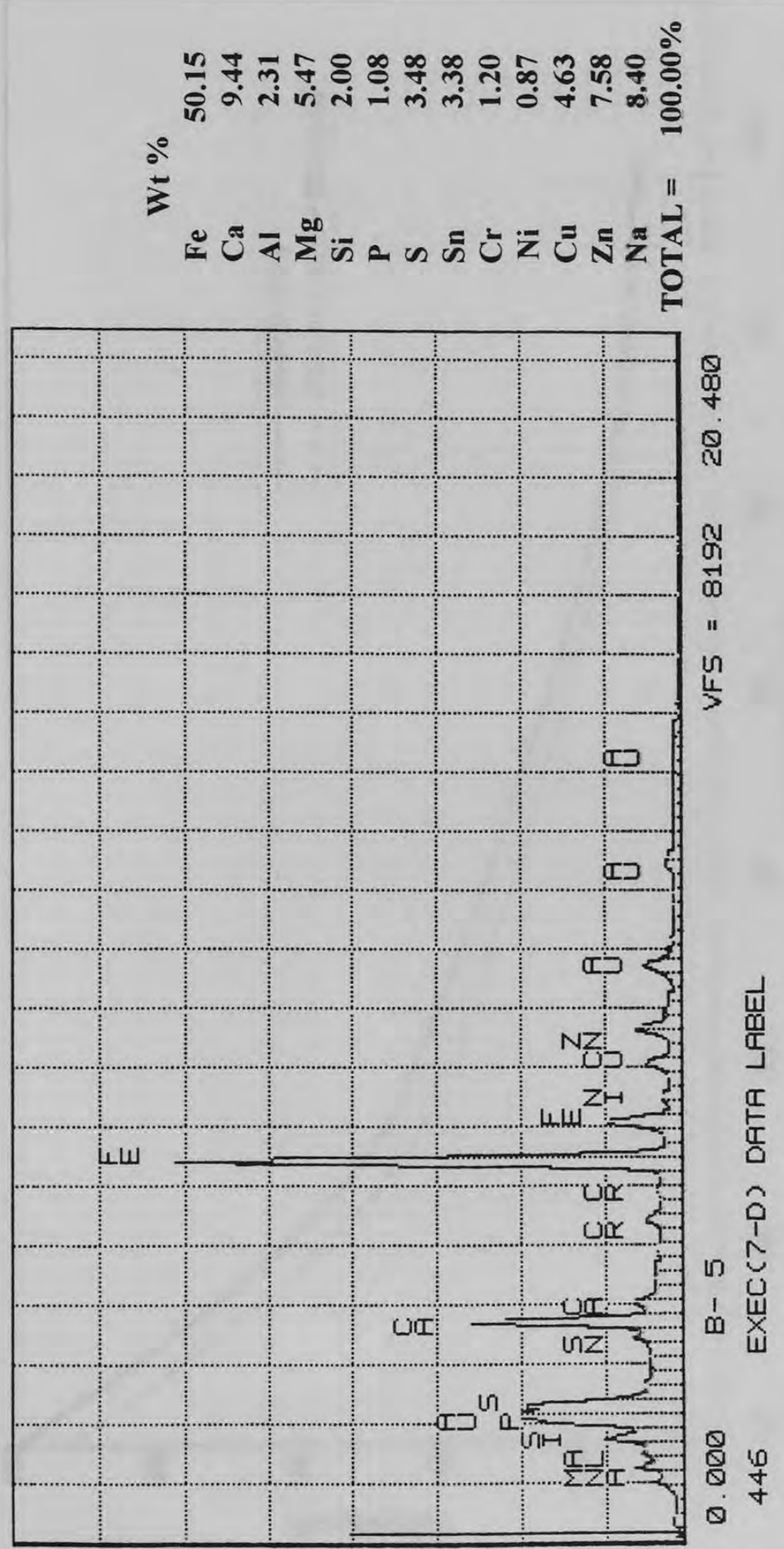

至 


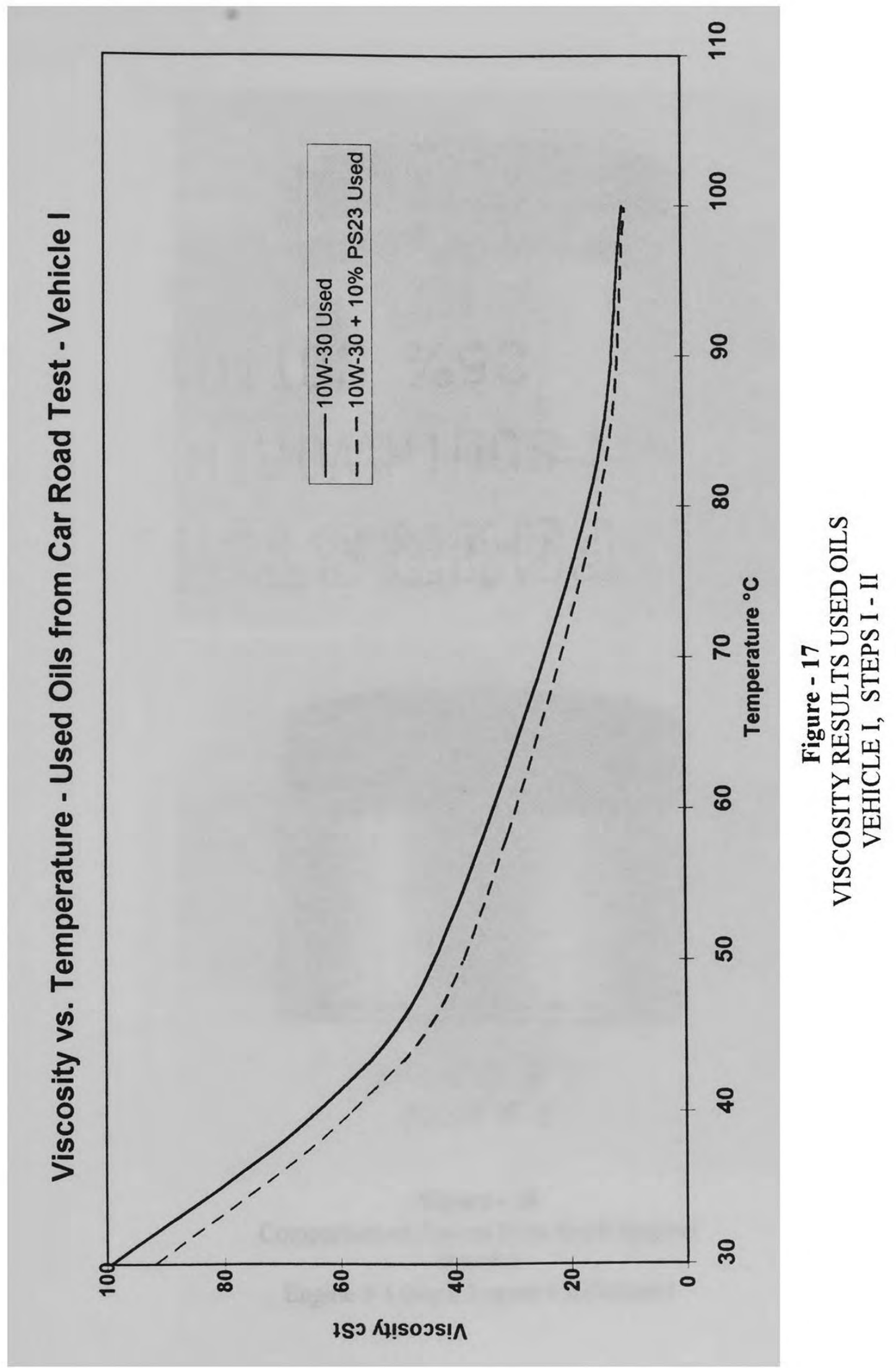




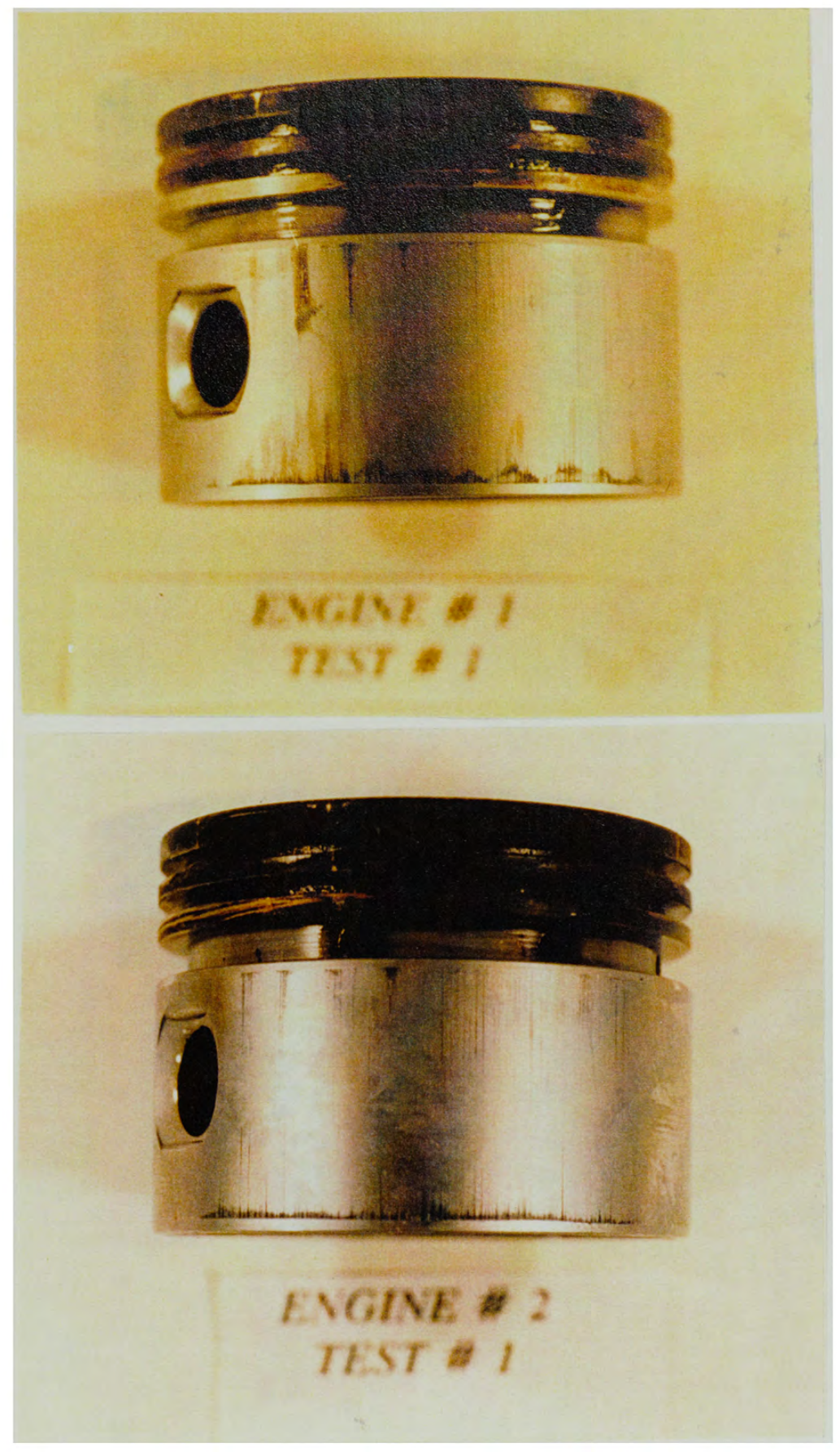

Figure - 18

Comparison of Pistons from Small Engines

Run \# 1

Engine \# 1 (top), Engine \# 2 (bottom) 


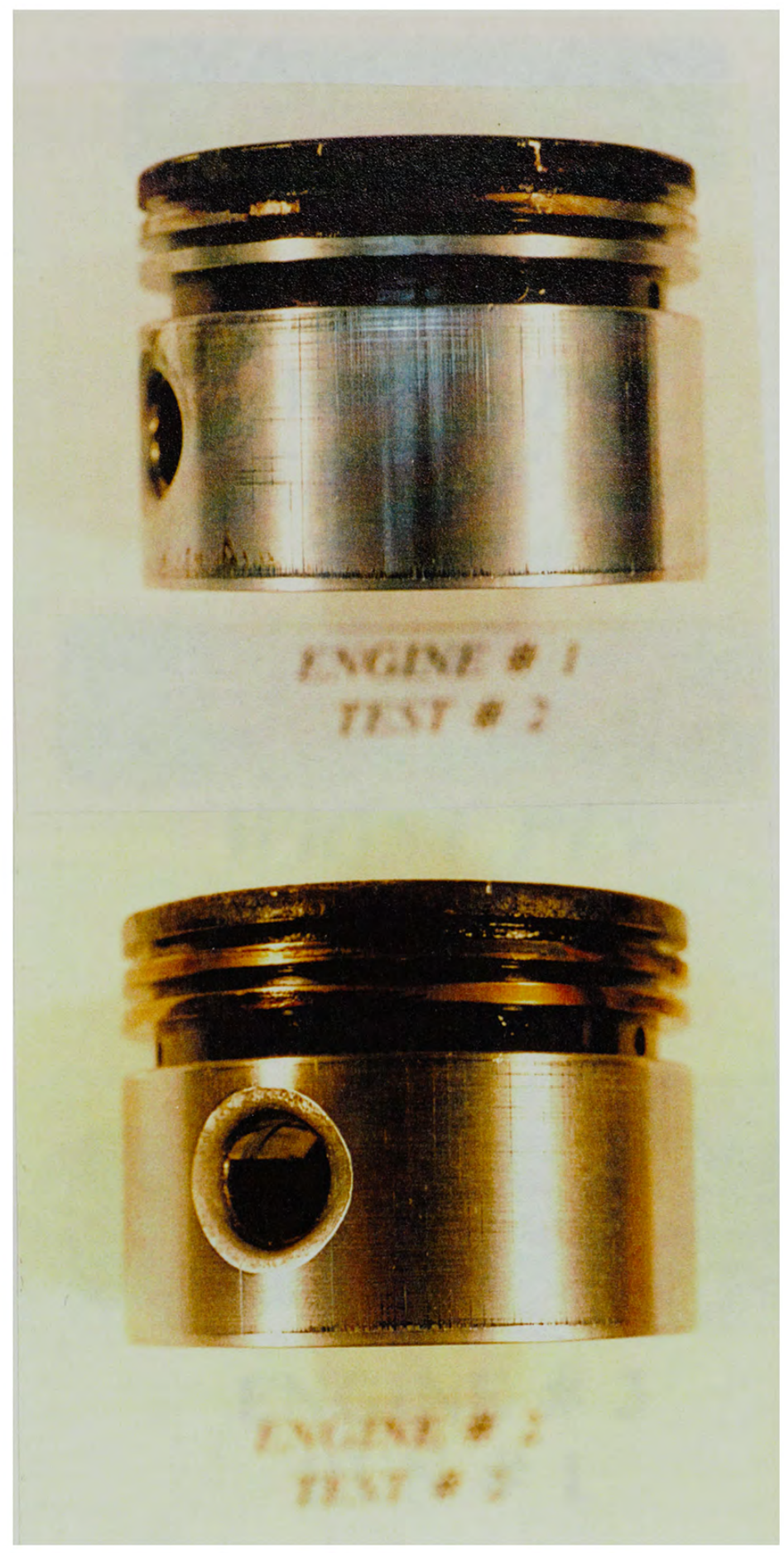

Figure - 19

Comparison of Pistons from Small Engines

Run \# 2

Engine \# 1 (top), Engine \# 2 (bottom) 


\section{WRIST PIN ENGINE \# 1 TEST \# 1}

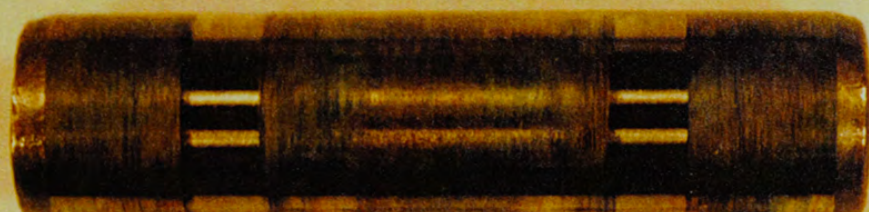

WRIST PIN

ENGINE \# 2 TEST \# 1

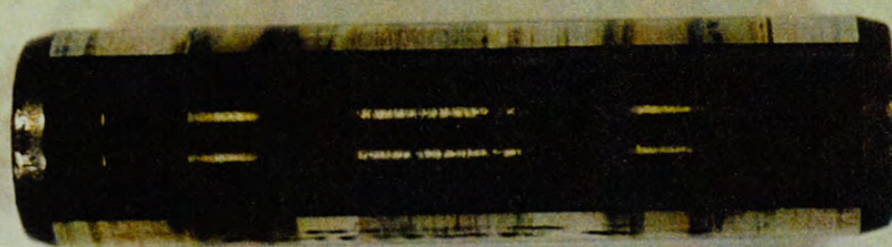

\section{ENGINE \# 3 RUN \# 1}

Figure - 20

Comparison of Wrist Pins from Small Engines

Run \# 1

Engine \# 1 (top), Engine \# 2 (center), Engine \# 3 (bottom) 

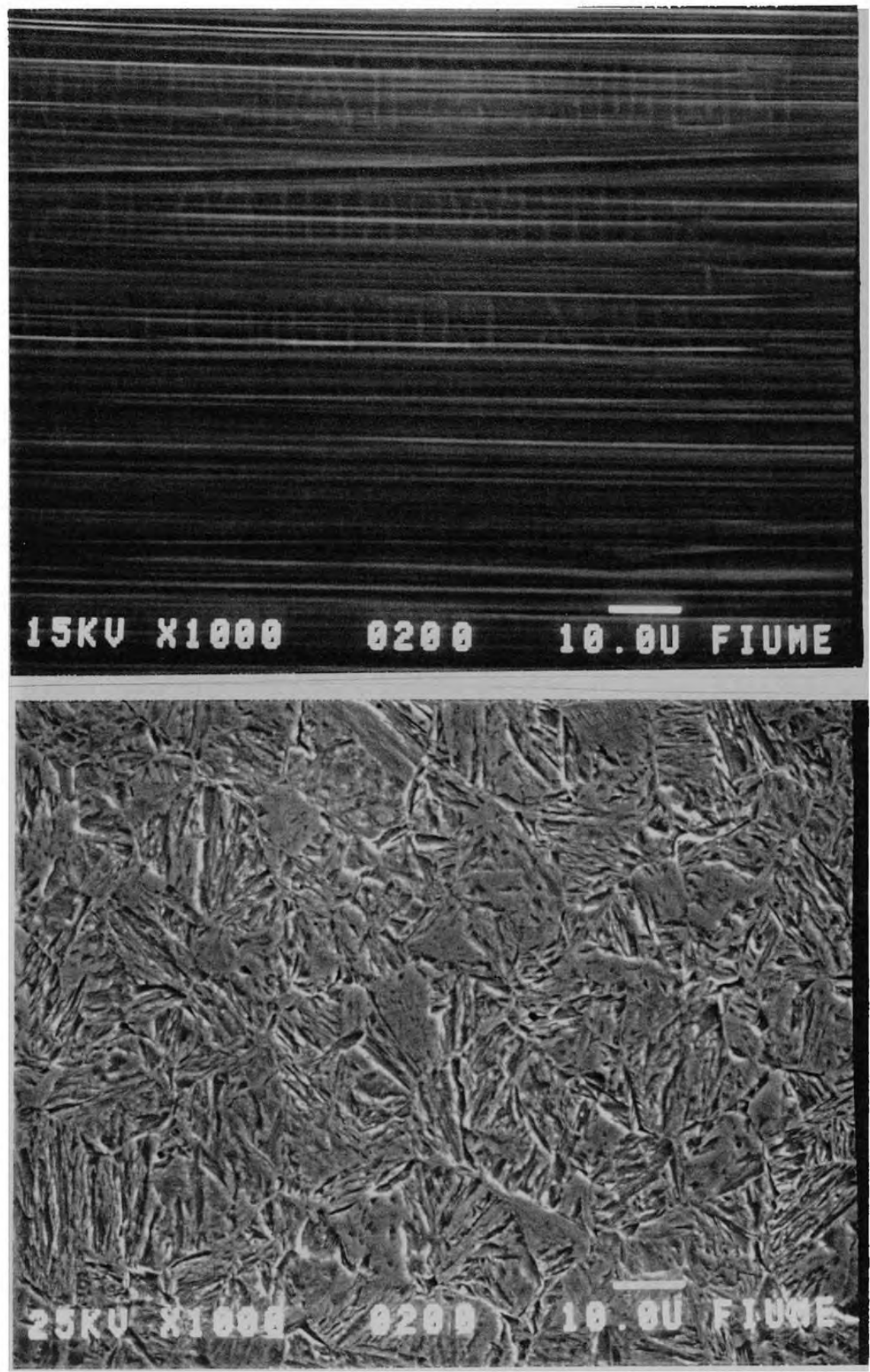

Figure - 21

New Wrist Pin Journal Surface (top)

Cross Section (bottom)

1000X Magnification 

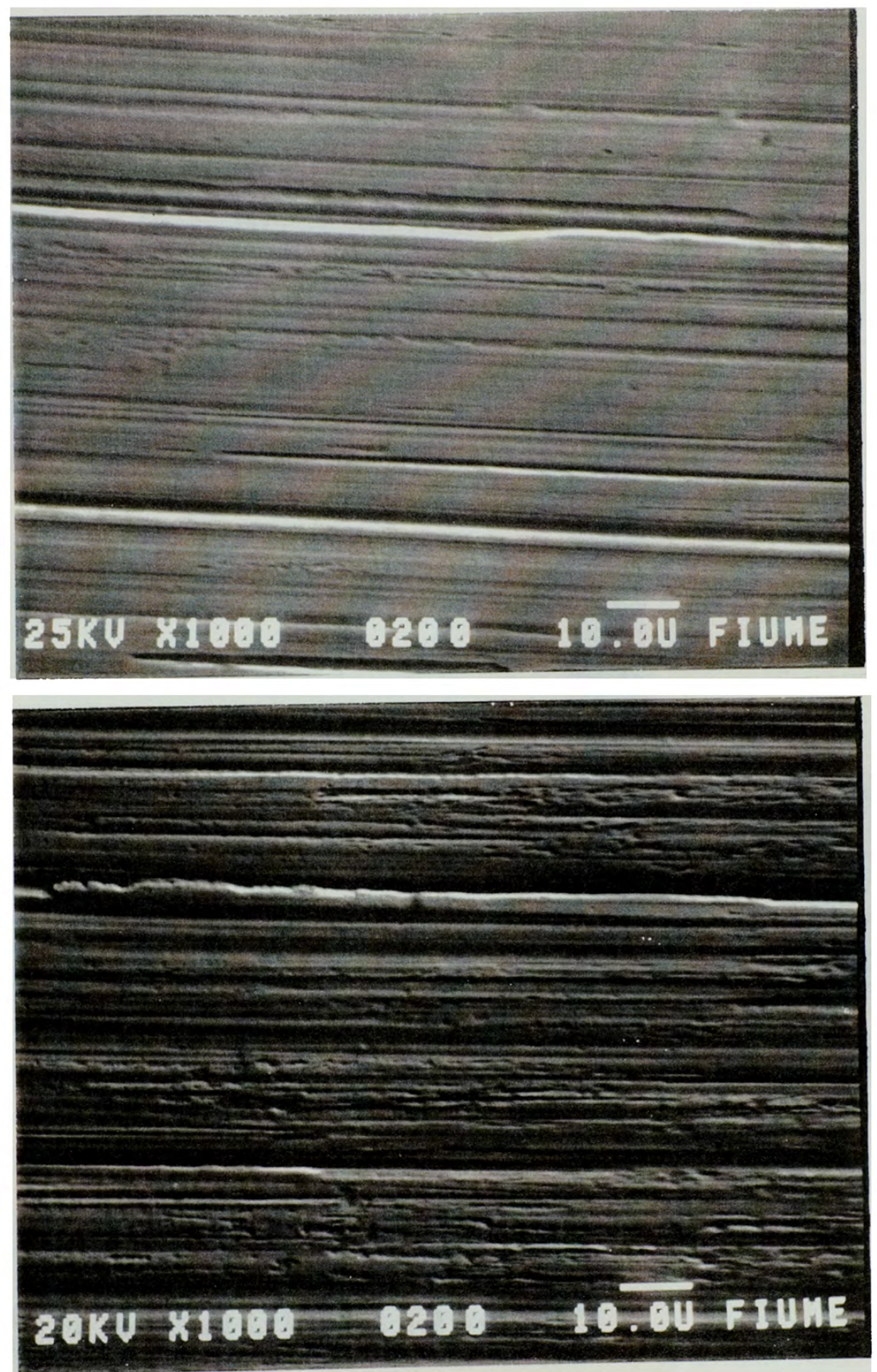

Figure - 22

Comparison of Wrist Pin Contact Surfaces

Run \# 1

Engine \#1 (top), Engine \# 2 (bottom) 


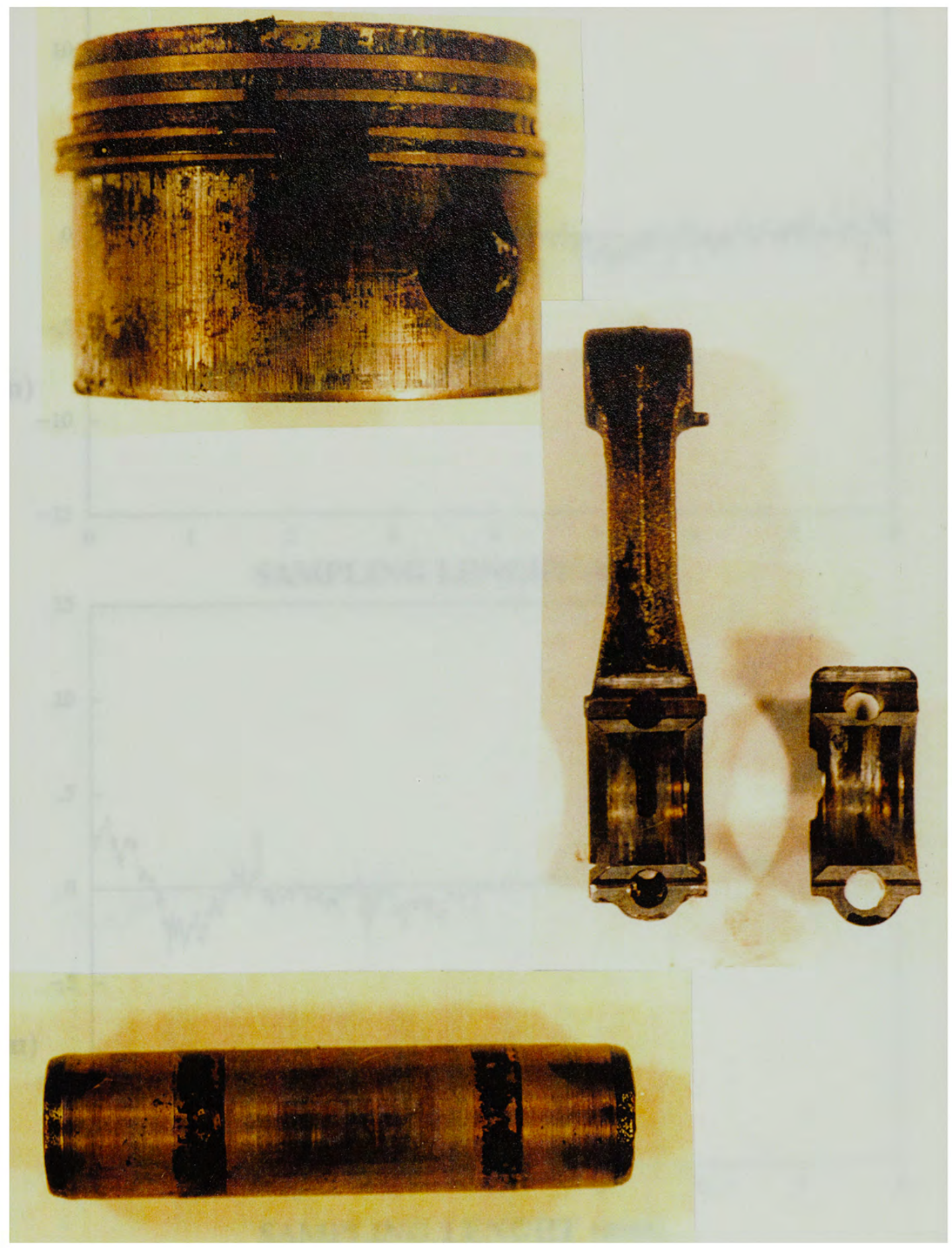

Figure - 23

Engine Parts - Engine \# 2

Run \# 3 

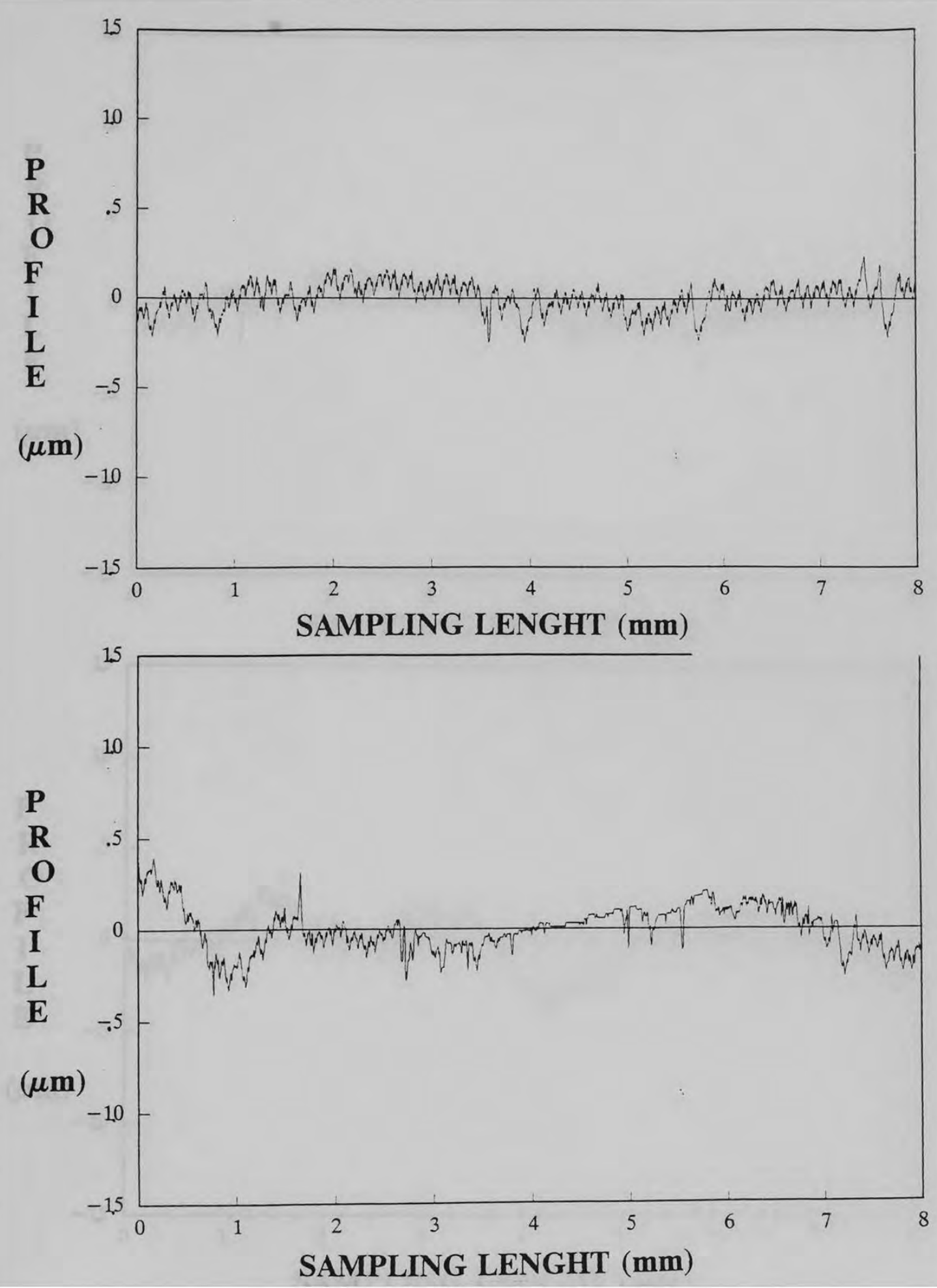

Figure - 24

Connecting Rod Top Bearing Surface Profiles - Engine \# 1

Using 10W-30 Motor Oil

New (top), After Run \# 1 (bottom) 

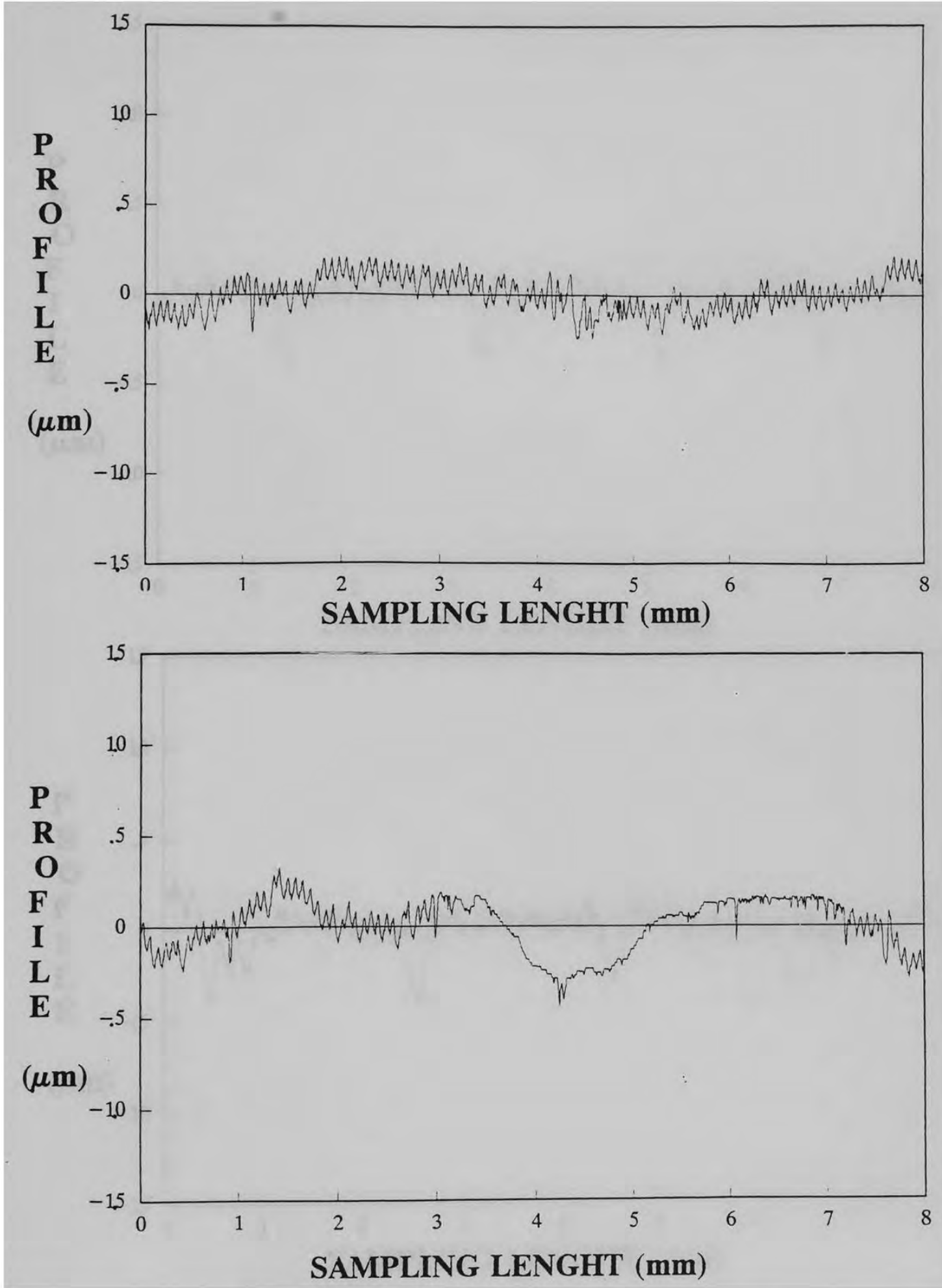

Figure - 25

Connecting Rod Top Bearing Surface Profiles - Engine \# 2

Using 10W-30 Motor Oil + 10\% PS-23

New (top), After Run \# 1 (bottom) 


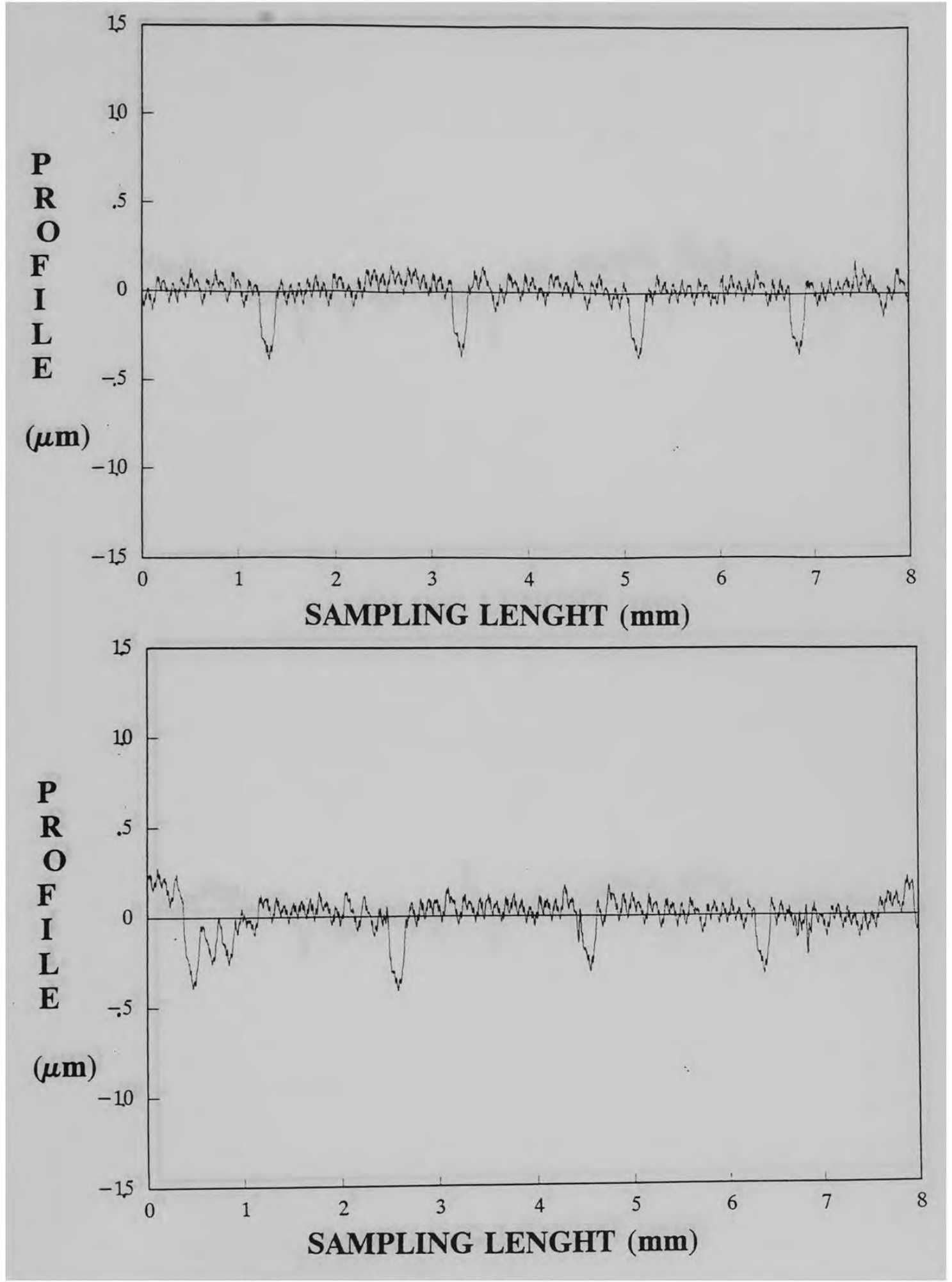

Figure - 26

Connecting Rod Bottom Bearing Surface Profiles - Engine \# 1

Using 10W-30 Motor Oil

New (top), After Run \# 1 (bottom) 

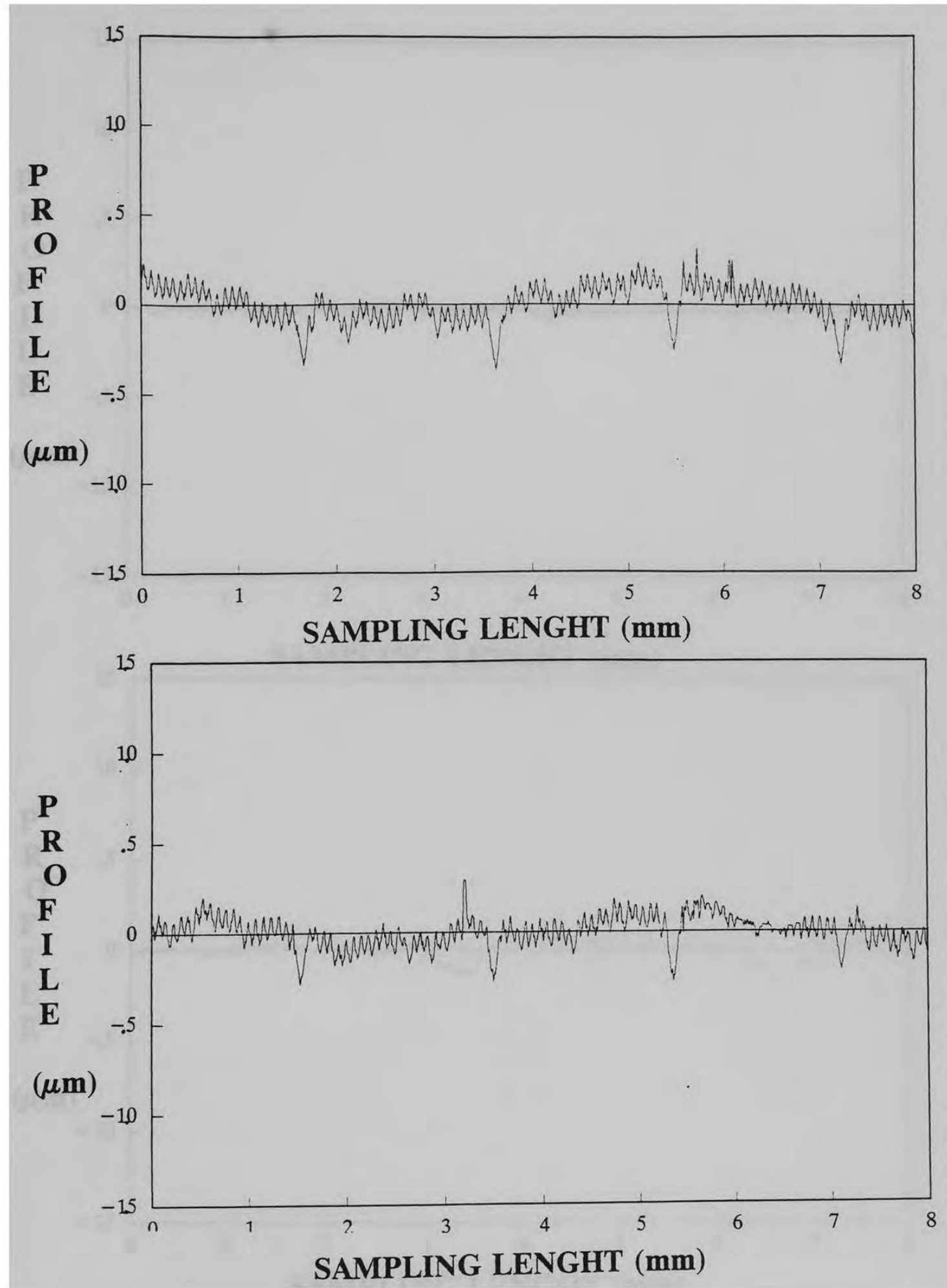

Figure - 27

Connecting Rod Bottom Bearing Surface Profiles - Engine \# 2

Using 10W-30 Motor Oil + 10\% PS-23

New (top), After Run \# 1 (bottom) 


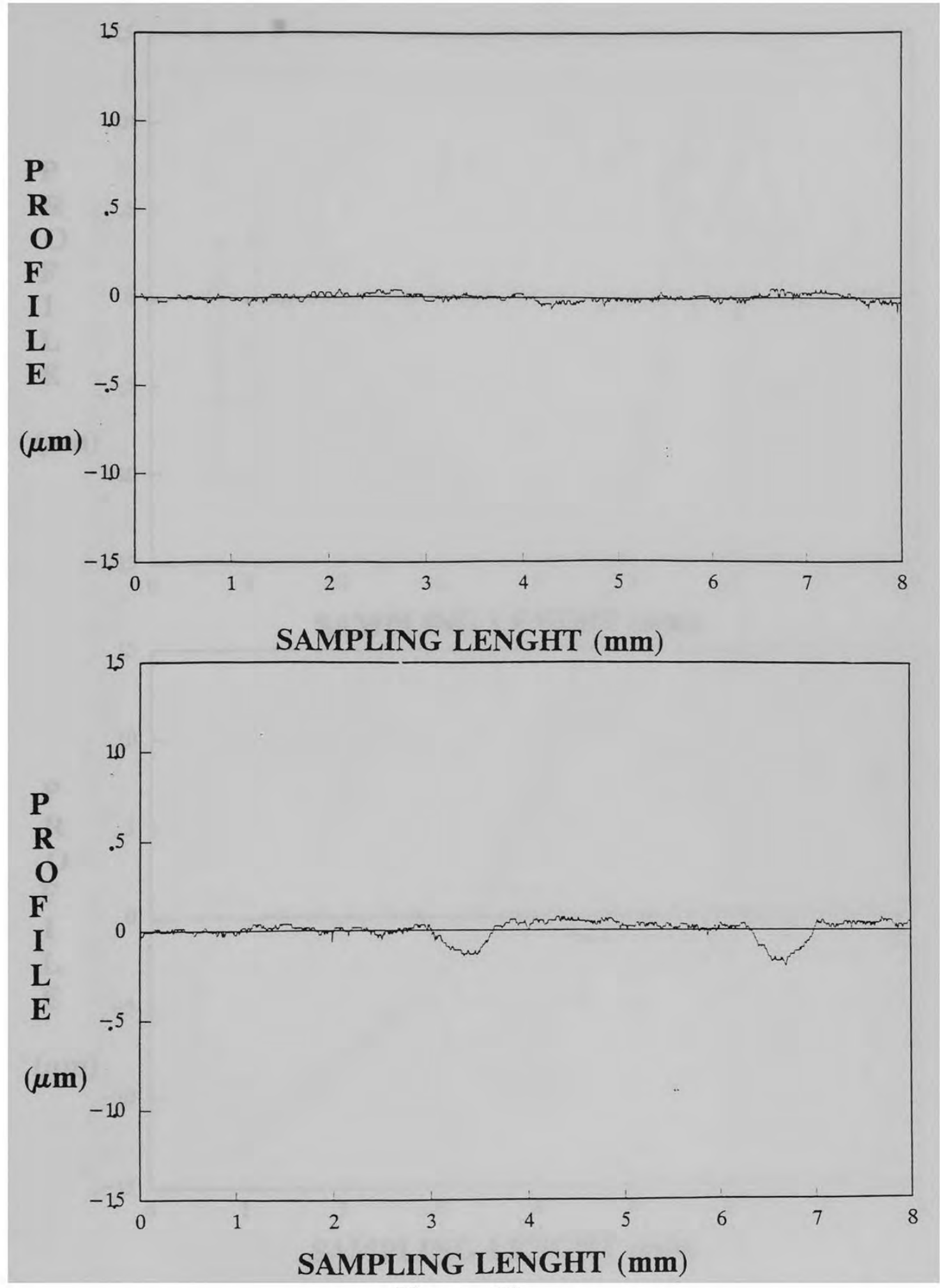

\section{Figure - 28}

Wrist Pin Surface Profiles - Engine \# 1

Using 10W-30 Motor Oil

New (top), After Run \# 1 (bottom) 


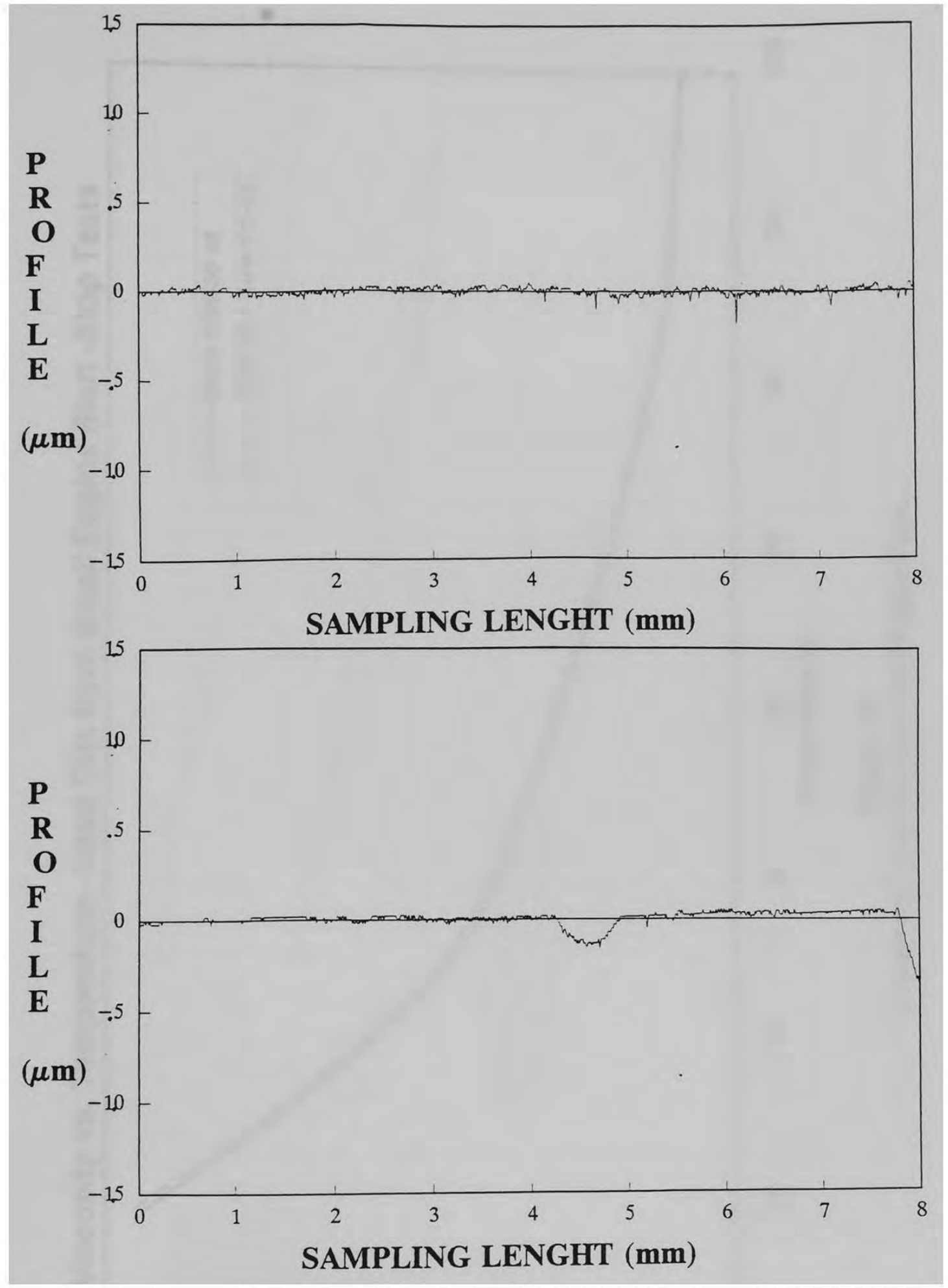

Figure - 29

Wrist Pin Surface Profiles - Engine \# 1

Using 10W-30 Motor Oil + 10\% PS-23

New (top), After Run \# 1 (bottom) 


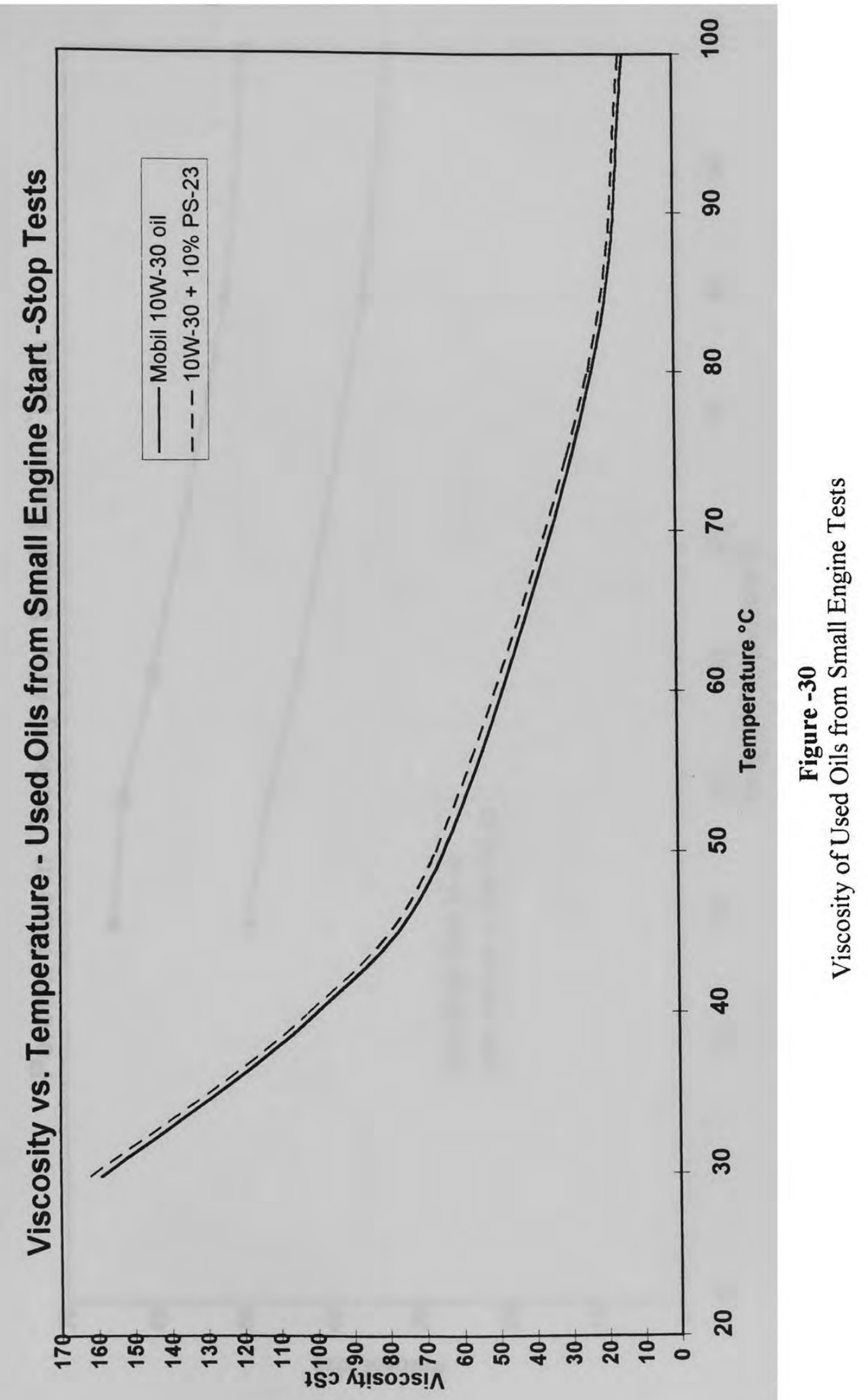




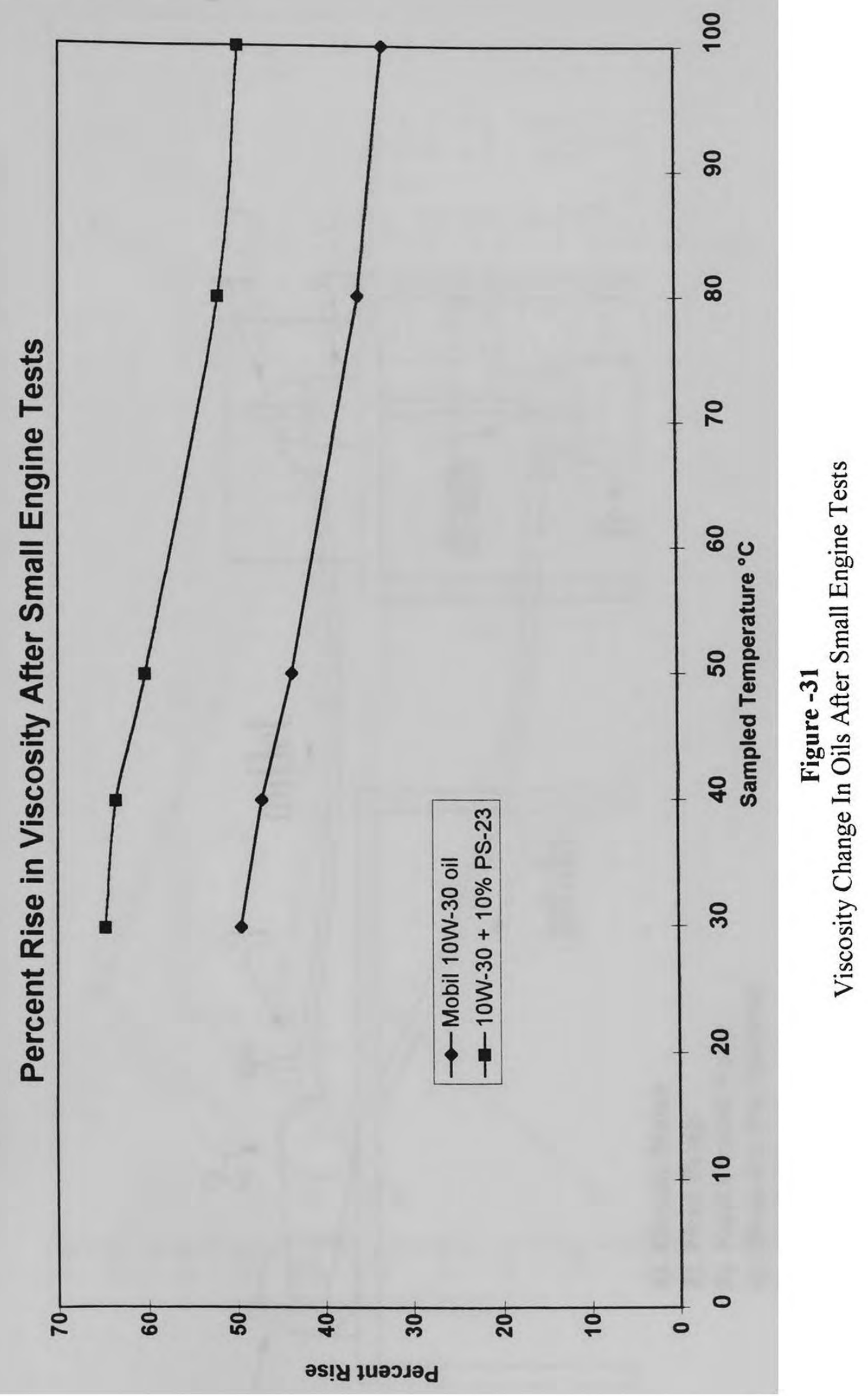




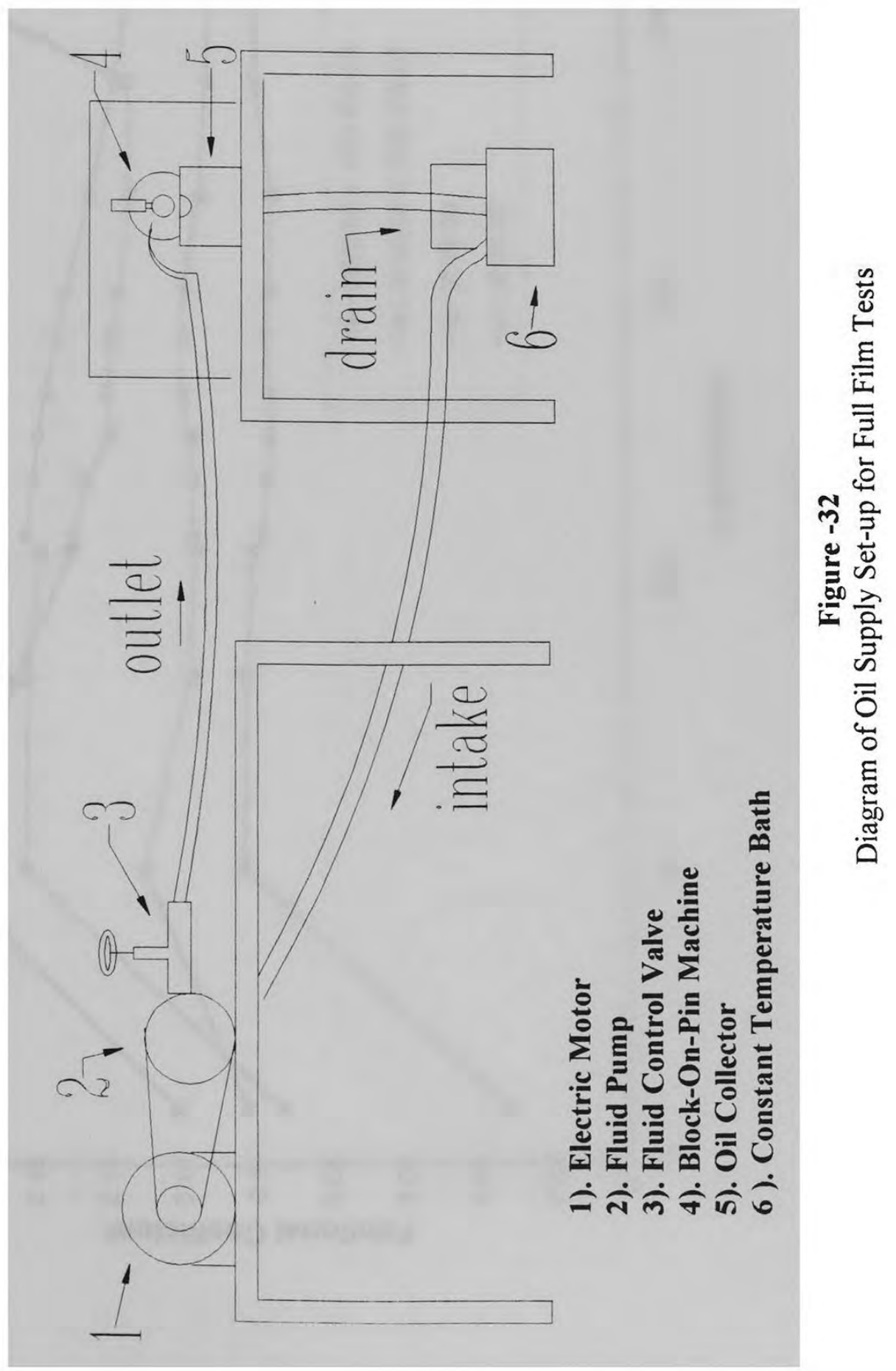




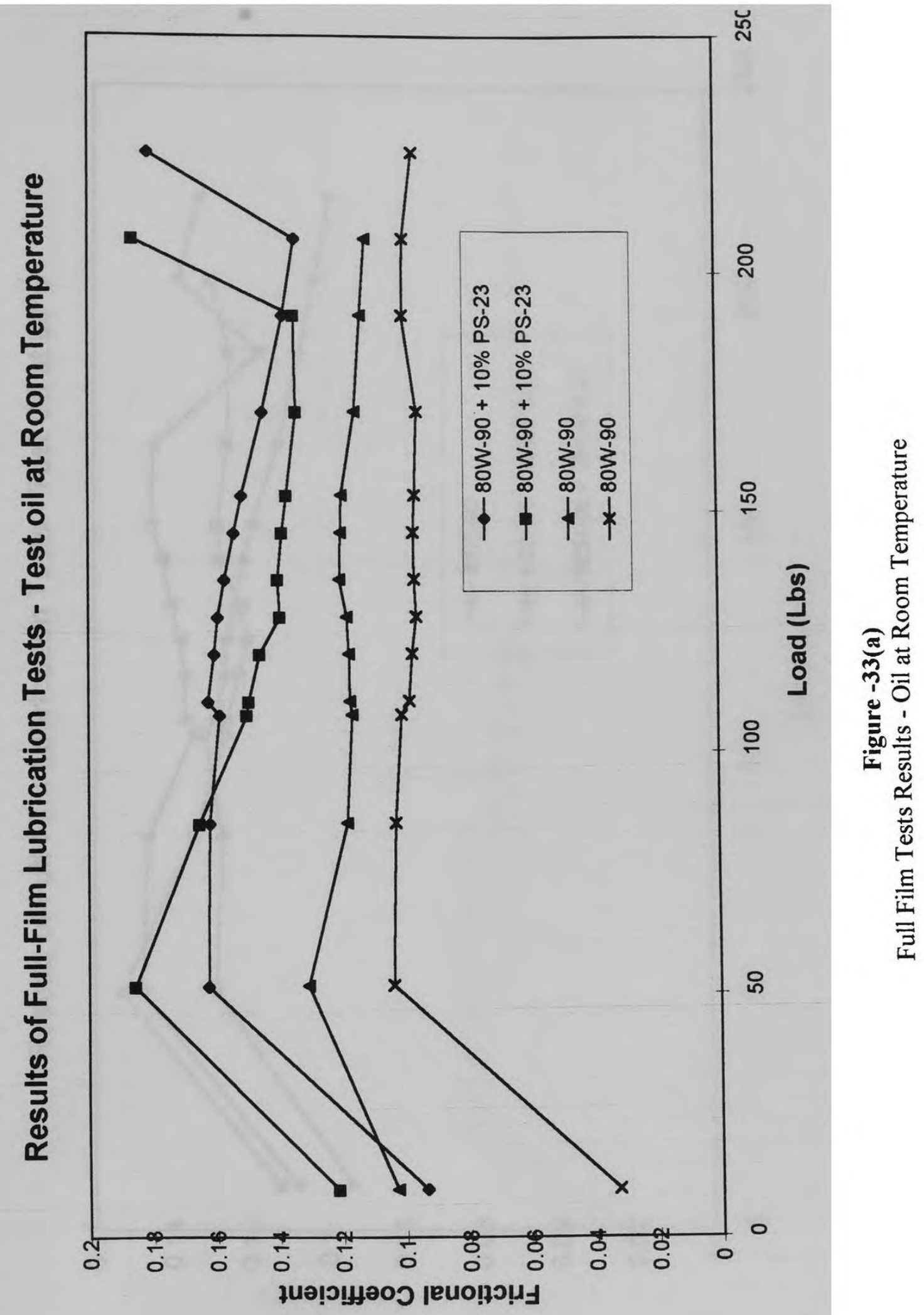




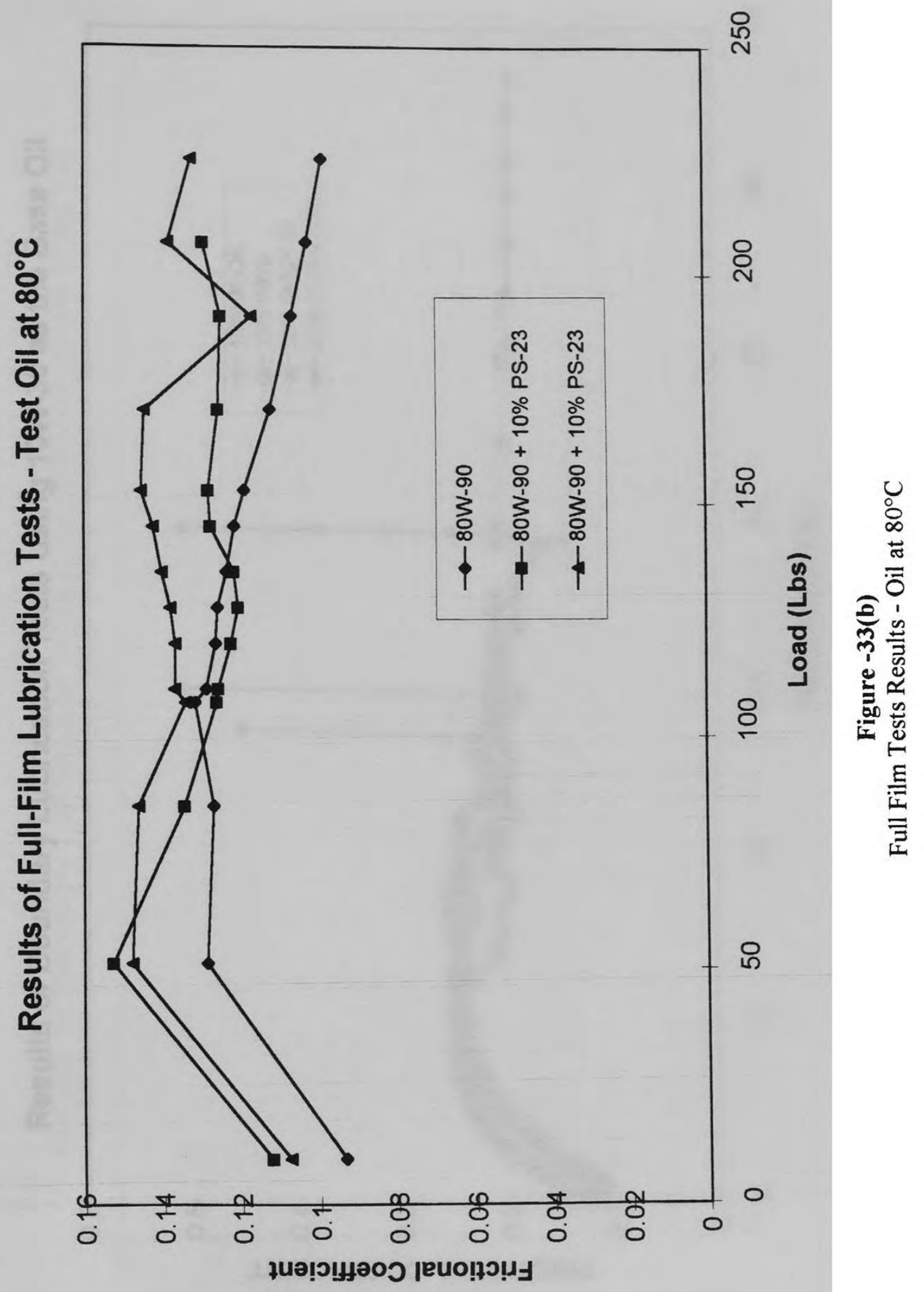




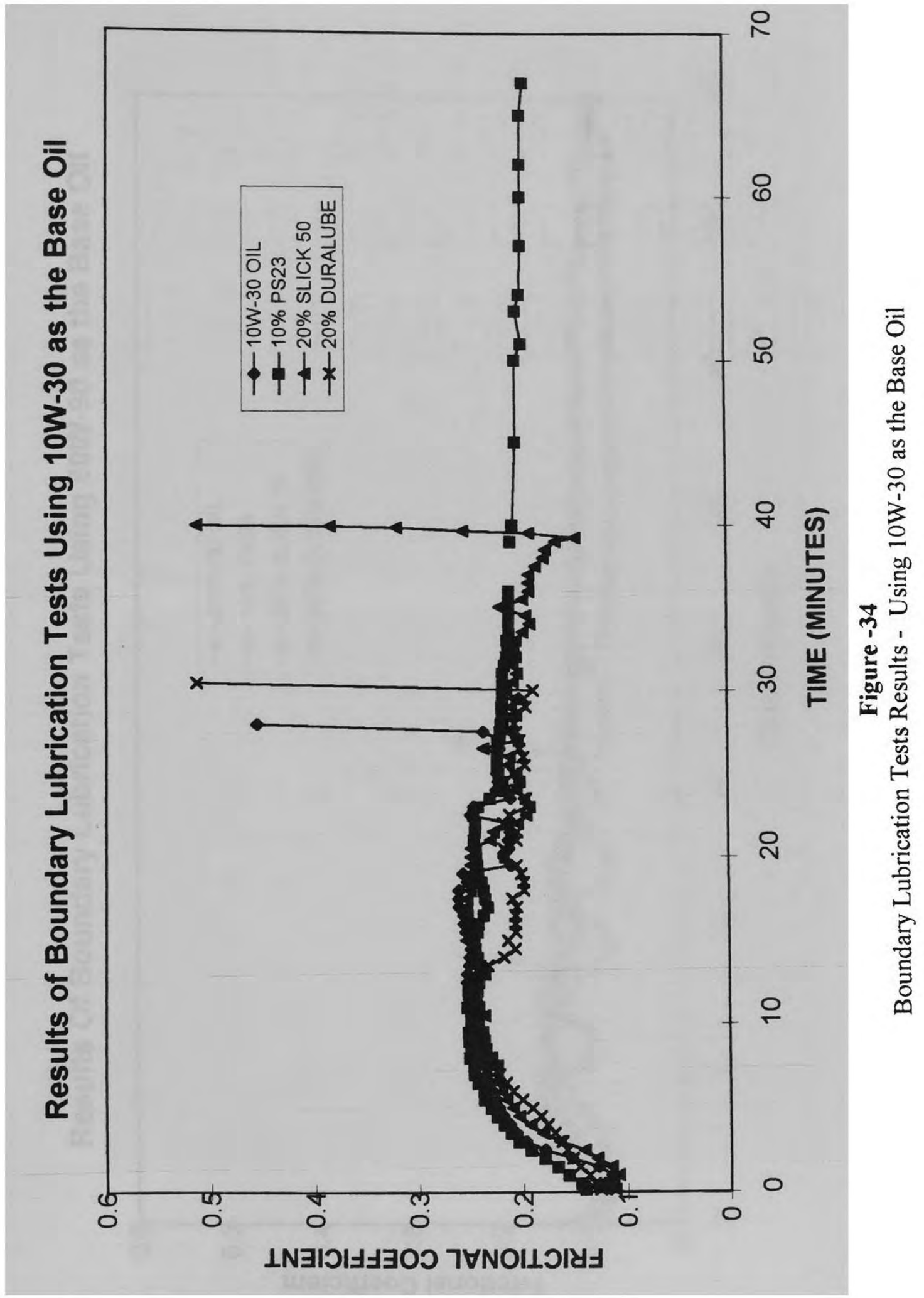




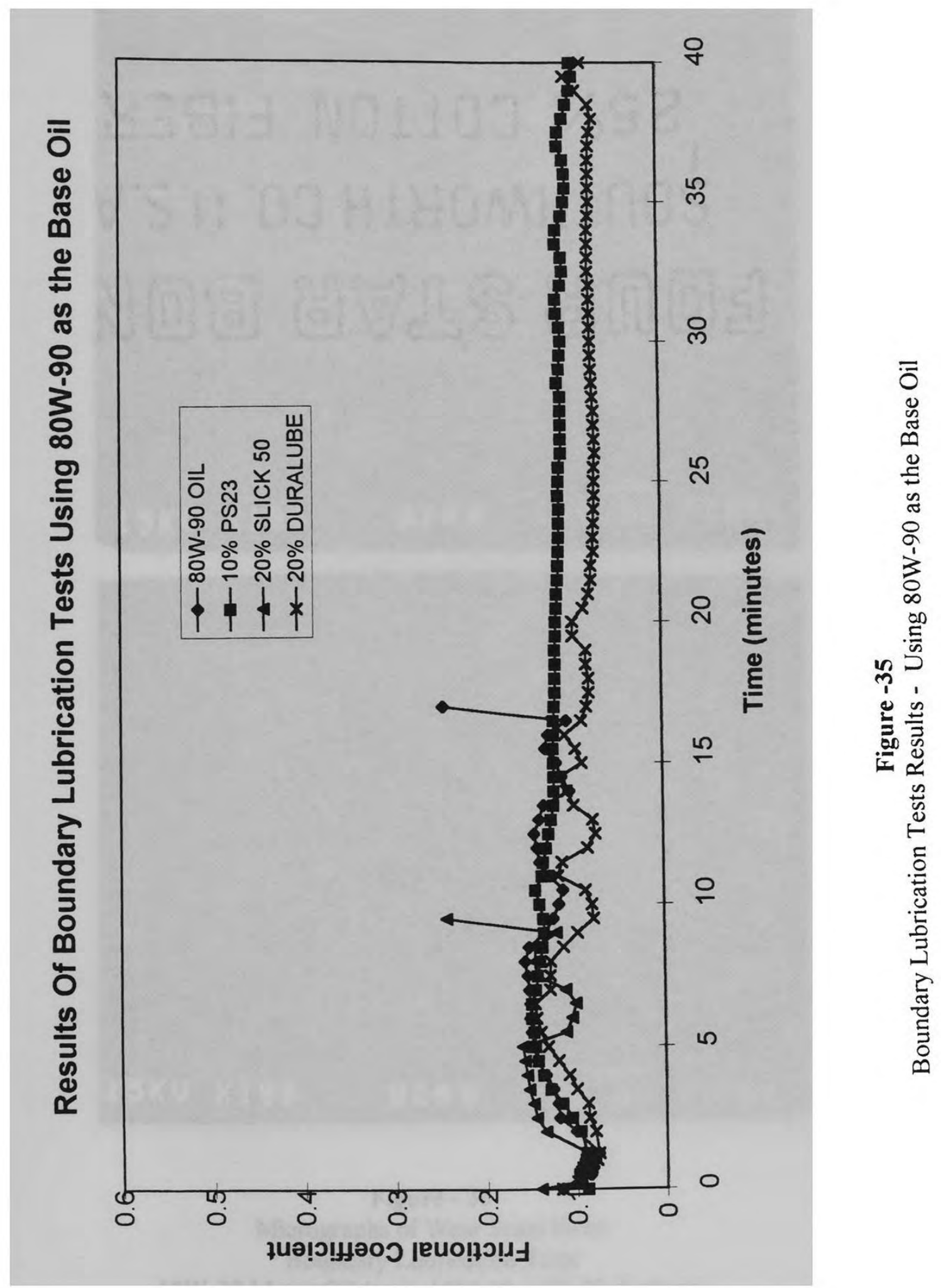



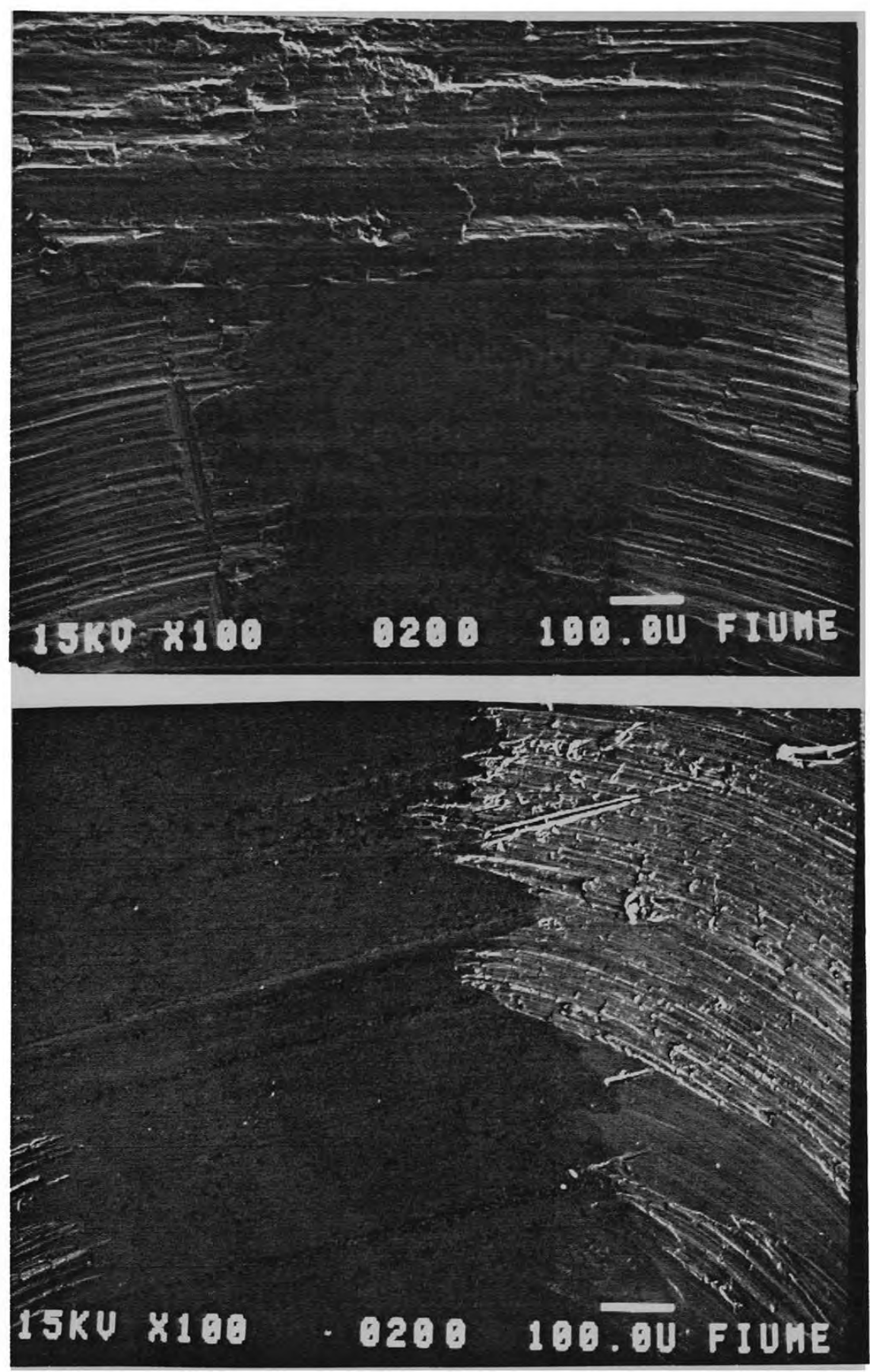

Figure - 36

Micrographs of Wear Scars From

Boundary Lubrication Tests

10W-30 Motor Oil (top), 10W-30 + PS-23 (bottom) 

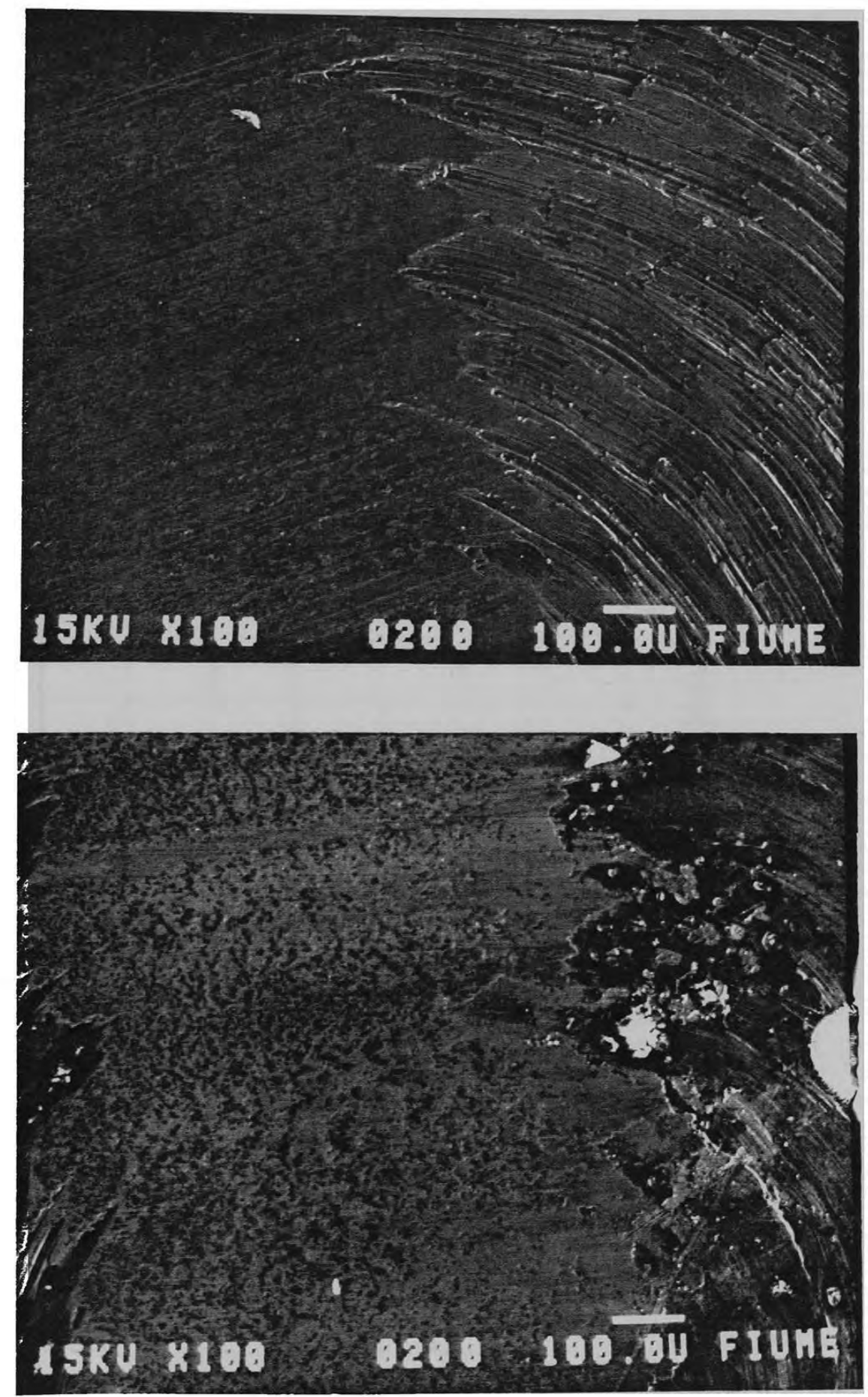

Figure - 37

Micrographs of Wear Scars From

Boundary Lubrication Tests

80W-90 Motor Oil (top), 80W-90 + PS-23 (bottom) 


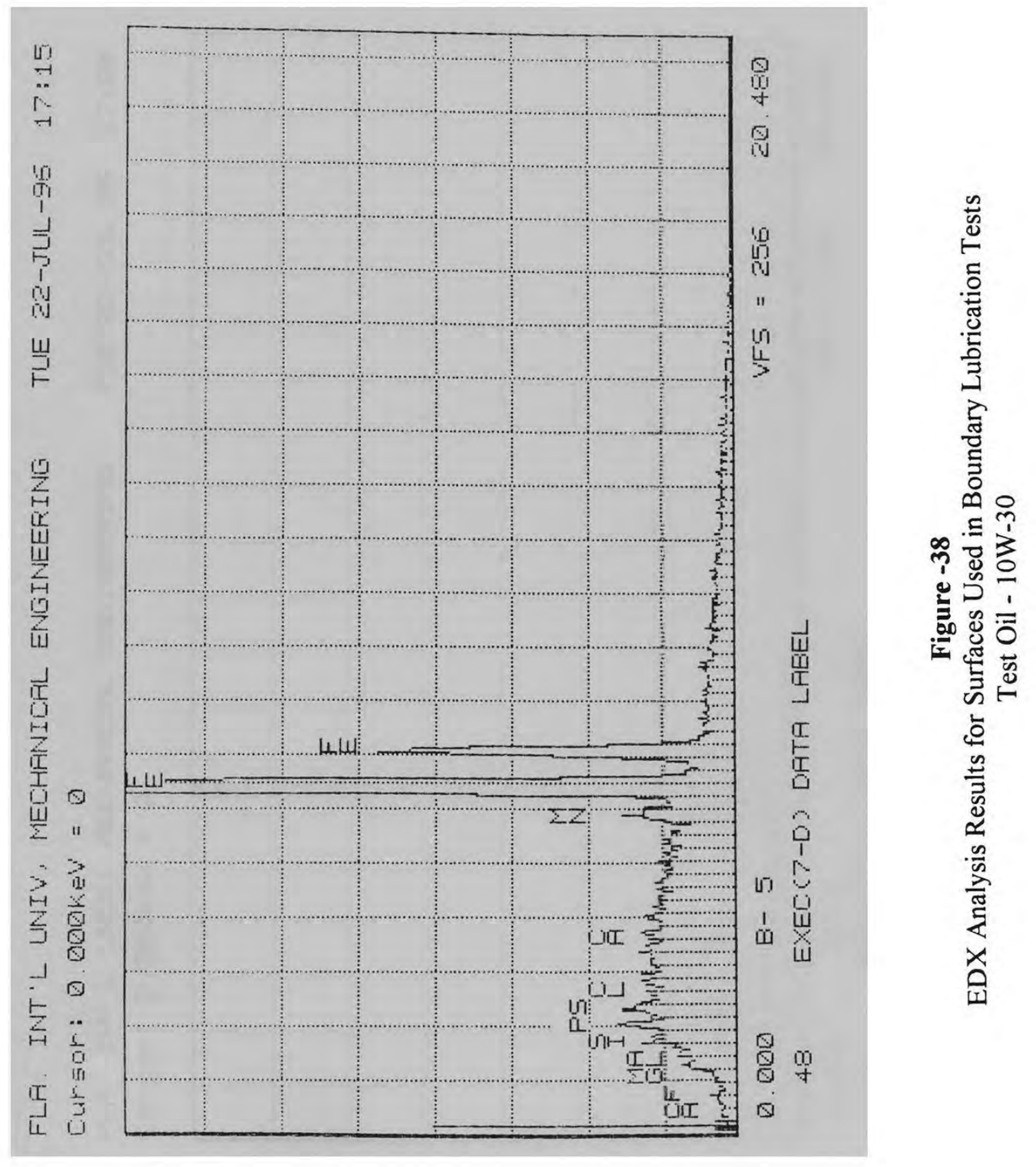




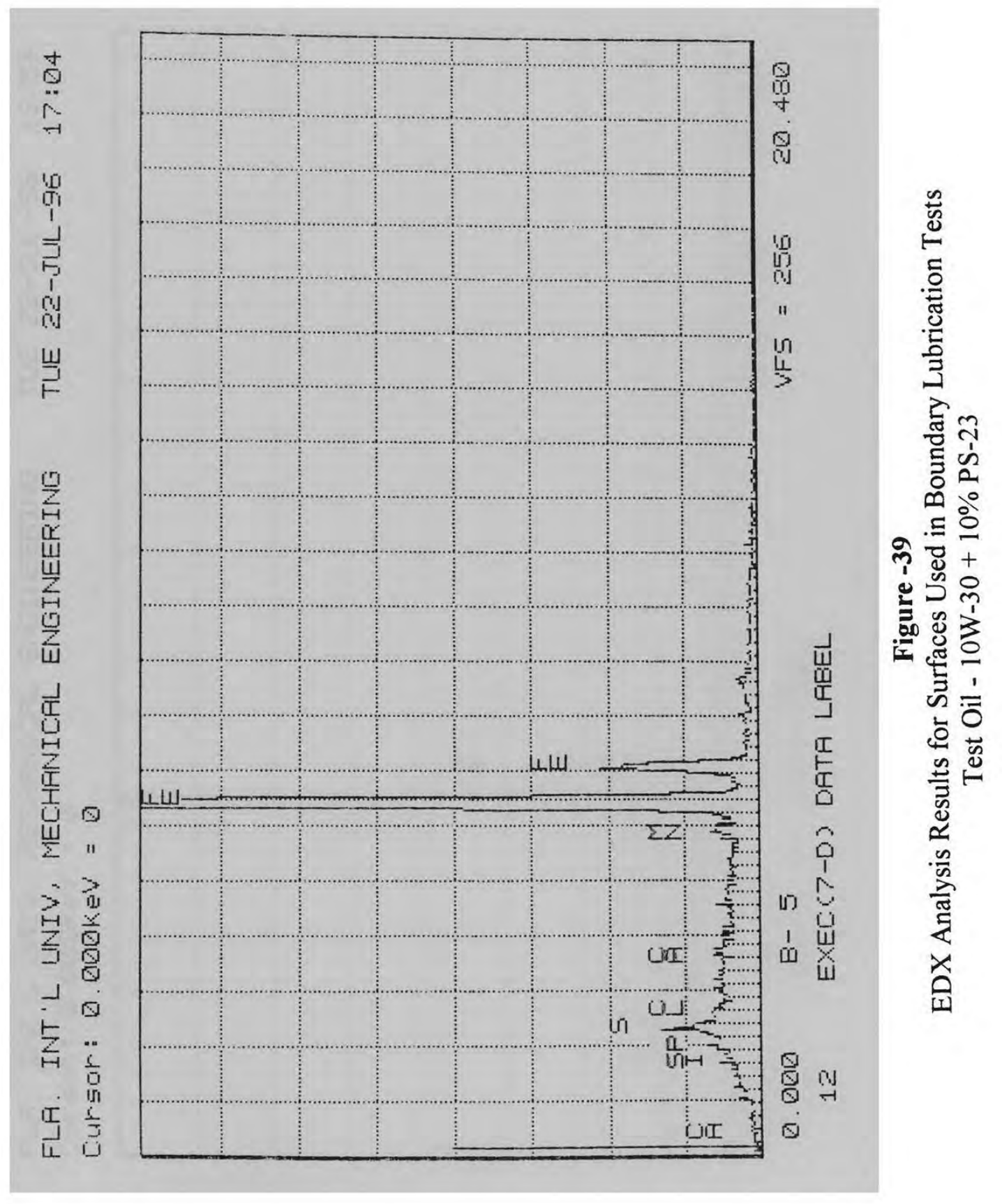




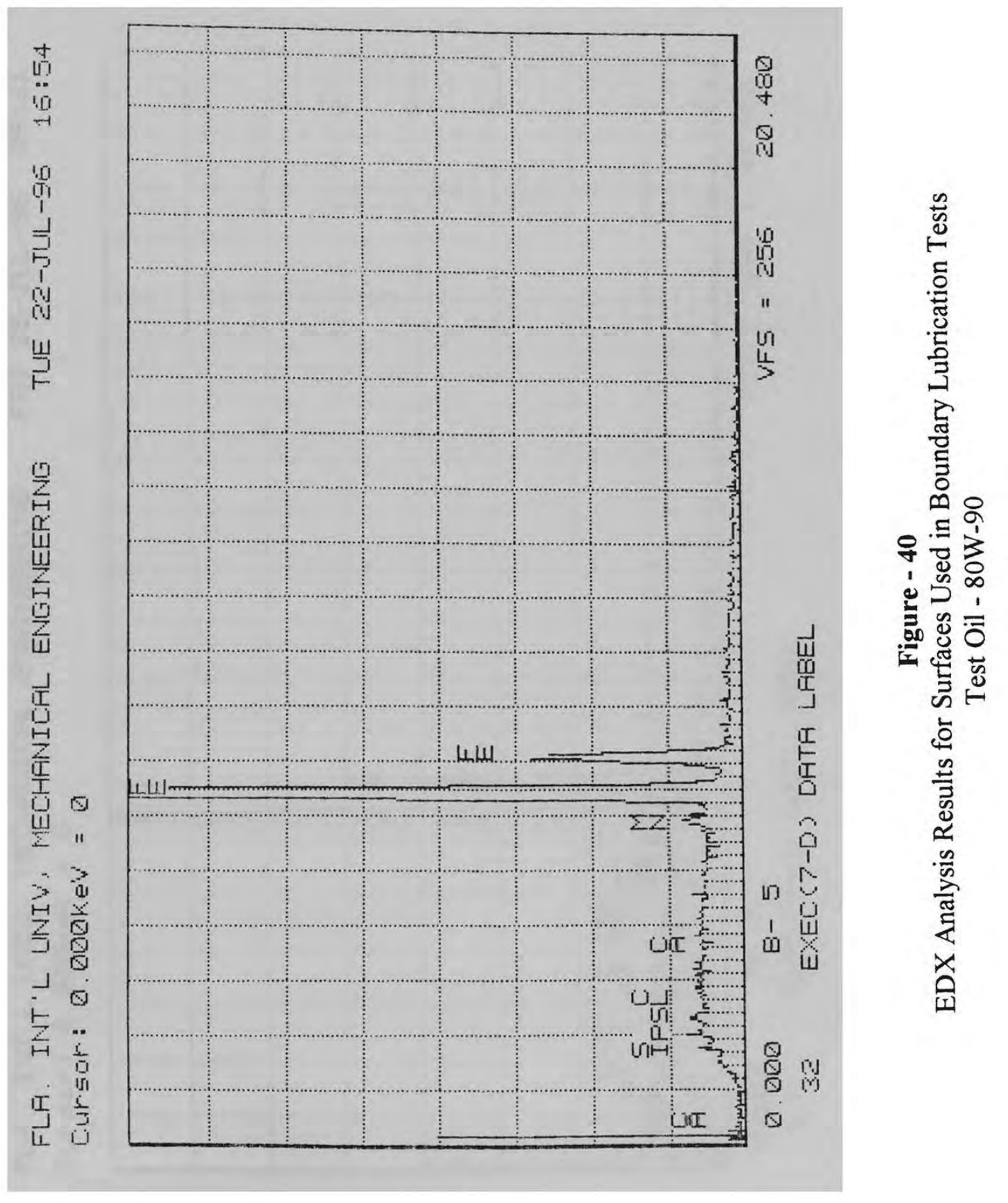




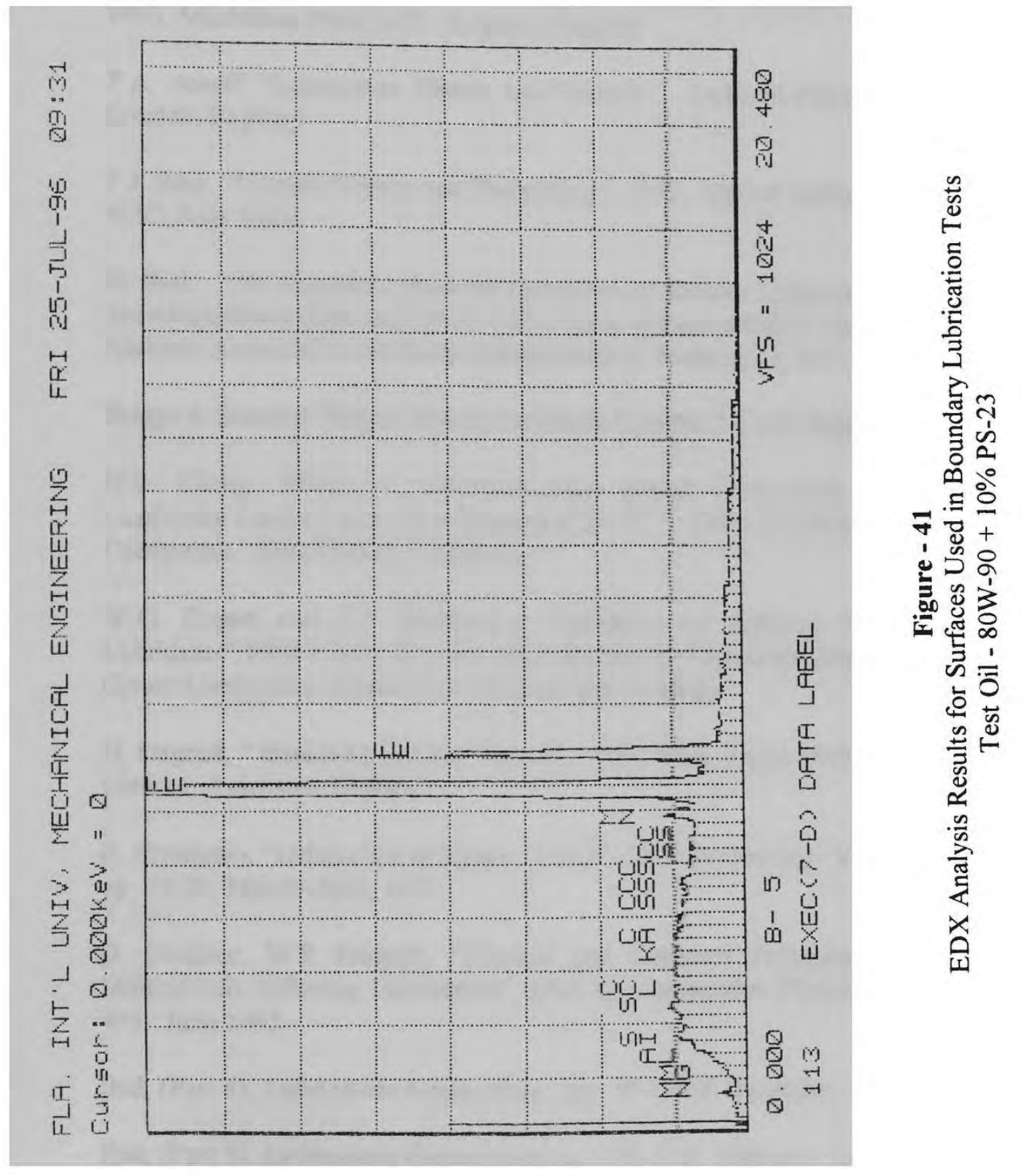




\section{REFERENCES}

J.F. Archard, "The Temperature of Rubbing Surfaces", Wear, 2, (1959).

R.D. Arnell et al, "TRIBOLOGY Principles and Design Applications", 1993, MacMillan Press LTD., London, England.

P.A. Asseff, "Lubrication Theory and Practice", Lubrizol Petroleum Products, London, England.

P.J. Blau, "Friction Science and Technology", 1995, Marcel Dekker, Inc. , N.Y., New York.

H. Blok, "The Postulate About the Constancy of Scoring Temperature:

Interdisciplinary Approach to the Lubrication of Cocentrated Contacts", 1970, National Aeronautics and Space Administration, Washington, D.C., USA

Briggs \& Stratton "Repair Manual for Single Cylinder 4 Cycle Engines", 1994

H.S. Cheng, "Wear of Aluminum-Alloy Matrix Composites in Lubricated Conformal Contact with Case Hardened Steel ${ }^{\odot}$.", 1993, STLE/ASME Tribology Conference, New Orleans, Louisiana.

W.G. Copan and J.P. Richardson, "Advances In Additive Technology For Lubricants",What's New In Lube oils? Institute of Petroleum Energy Economics Group Conference, March 10, 1992, London, England.

H. Dagnall, “ Exploring Surface Texture”, 1986, Rank Taylor Hobson Limited, Leicester, England.

R. Errichello, "Lubrication of Gears - Part 1", Gear Technology, Vol 8 No.2, pp. 18-26, March-April, 1991.

D. Godfrey, W.R Herguth, "Physical and Chemical Properties Of Industrial Mineral Oils Affecting Lubrication", (Part 2), Lubrication Engineering, pp. 493495, June 1995

Ibid, (Part 4), Lubrication Engineering, pp.. 977-979, December, 1995.

Ibid, (Part 5), Lubrication Engineering, pp. 145-148, February, 1996.

J. Greenwood, "Presentation of Elastohydrodynamic Film Thickness

Results", Journal of Mechanical Engineering Science, Vol 11 No. 2, 1969. 
J. Halling, " Principles of Tribology", 1975, The MacMillan Press LTD., London, England

B.J. Hamrock, “Fundamentals of Fluid Film Lubrication”, 1994, McGraw-Hill.

K.L. Johnson, " Regimes of Elastohydrodynamic Lubrication", Journal of Mechanical Engineering Science, Vol 12 No. 1, 1970.

B.W. Kelley, A. Lemanski, "Lubrication of Involute Gearing”, Proc. Inst.

Mechanical Engineers, Vol 182, Part 3A, pp178-184, 1968.

B.Latto and J.Yang, "Thermo-Oxidation Effect on Viscosity of 10W30 Oil With XM-5 or STP ", Lubrication Engineer, Vol.47 No. 6, pp. 455-461 , June 1991.

S.C. Lee, "Scuffing Theory Modeling and Experimental Correlations", Transactions of the ASME, Vol 113, pp 327-334, April, 1990.

Yichao Lin, "Antifriction and Antiwear Characteristics of Molybdenum Dithiophosphate in Engine Oils ", Lubrication Engineering, Vol. 51 No. 10, pp. 855-860, October 1995

R.M. Matveevsky, "Evaluation of Temperature Stability of a Lubricant on Rubbing Surfaces", Tribology, Vol 2, pp 115-117, 1968.

H. Schaub et al, "Engine Durability, Emissions and Fuel Economy Studies with Special Boundary Lubricant Chemistry”, SAE Technical Paper No. 941983, October, 1994.

Alphonse Schilling, "Motor Oils and Engine Lubrication", 1968, Scientific Publications, London, England.

G. Trabert, "Advances in Lubricant Technology", IEEE Cement Industry Technical Conference, 1990.

M.B. Ttreuhaft et al, "The Use of Radioactive Tracer Technology in Studying Lubricant Chemistry to Enhance Bearing and Ring Wear Control in an Operating Engine", SAE Technical Paper No. 941982, October, 1994

A.B. Vipper, W. Bartz, "Antifriction Action of Lubricant Additives", Lubrication Science, Vol 7 No.3, pp. 247-259, April 1995.

B. Wilson, "Slick 50 - a proven PTFE-based boundary lubricant for engines", Industrial lubrication and Tribology, Vol. 47 No. 4, pp 6-8, July/August 1995. 
From marketing literature supplied by Lubrioil S.A., manufacturer of PS-23® 